B $\begin{aligned} & \text { Africa Growth } \\ & \text { Initiative }\end{aligned}$ at BROOKINGS

\title{
A GENERAL EQUILIBRIUM MODEL FOR ANALYZING AFRICAN RURAL SUBSISTENCE ECONOMIES AND AN AFRICAN GREEN REVOLUTION
}

John W. McArthur and Jeffrey D. Sachs 


\section{$B$ Africa Growth \\ at BROOKINGS}

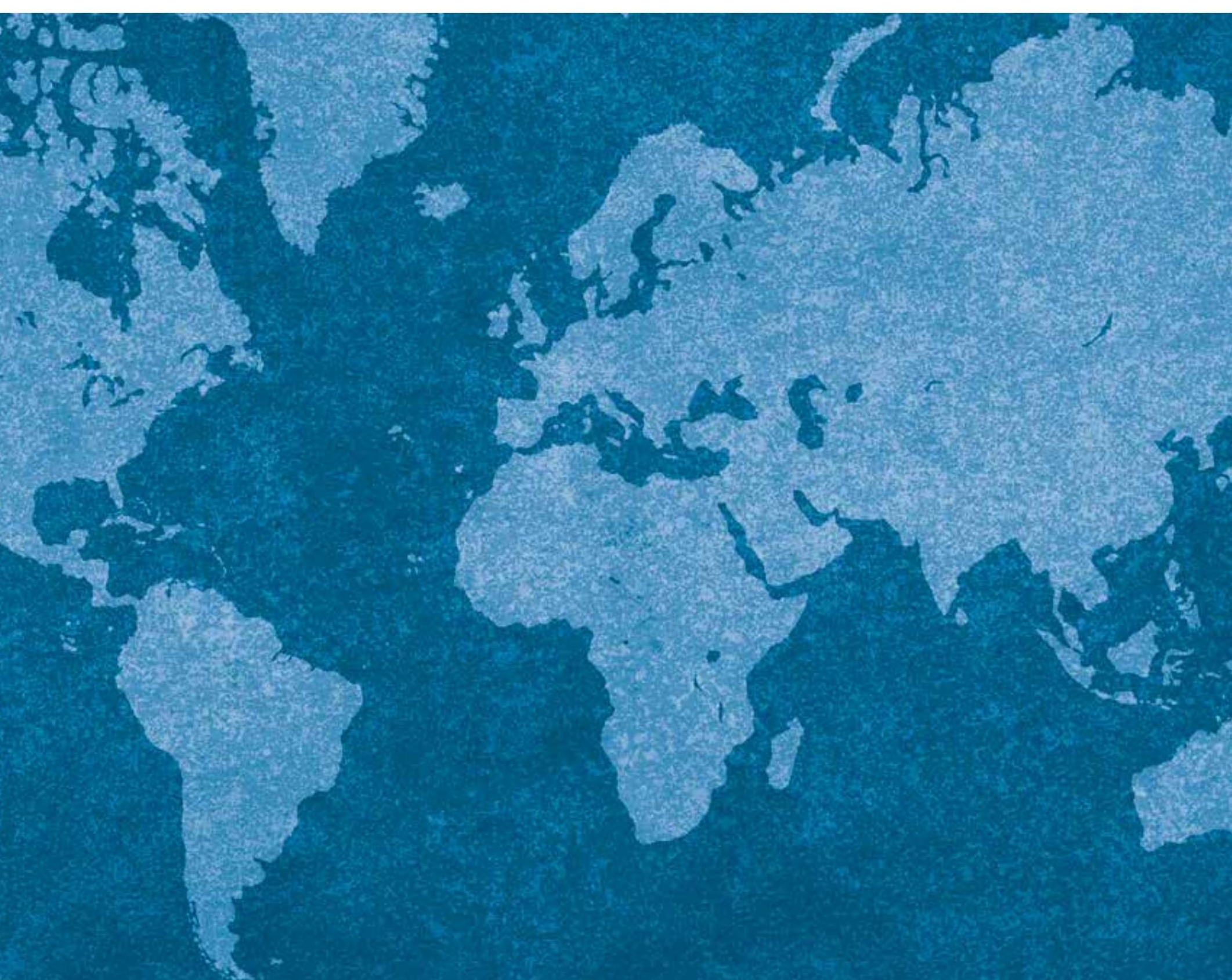


John W. McArthur is a senior fellow with the U.N. Foundation and the Fung Global Institute, and a nonresident senior fellow in Global Economy and Development at the Brookings Institution.

Jeffrey D. Sachs is director of the Earth Institute at Columbia University.

\begin{abstract}
:
How can foreign aid support economic growth in Africa? This paper presents a geographically indexed general equilibrium model that enables green revolution-focused macroeconomic analysis in low-income African settings. The model is flexible to parameterization and highlights the role of farmers' constraints to self-financing of inputs alongside minimum subsistence consumption requirements. It includes particular attention to the challenge of soil productivity and to the effects of official development assistance (ODA) for agricultural inputs and road building. Uganda is used as an illustrative case. The economy's labor force is predominantly still located in rural areas and remains overwhelmingly focused on staple food production. Under plausible economy-wide parameters, a foreignfinanced green revolution package shows a clear anti-Dutch disease result, in which the temporary boost in targeted ODA yields permanent productivity and welfare effects at relatively low cost.
\end{abstract}

\title{
Acknowledgements:
}

The corresponding author is John W. McArthur who can be reached at jmcarthur@brookings.edu. The authors thank Christopher Adam, Mwangi Kimenyi, Oliver Morrissey, John Page, Francis Teal, participants in the Brookings Africa Growth Initiative seminar, and participants in the Oxford Centre for the Study of African Economies annual conference for helpful comments and discussions during various stages of this research. This paper updates a previous version originally written in 2008 while the first author was a researcher at the Earth Institute at Columbia University. A grant to the Institute from the Bill \& Melinda Gates Foundation is gratefully acknowledged for supporting the original research effort. RAND Santa Monica's Labor and Population and RAPID programs are also gratefully acknowledged for generously hosting the first author as a visitor while conducting the latest round of research and writing.

The Brookings Institution is a private non-profit organization. Its mission is to conduct high-quality, independent research and, based on that research, to provide innovative, practical recommendations for policymakers and the public. The conclusions and recommendations of any Brookings publication are solely those of its author(s), and do not reflect the views of the Institution, its management, or its other scholars.

Brookings recognizes that the value it provides is in its absolute commitment to quality, independence and impact. Activities supported by its donors reflect this commitment and the analysis and recommendations are not determined or influenced by any donation. 


\section{CONTENTS}

Abstract. .....................

Acknowledgments. ......................

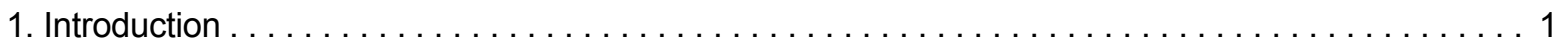

2. An Illustrative African Economy: Uganda $\ldots \ldots \ldots \ldots \ldots \ldots \ldots \ldots \ldots \ldots \ldots \ldots \ldots \ldots \ldots \ldots \ldots \ldots$

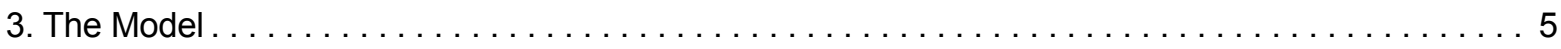

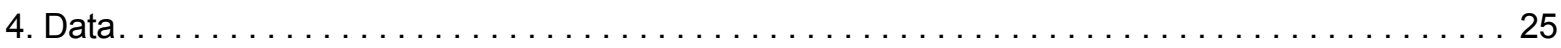

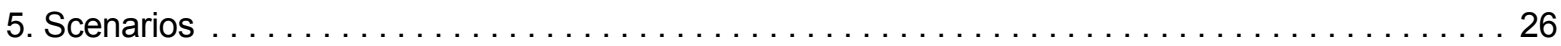

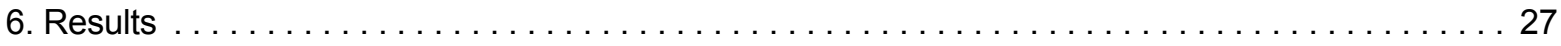

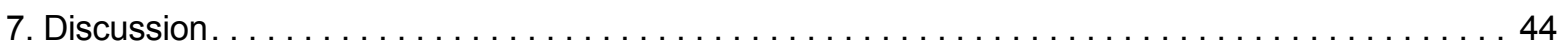

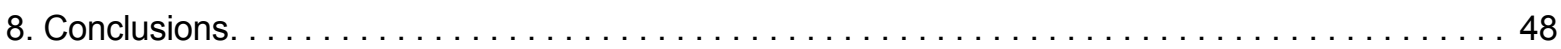

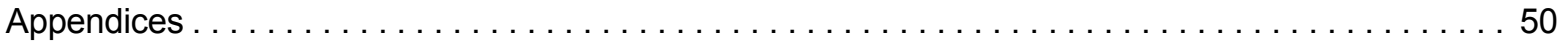

\section{List of Tables}

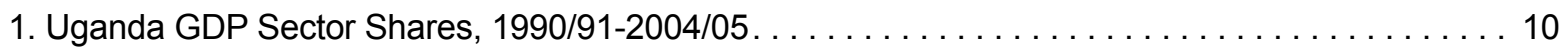

2. Sectoral Decomposition of Ugandan Labor Force and Value Added, $2002 \ldots \ldots \ldots \ldots \ldots \ldots 11$

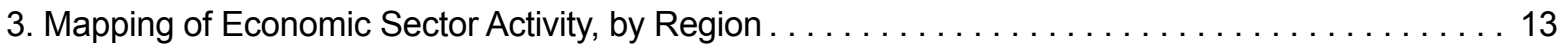

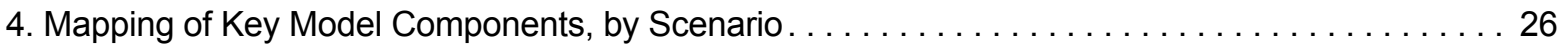

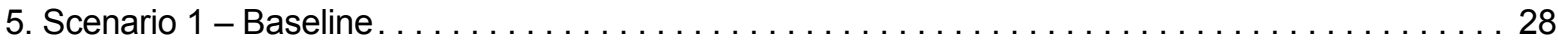

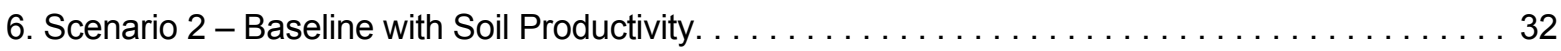

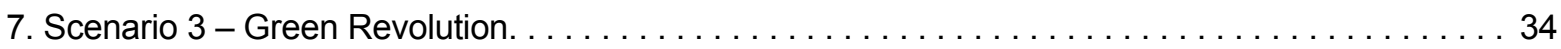

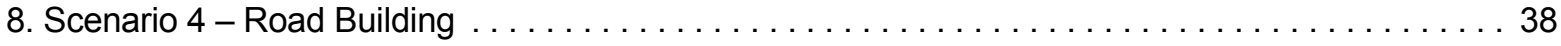

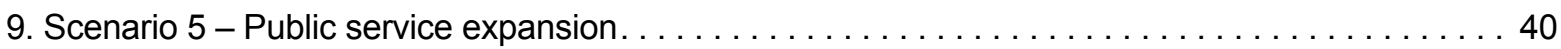

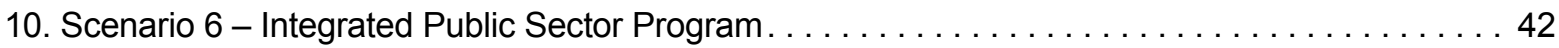

\section{List of Figures}

1. Uganda's Cereal Production per Capita, $1961-2010 \ldots \ldots \ldots \ldots \ldots \ldots \ldots \ldots \ldots \ldots$

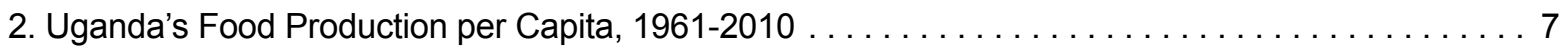

3. Uganda's Cereal Yields, $1961-2010 \ldots \ldots \ldots \ldots \ldots \ldots \ldots \ldots \ldots \ldots \ldots \ldots \ldots \ldots$

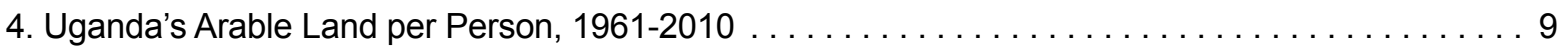

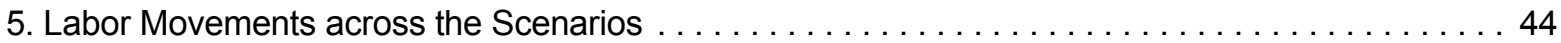

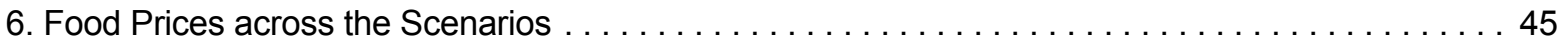

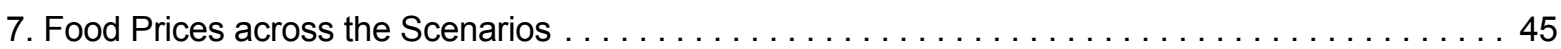

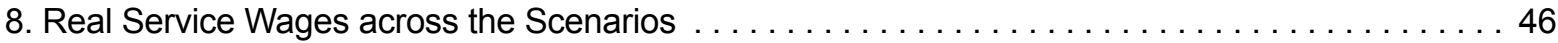

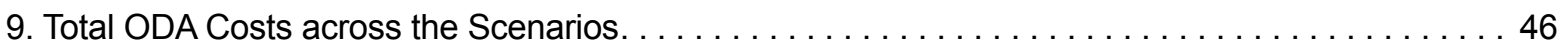




\title{
A GENERAL EQUILIBRIUM MODEL FOR ANALYZING AFRICAN RURAL SUBSISTENCE ECONOMIES AND AN AFRICAN GREEN REVOLUTION
}

\author{
John W. McArthur and Jeffrey D. Sachs
}

\section{INTRODUCTION}

$\mathbf{H}$ ow can foreign aid support economic growth in sub-Saharan Africa? ${ }^{1}$ An assessment of this important question must begin by recognizing that the majority of the region's extremely poor people live in rural areas and depend primarily on subsistence agriculture for their livelihoods. Modern input technologies now exist to boost small-holder productivity in these settings, where there is also commonly a need to address soil nutrient dynamics as a core component of any agricultural productivity strategy. Among other factors, Malawi's progress in doubling average national maize yields since 2005 through an aid-supported input subsidy program has prompted analysis around the merits of increasing public finance to small-holder agriculture throughout Africa (e.g., Morris et al. 2007; Diao, Headey and Johnson 2008; Duflo, Kremer and Robinson 2011).

The overall positive average relationship between aid and economic growth is described by Clemens et al. (2012) in their dissection of earlier high-profile studies on the same topic. In the course of their analysis, Clemens and colleagues differentiate between two categories of aid. One is dubbed "early impact" aid and includes support for sectors like roads, energy, banking, agriculture and industry, any of which might be expected to boost growth in the short to medium term. The other category entails activities "whose growth effect might arrive far in the future or not at all" ( $p$. 599). This includes social sector areas like education, health, water and humanitarian assistance. The segmented analysis of aid can be compared with more aggregate-style assessments, such as in the prominent recent paper by Werker, Ahmed and Cohen (2009). Although the distinction between aims and effects across aid types has received some research attention (e.g., Gomanee, Girma and Morrissey 2005; Gomanee et al. 2005; Roodman 2007), the topic generally still receives inadequate focus in the economics literature.

At the same time, evidence is accumulating on the positive aggregate relationship between agricultural productivity improvements, poverty reduction and economic growth (e.g., Christiaensen, Demery and Kuhl 2011). There is therefore a need to link the "aid and growth" questions with the "agriculture and growth" questions, especially in the African context. This includes the need for a model to analyze the structural macroeconomic dynamics that would result from publicly financed staple food productivity improvements in rural African economies. 
To explore how those dynamics might evolve, this paper introduces a simulation model for green revolution-type shifts from low- to high-productivity staple food production in a predominantly rural African subsistence economy suffering from soil nutrient depletion. The transition is instigated by introducing a publicly financed package of modern agricultural inputs and expanding road infrastructure. The public subsidy helps to overcome farm-level credit constraints. Most low-income country governments cannot afford to finance a green revolution input package through their own budget envelopes, so the model assumes that they can be financed by official development assistance (ODA). A distinction is drawn between ODA targeted for agriculture, ODA for roads and ODA for social services like health and education. Each type of aid is shown to have very different macroeconomic consequences.

To provide a first approximation of the relevant macroeconomic dynamics, the model includes a planned public service delivery sector mixed with five market-based productive sectors and an imported goods sector. A green revolution-type boost in cereal yields from 1 ton per hectare to 2 or 3 tons per hectare would mark a tremendous direct supply-side structural change in a typical African economy. Because cereals and other staple foods in subsistence economies are mainly consumed on farms and in local markets, they are overwhelmingly nontradable goods with locally determined prices. A boost in supply should have strong deflationary pressures for the majority of the population's main consumption good. Therefore, unlike ODA for consumption or for investments with small supply-side effects, ODA increases to support an African green revolution are expected to have anti-Dutch disease effects through real exchange rate depreciation. The multisector model presented here shows this indeed to be the case under plausible economy-wide parameters.

The development of an applied economic model to capture ODA-financed rural productivity boosts and potential real exchange rate depreciation marks a departure from previous papers on Dutch disease, such as those by Corden (1984), van Wijnbergen (1984), and Sachs and Warner (1995). These papers focus mainly on natural resource boom economies, rather than target-linked increases in finance meant to improve productivity directly. The model here also marks a counterpoint to the argument of Rajan and Subramanian $(2008,2011)$ that ODA negatively affects growth potential through the price competitiveness of the manufacturing sector.

This paper builds on the logic presented in Adam and Bevan's (2006) careful consideration of aid's supply-side productivity effects in a model calibrated to Uganda. In a migration-free model with Engel curve attributes, they focus on public-infrastructure-induced productivity spillovers and learning by doing in the export sector. Their model shows that welfare effects and real exchange rate dynamics are highly sensitive to the location of productivity effects and the composition of domestic demand. They emphasize aggregate linkages to rural productivity in agricultural sectors, but do not explore these dynamics in detail, and outline the need for more careful consideration of supply-side effects in these and other sectors.

The current paper takes up that challenge by building a subsistence threshold-based framework that shows a clear poverty-trap dynamic in which low-input agriculture and soil nutrient depletion result in economic stagnation. The model here does not aim to provide specific point estimates of macroeconomic effects. Instead, in line with the arguments of Robinson and Lofgren (2005), it aims to outline medium-term structural economic shifts that would 
be prompted by agricultural green revolutions in Africa. Some aspects are similar to the nontradable agriculture analytical model in Matsuyama (1992), although here staple foods are treated as nontradable due to the reality of subsistence food economies with low private and public capital stocks, rather than as a product of overall economy openness. Indeed, one important part of the model is the ability for farm labor to shift easily between nontradable (food) and tradable (cash crop) sectors while remaining on farm.

The approach presented here differs from models by Lofgren, Harris and Robinson (2002), which follow the Derviş, de Melo and Robinson (1982) tradition of a standardized, mixed-complementarity computable general equilibrium (CGE) model that can be applied across countries with minimal adjustments. The main features of the model by Lofgren and colleagues are household consumption of nonmarketed commodities, transaction costs for marketed commodities, and a framework that allows any "activity" to produce multiple commodities and any commodity to be produced by multiple activities. Production technologies follow a nested framework anchored mainly in constant elasticity of substitution. Labor is mobile across sectors, but not across geographies. The government sector is monolithic and exogenous. The core Lofgren, Harris and Robinson model has been applied to many countriesincluding Dorosh, El-Said and Lofgren's (2002) application to Uganda, which emphasizes agricultural productivity shocks. The authors find that direct positive productivity shocks provide less of a rural welfare boost than investments to decrease marketing margins.

Other prominent Africa-focused macroeconomic models have emphasized social development outcomes. Agenor and colleagues (Agenor, Bayraktarb and El Aynaoui 2005; Agenor, Bayraktarb and Pinto 2005) and Pinto and Bayraktarb (2005) created a model for Ethiopia and Niger in which cross-country regression coefficients estimate the effects of, for example, per capita income and health expenditures on malnutrition and infant mortality. The real economy is limited to a single representative sector with a parameterized elasticity on poverty.

Meanwhile, the MAMS "maquette" developed by Bourguignon and colleagues (see Bourguignon et al. 2004 for the original model) was novel for its decomposition of government sectors, emphasizing interactions between labor markets, infrastructure, and the achievement of outcome targets for poverty, education, health and water and sanitation (for the details, see Lofgren and Diaz-Bonilla 2006). Its major contribution is the ability to show the evolution of intermediate outcomes en route to the Millennium Development Goals and highlight the implications of various sequencing permutations among sectors (Bourguignon and Sundberg 2006a, 2006b). For example, early simulations found that investments in infrastructure have large spillover effects that reduce the need for ODA in later periods. In applying the MAMS model to Ethiopia, Bourguignon and Sundberg (2006a) find that the front-loading of aid disbursements also poses serious Dutch disease risks in the short run. The original MAMS model had a single representative productive sector, which did not permit evaluation of subsistence dynamics, poverty traps, and the evolution out of staple crop agriculture. More recent applications of MAMS have adapted the core Lofgren et al. (2002) framework as the basis for incorporating more detailed dynamics among productive sectors (Lofgren, Cicowiez and Diaz-Bonilla 2013). At most recent count, the MAMS approach has been used for scenario assessment across more than 45 countries (lbid.) 
Meanwhile, very few previous models have integrated the biophysical aspects of agricultural productivity into a developing country CGE framework. Soil nutrient dynamics are particularly crucial for understanding Africa's unique agricultural challenge because they have significant effects on both yields and farmers' choices for fertilizer use (Marenya and Barrett 2009; Matsumoto and Yamano 2009). Alfsen and colleagues (1997) present one notable study in this regard. They use Aune and Lal's (1995) Tropical Soil Productivity Calculator in a 17-sector closed public sector model to show the contribution of soil nutrients to the growth of gross domestic product (GDP), as long as fertilizer support is not detracting from other forms of investment.

A limitation of Alfsen and colleagues' model is that it treats soil nutrients as theoretically subject to infinite accumulation. It also does not allow for the practical reality of zero fertilizer use among large numbers of small-holder farmers, because the fertilizer term enters as a simple input in a Cobb-Douglas production function and zero input implies zero output. Wiig and colleagues (2001) pursued a similar strategy to introduce soil degradation as a time-dependent Hicks neutral productivity coefficient in the agricultural production functions. The 20 -sector model of structural adjustment programs in Tanzania embeds the same core limitations as Alfsen and colleagues, but nonetheless finds that the inclusion of soil nutrient dynamics reveals a 5 percent decrease in GDP levels at the end of a 10-year period.

In comparison with our model, the most similarly green revolution-spirited CGE approach is that of Breisinger and colleagues (2011), which extends the approach of Lofgren, Harris and Robinson (2002) to include within-country disaggregation by agroecological zone, crop market and income group. Their model is applied to Ghana, and a green revolution is achieved through exogenously defined total factor productivity improvements to achieve target yields, prompting greater input use through factor markets. Foreign savings are fixed, so incremental investments are all financed through domestic resources. The green revolution and its spillover effects are found to be significantly pro-poor.

The model presented in this paper has several novel features. First, its green revolution-focused structure is very relevant to those low-income African economies that are still dominated by subsistence agriculture. The model highlights the role of farmers' constraints to self-financing of inputs alongside minimum subsistence consumption requirements for freeing up labor to sectors outside of food production. Second, it explicitly incorporates a soil nutrient capital equation in the agricultural production functions. Third, it allows for multiple forms of geographic variation in underlying productivity within a country. Fourth, it includes three differentiated channels of public and foreign finance-one for agricultural inputs, one for road building, and another for social services like health and education. This allows direct comparison of the macroeconomic consequences of ODA-backed public finance for each channel. Of particular importance, the model is structured such that ministry-level public budgets can be entered directly as parameters, including discontinuous shifts from year to year.

Uganda is used as an illustrative case. Its economy is suitable because even amid its relative economic success during the past two decades, most of the country's labor has still been located in rural areas and remains overwhelmingly focused on staple food production. Rural productivity remains extremely low, and more than a third of 
the country still lives in extreme poverty. Ever since Winston Churchill described Uganda as the "pearl of Africa" a century ago, the stereotypical view of the country's agriculture has been one of high productivity and potential. But the reality is much more subtle and includes major variations across the country's climatic zones, soil types and changes in soil nutrient availability over time. Soil nutrient losses have been considerable, and nutrient stocks have fallen below critical levels in many parts of the country. With four major regions (see Map 1), Uganda's economy is therefore suitably representative of many of the core issues of African economic development and has the potential for broader application to other countries.

The paper proceeds in six sections. Following this introduction, Section 2 briefly summarizes key elements of Uganda's economy, with emphasis on the staple agriculture sector. Section 3 presents the general equilibrium model. Section 4 briefly describes the approach to data parameterization. Section 5 presents key scenarios using the model. Section 6 presents a discussion of the results, and then a final section concludes. 


\section{AN ILLUSTRATIVE AFRICAN ECONOMY: UGANDA}

ganda faces many core challenges common across low-income African subsistence economies. This country

of more than 34 million people saw a slight uptick in economic growth in the late 2000s but its growth has been inconsistent and poverty is still pervasive. Some of the economy's key characteristics are described here. These draw from sources mainly published during the course of the early 2000 s and thus present a thematic overview rather than a precise snapshot at a single point in time. We note, for example, that these data do not include the economic complexities deriving from Uganda's recent commencement of oil production.

As of 2009, approximately 38 percent of Uganda's population lived below the international extreme poverty line of $\$ 1.25$ per day (World Bank 2012). The vast majority of the country's poverty is concentrated in rural areas, where most Ugandans are engaged in crop agriculture. Infrastructure is limited. Only approximately 10 percent of households had electricity as of the early 2000s (Okidi et al. 2005b). For decades, gross domestic saving rates have been extremely low, well below 10 percent of GDP, although they have climbed as high as 13 percent in recent years, likely linked to the commencement of oil production. A 1997 Bank of Uganda survey found that fewer than a quarter of rural Ugandans had ever saved and that 85 percent of the other three-quarters cited low income as the primary factor for not doing so (Musinguzi and Smith 2000).

\section{Figure 1: Uganda's Cereal Production per Capita, 1961-2010}

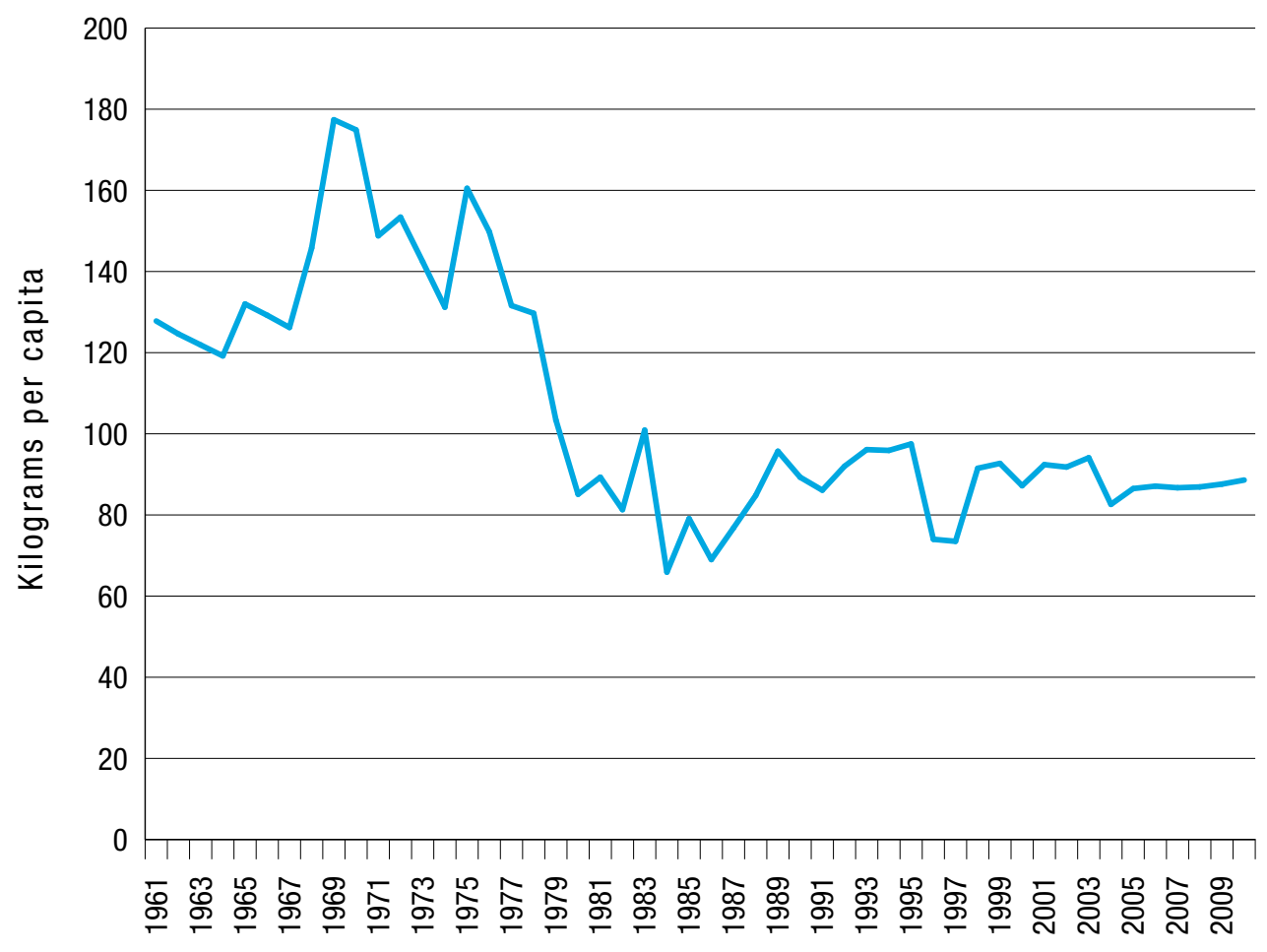

Source: World Bank (2012). 


\section{Staple Food Agriculture}

Uganda's staple agriculture sector has experienced general long-term stagnation. Figure 1 presents trend data for cereal production per capita from 1961 to 2010 . From a peak of nearly 180 kilograms per person in 1969, output has been stagnant, at less than 100 kilograms per person, since the early 1980s. Figure 2 indicates similar trends for a broader index of food production per capita. Figure 3 shows relative stagnation in land productivity too, with yields hovering at approximately 1.4 to 1.6 tons per hectare for three decades. These yields are slightly higher than the African average, but need to be considered in light of rapid population growth and the long-term decline in available arable land per person, from 0.5 hectares in the early 1960 s to 0.2 hectares today, as shown in Figure $4 .{ }^{2}$ Siriri, Bekunda and Jama (2005) find that yields are typically one-quarter to one-tenth of current potential. This is significantly driven by the low usage of modern farm inputs. Fewer than a third of agricultural households use improved seeds, and only 8 percent use inorganic fertilizer (Okoboi and Barungi 2012). Yet despite the stagnation, Uganda has not become a marked food importer. The country engages in almost no staple crop trade, and in recent years nearly all its imported food was wheat and maize aid for conflict-affected areas in the north.

\section{Figure 2: Uganda's Food Production per Capita, 1961-2010}

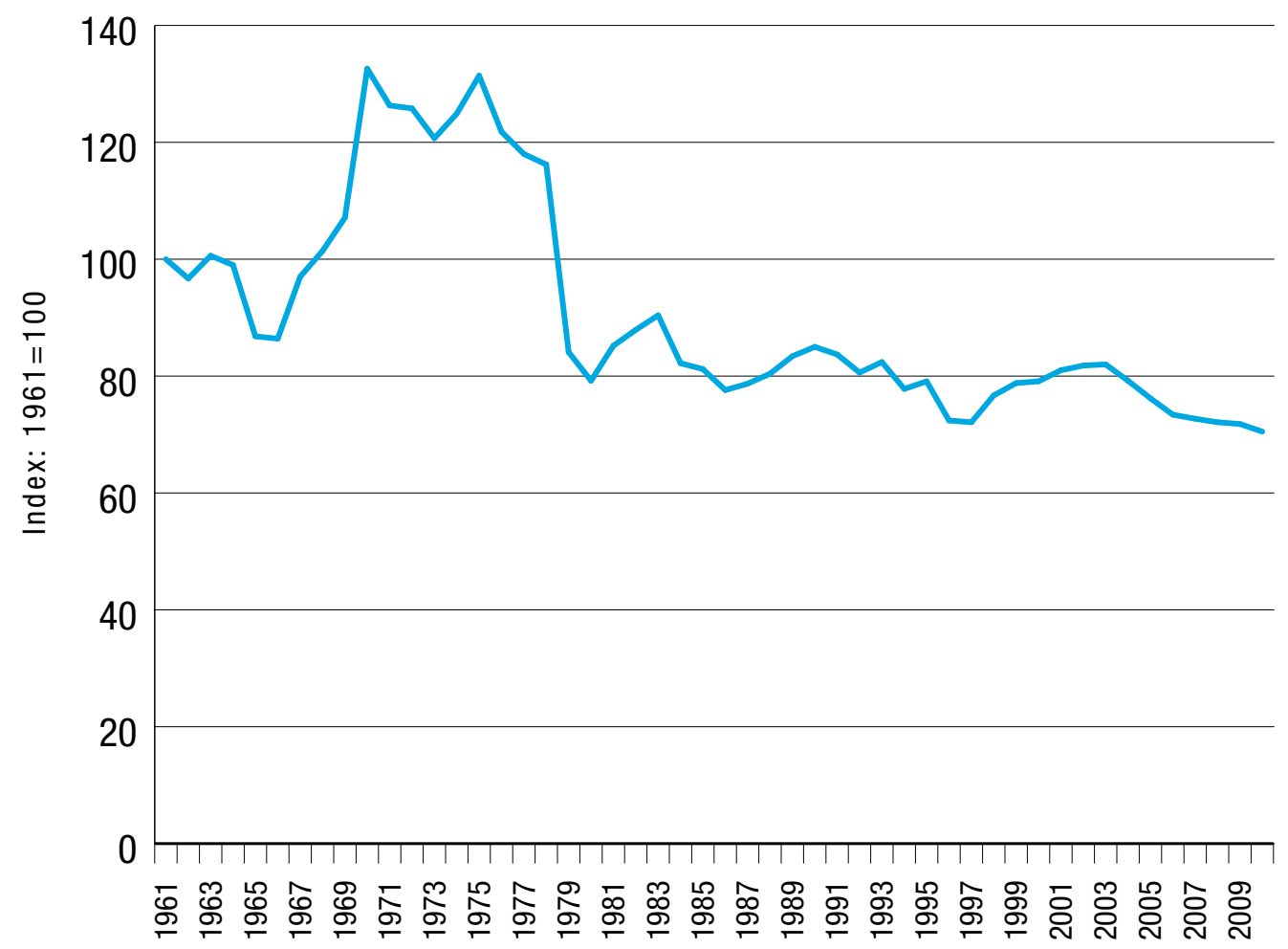

Source: World Bank (2012). 


\section{Figure 3: Uganda's Cereal Yields, 1961-2010}

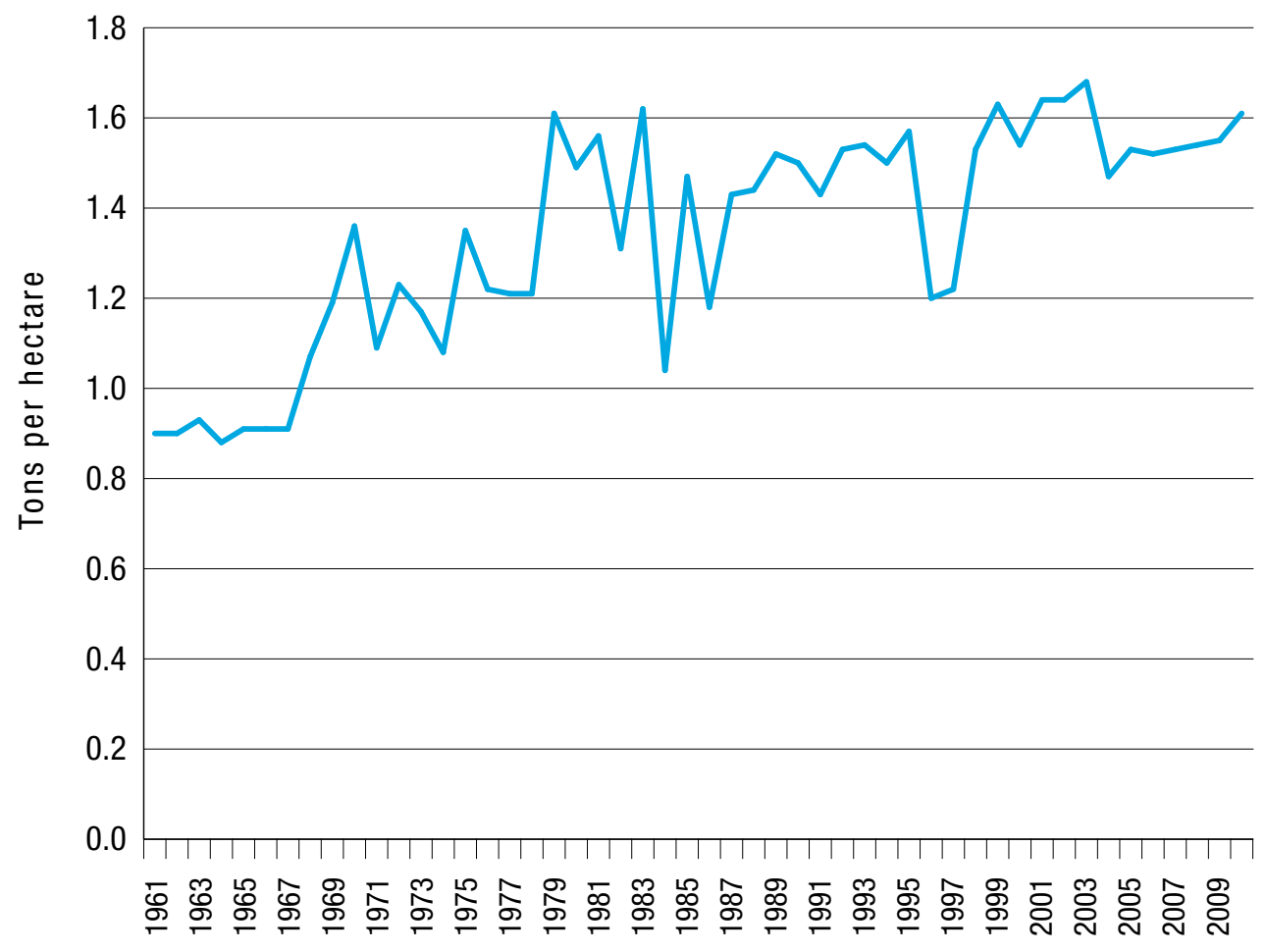

Source: World Bank (2012).

Like much of Africa, Uganda faces a major soil nutrient challenge. For many years, agricultural output was maintained through land clearing, but population pressures and a lack of fallowing mean that farmers are now mining nutrients at faster rates and decreasing long-term yields in the process. Data compiled by Ssali (2002) and Ruecker (2005) indicate that a large portion of Uganda's soil is now below the so-called critical 3 percent value for soil organic matter. Henao and Baanante (2006) estimate loss rates for nitrogen, phosphorous and potassium to be among the highest in Africa, at more than 60 kilograms per hectare per year. The consequences are significant. Nkonya and colleagues (2005) estimate a cost of \$153 per household per year to replenish mined soil nutrients at market prices, equivalent to nearly a fifth of GDP at the time of calculation. Fallow periods have fallen from 10 to 15 years a century ago down to 2 and even 0 years (Nandwa and Bekunda 1998). In large parts of the country, fewer than 10 percent of farms are even using fallows (Pender et al. 2001). Fertilizer is necessary, even if not sufficient, to stop and reverse the patterns of nutrient decline and address the soil nutrient challenge. However, cost is a barrier because staple crop farmers often face poor relative returns on fertilizer, often with a "value to cost ratio" of 1 or less (e.g., Wortmann and Kaizzi 1998; de Jager, Onduru and Walaga 2003; Kaizzi 2002; Nkonya et al. 2005; Matsumoto and Yamano 2009). ${ }^{3}$

Uganda's internal geographic heterogeneity underscores the disparate range of farming systems across Africa. Ruecker and colleagues (2003) used four climate variables to construct seven categories of agricultural potential 


\section{Figure 4: Uganda's Arable Land per Person, 1961-2010}

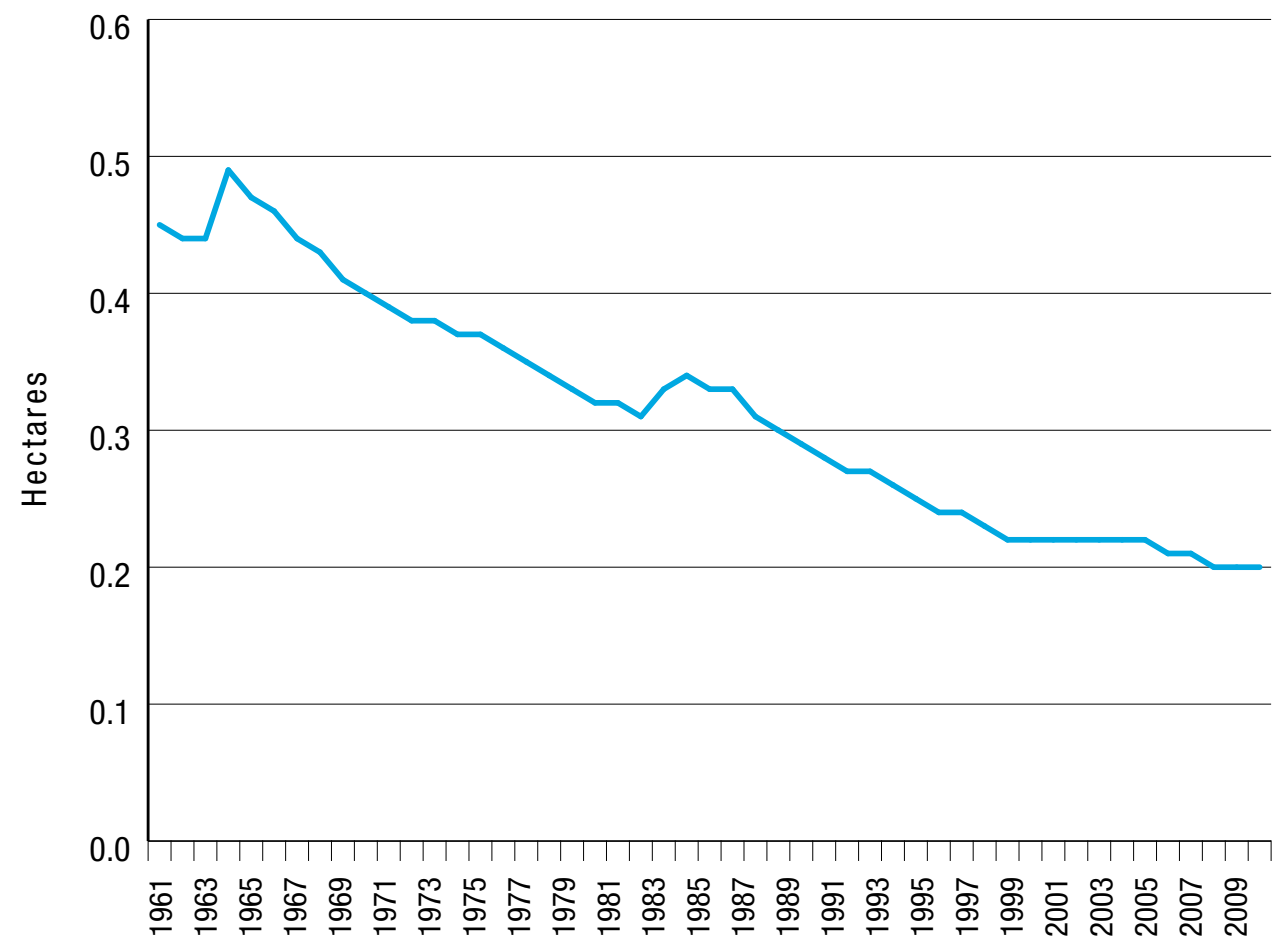

Source: World Bank (2012).

across the country, as summarized in Maps $2(a-d)$ and 3. First, annual precipitation cycles affect the extent of water availability throughout the year. The northeastern section of the country has unimodal rainfall, while the southern and central areas, which are closer to the equator, have bimodal rainfall. Second, the length of growing period is measured as the period over which mean monthly rainfall exceeds half the mean potential evapotranspiration. This ranges from less than 5 months in the northeastern districts to 10 or more months in the central region and in the southwestern highlands. Third, the actual level of annual precipitation varies tremendously throughout the country and changes at a steep gradient, particularly in the "crescent" around Lake Victoria. Fourth, extreme temperatures constrain agricultural productivity. The range of growing conditions results in significant variations in the concentration of staple crop by region.

\section{Other Key Sectors}

Cash crops, especially coffee, have historically been a major driver of Uganda's growth and poverty reduction. However, fewer than 10 percent of the country's farm households grow coffee, and its share of exports has declined significantly (Kappel, Lay and Steiner 2005; Bussolo et al. 2006). As of the mid-2000s, cotton, tea and tobacco had increased in volume and total value exported, while flower exports had also been introduced. Fisheries have overtaken coffee in overall export value, but only a small share of the population is engaged in that source of 
economic activity. In any case, all the export shares need to be considered in the context of Uganda's low overall export/GDP ratio, at approximately 24 percent.

Manufacturing remains a small element of the economy, historically accounting for less than 10 percent of GDP, as indicated in Table 1. Table 2 shows that the sector still employed less than 4 percent of the labor force as of 2002. The service sectors—including wholesale and retail trade, transport, communications and construction—employed

\section{Table 1: Uganda GDP Sector Shares, 1990/91-2004/05}

\begin{tabular}{|c|c|c|c|c|}
\hline MONETARY SECTORS & 1990/91 & $1994 / 95$ & 1999/00 & $2004 / 05$ \\
\hline Agriculture & $22.7 \%$ & $25.2 \%$ & $20.3 \%$ & $18.7 \%$ \\
\hline Cash crops & $2.8 \%$ & $6.3 \%$ & $3.6 \%$ & $2.8 \%$ \\
\hline Food crops & $12.3 \%$ & $12.2 \%$ & $10.7 \%$ & $10.2 \%$ \\
\hline Livestock & $4.1 \%$ & $3.4 \%$ & $3.4 \%$ & $2.7 \%$ \\
\hline Forestry & $1.1 \%$ & $0.9 \%$ & $0.7 \%$ & $0.7 \%$ \\
\hline Fishing & $2.4 \%$ & $2.3 \%$ & $2.0 \%$ & $2.3 \%$ \\
\hline Mining \& quarrying & $0.3 \%$ & $0.3 \%$ & $0.8 \%$ & $0.9 \%$ \\
\hline Manufacturing & $5.7 \%$ & $7.2 \%$ & $9.4 \%$ & $9.0 \%$ \\
\hline Electricity/water & $0.9 \%$ & $1.3 \%$ & $1.4 \%$ & $1.3 \%$ \\
\hline Construction & $4.8 \%$ & $5.5 \%$ & $7.6 \%$ & $9.3 \%$ \\
\hline Wholesale \& retail trade & $12.3 \%$ & $12.0 \%$ & $11.2 \%$ & $10.9 \%$ \\
\hline Hotels \& restaurants & $1.3 \%$ & $1.8 \%$ & $2.4 \%$ & $3.3 \%$ \\
\hline Transport/communication & $4.0 \%$ & $3.9 \%$ & $5.3 \%$ & $7.7 \%$ \\
\hline Road & $2.9 \%$ & $3.0 \%$ & $3.7 \%$ & $3.5 \%$ \\
\hline Rail & $0.3 \%$ & $0.2 \%$ & $0.2 \%$ & $0.1 \%$ \\
\hline Air \& support services & $0.4 \%$ & $0.4 \%$ & $0.5 \%$ & $0.5 \%$ \\
\hline Communications & $0.4 \%$ & $0.4 \%$ & $0.9 \%$ & $3.6 \%$ \\
\hline Community services & $15.4 \%$ & $17.0 \%$ & $20.4 \%$ & $20.0 \%$ \\
\hline General government & $3.2 \%$ & $4.5 \%$ & $4.3 \%$ & $4.2 \%$ \\
\hline Education & $3.9 \%$ & $4.0 \%$ & $6.1 \%$ & $6.4 \%$ \\
\hline Health & $1.5 \%$ & $1.3 \%$ & $2.2 \%$ & $2.3 \%$ \\
\hline Rents & $3.2 \%$ & $3.5 \%$ & $4.3 \%$ & $3.8 \%$ \\
\hline Miscellaneous & $3.6 \%$ & $3.8 \%$ & $3.6 \%$ & $3.2 \%$ \\
\hline TOTAL MONETARY & $67.4 \%$ & $74.1 \%$ & $78.7 \%$ & $81.0 \%$ \\
\hline \multicolumn{5}{|l|}{ NON-MONETARY SECTORS } \\
\hline Agriculture & $28.4 \%$ & $22.3 \%$ & $16.9 \%$ & $14.8 \%$ \\
\hline Food crops & $25.7 \%$ & $19.9 \%$ & $13.7 \%$ & $11.9 \%$ \\
\hline Livestock & $1.3 \%$ & $1.2 \%$ & $1.9 \%$ & $1.7 \%$ \\
\hline Forestry & $1.1 \%$ & $0.9 \%$ & $1.2 \%$ & $1.0 \%$ \\
\hline Fishing & $0.3 \%$ & $0.3 \%$ & $0.3 \%$ & $0.3 \%$ \\
\hline Construction & $0.8 \%$ & $0.7 \%$ & $0.6 \%$ & $0.5 \%$ \\
\hline Owner-occupied dwelling & $3.3 \%$ & $2.9 \%$ & $3.7 \%$ & $3.7 \%$ \\
\hline TOTAL NON-MONETARY & $32.6 \%$ & $25.9 \%$ & $21.3 \%$ & $19.0 \%$ \\
\hline
\end{tabular}

Source: Data from Uganda Ministry of Finance, Planning and Economic Development 2005; authors' calculations. 
Table 2: Sectoral Decomposition of Ugandan Labor Force and Value Added, 2002

\begin{tabular}{|c|c|c|c|c|c|c|c|}
\hline Sector & Rural labor & $\begin{array}{c}\% \text { of } \\
\text { national } \\
\text { labor force }\end{array}$ & $\begin{array}{l}\text { Urban } \\
\text { labor }\end{array}$ & $\begin{array}{c}\% \text { of } \\
\text { national } \\
\text { labor force }\end{array}$ & Total labor & $\begin{array}{c}\% \text { of } \\
\text { national } \\
\text { labor force }\end{array}$ & $\begin{array}{l}\% \text { of Net } \\
\text { Value } \\
\text { Added }\end{array}$ \\
\hline $\begin{array}{l}\text { Staples and cash } \\
\text { crops }\end{array}$ & $4,796,824$ & $69.0 \%$ & 115,768 & $1.7 \%$ & $4,912,592$ & $70.7 \%$ & $18.3 \%$ \\
\hline Animal farming & 260,581 & $3.7 \%$ & 22,298 & $0.3 \%$ & 282,879 & $4.1 \%$ & $2.1 \%$ \\
\hline $\begin{array}{l}\text { Mining \& } \\
\text { quarrying }\end{array}$ & 14,616 & $0.2 \%$ & 5,124 & $0.1 \%$ & 19,740 & $0.3 \%$ & $0.3 \%$ \\
\hline $\begin{array}{l}\text { Tradable } \\
\text { manufacturing }\end{array}$ & 208,296 & $3.0 \%$ & 64,737 & $0.9 \%$ & 273,033 & $3.9 \%$ & $10.6 \%$ \\
\hline Utilities & 5,508 & $0.1 \%$ & 8,861 & $0.1 \%$ & 14,369 & $0.2 \%$ & $3.9 \%$ \\
\hline $\begin{array}{l}\text { Non-tradable } \\
\text { local capital } \\
\text { goods }\end{array}$ & 58,774 & $0.8 \%$ & 49,934 & $0.7 \%$ & 108,708 & $1.6 \%$ & $11.6 \%$ \\
\hline $\begin{array}{l}\text { Non-tradable } \\
\text { services }\end{array}$ & 190,815 & $2.7 \%$ & 222,521 & $3.2 \%$ & 413,336 & $5.9 \%$ & $28.4 \%$ \\
\hline $\begin{array}{l}\text { Tradable } \\
\text { services }\end{array}$ & 105,806 & $1.5 \%$ & 117,219 & $1.7 \%$ & 223,025 & $3.2 \%$ & $8.1 \%$ \\
\hline Public service & 317,228 & $4.6 \%$ & 188,741 & $2.7 \%$ & 505,969 & $7.3 \%$ & $16.7 \%$ \\
\hline Other & 99,193 & $1.4 \%$ & 97,193 & $1.4 \%$ & 196,386 & $2.8 \%$ & \\
\hline Totals & $6,057,641$ & $87.2 \%$ & 892,396 & $12.8 \%$ & $6,950,037$ & $100.0 \%$ & $100.0 \%$ \\
\hline
\end{tabular}

Source: Uganda Bureau of Statistics 2004; Uganda 2002 Social Accounting Matrix; authors' calculations.

approximately 9 percent of the labor force, split fairly evenly between urban and rural areas, accounting for approximately one-third of GDP. Government accounted for the largest share of GDP, at approximately 20 percent, and 7 percent of the labor force. Most of the public labor force is situated in rural areas where the population lives, but approximately one-third is based in urban areas, in particular the public administration hub of Kampala.

\section{Transport Costs and Infrastructure}

A key attribute of Uganda's economy is its limited infrastructure and high transport costs, which are among the highest in the world (Buys 2006). In multiple sectors, including food, these costs provide both implicit protection for domestic producers and implicit protection on exports (Milner et al. 2000; Rudaheranwa 2006). The World Bank (2006) reports that $\$ 80-90$ per ton is required to cover fertilizer transportation from the port of Mombasa to Kampala, and another $\$ 30-35$ is needed to reach Mbarara in southwest Uganda. Poor roads are responsible for much of these high costs. According to the 2005 National Transport Plan, only 5 percent of the country's roads are paved, and only approximately 40 percent of those are in good condition (Uganda Ministry of Works, Housing, and Communications and TAHAL Engineers 2005). 


\section{THE MODEL}

\section{Key Attributes}

ur macroeconomic model has several fundamental attributes aligned with the key elements of many low-
income African economies:

- The first is a dominant factor of rural subsistence economic stagnation, with low savings and flat incomes in the absence of productivity increases in agriculture.

- The second is a minimum subsistence food requirement that underpins the thresholds for agricultural diversification, savings and labor switching to other sectors.

- The third is geographic variation in both productivity levels and locations of production. The model allows agricultural productivity, including soil productivity and depletion rates, to vary by region. Agriculture only takes place in rural areas, and manufacturing is restricted to urban areas.

- The fourth is a constraint to self-financing agricultural inputs, especially fertilizer, among small-holder farmers.

- The fifth is a soil nutrient depletion and accumulation process that directly feeds into agricultural production functions.

- The sixth is an emphasis on road infrastructure, with an "iceberg" transport cost structure that directly affects relative prices for key inputs and outputs, particularly in agriculture, and decreases in the presence of road improvement.

- The seventh is labor mobility from rural to urban areas, with migration parameterized to respond to relative wages.

- The eighth is a public service delivery sector that can map easily to public sector accounts, allowing differentiation between capital and recurrent accounts, plus specific budget variations by year, geographic zone, subsector and import content.

The model's key contribution is to allow these dynamics to be analyzed in an integrated manner. In this paper, the dynamics are presented using indicative values aligned with the Ugandan economy.

\section{Core Structure}

The model follows a recursive structure over 10 periods, with decisions depending on past and present periods but no forward-looking dynamics. The productive economy includes both tradable and nontradable sectors. There are no intermediate goods. The two domestic tradable sectors are cash crops and manufacturing, both of which are assumed to have zero domestic consumption, fixed numeraire tradable prices and infinite elasticity of demand. In reality, Uganda's manufacturing sector is very small and includes a focus on import substitution, so the assumption of full export orientation is made for the purposes of simplification within the model's core focus on rural and rural-urban dynamics. 
Implicit in the model is a fixed nominal exchange rate, so changes in domestic prices indicate changes in the real exchange rate. There is also an imported sector that provides consumption goods and capital goods for investment with infinitely elastic supply at fixed prices. The nontradable sectors are staple food production, rural services and urban services, all of which have locally determined prices. The government sector includes rural road building, urban public administration and economy-wide health and education. In line with African economies' real world need to follow a medium-term expenditure framework, public services follow a preprogrammed expenditure plan.

The model allows flexibility around the number of urban and rural geographic units. The exact number of units included in a simulation is ultimately defined by data availability and computational capacity. In applying the model to Uganda, the simulations include four rural units-mapping to the country's Eastern, Western, Central and Northern regions-and one urban unit, Kampala. Table 3 maps the sectors to regions. The two agricultural sectors, cash crops and staple foods, only take place in the rural areas, as does the rural service sector. Manufacturing only takes place in urban areas, as does the urban service sector. Food is produced in the rural sectors to feed both the local rural population and the urban population. Cash crops and manufactured goods are entirely for export. As of the middle of the last decade, Kampala accounted for approximately 85 percent of the country's urban economic activity so this is assumed to be a reasonable simplification of the underlying national economy.

The model's emphasis on Engel's law and nonhomothetic preferences links squarely to its rural/urban divide because rural staple food production must satisfy a minimum level of aggregate per capita food requirements for both rural and urban populations. The model employs a savings-driven neoclassical closure with a fixed savings rate that applies on incomes above the minimum food basket, and private saving is set equal to productive sector invest-

\section{Table 3: Mapping of Economic Sector Activity, by Region}

\begin{tabular}{|c|c|c|c|c|c|c|}
\hline \multirow[b]{2}{*}{ Sector } & \multirow[b]{2}{*}{ Price (T/NT) } & \multicolumn{4}{|c|}{ Rural Regions } & \multirow{2}{*}{$\begin{array}{c}\text { Urban Region } \\
\text { Kampala }\end{array}$} \\
\hline & & Western & Eastern & Northern & Central & \\
\hline Staple foods & NT & $\sqrt{ }$ & $\sqrt{ }$ & $\sqrt{ }$ & $\sqrt{ }$ & \\
\hline Cash crops & $\mathrm{T}$ & $\sqrt{ }$ & $\sqrt{ }$ & $\sqrt{ }$ & $\sqrt{ }$ & \\
\hline Rural service & NT & $\sqrt{ }$ & $\sqrt{ }$ & $\sqrt{ }$ & $\sqrt{ }$ & \\
\hline Urban service & NT & & & & & $\sqrt{ }$ \\
\hline Manufacturing & $\mathrm{T}$ & & & & & $\sqrt{ }$ \\
\hline $\begin{array}{l}\text { Imported capital \& } \\
\text { consumption goods }\end{array}$ & $\mathrm{T}$ & $\sqrt{ }$ & $\sqrt{ }$ & $\sqrt{ }$ & $\sqrt{ }$ & $\sqrt{ }$ \\
\hline \multicolumn{7}{|l|}{ Government sector } \\
\hline Roads & NT & $\sqrt{ }$ & $\sqrt{ }$ & $\sqrt{ }$ & $\sqrt{ }$ & \\
\hline Administration & NT & & & & & $\sqrt{ }$ \\
\hline Health & NT & $\sqrt{ }$ & $\sqrt{ }$ & $\sqrt{ }$ & $\sqrt{ }$ & $\sqrt{ }$ \\
\hline Education & NT & $\sqrt{ }$ & $\sqrt{ }$ & $\sqrt{ }$ & $\sqrt{ }$ & $\sqrt{ }$ \\
\hline $\begin{array}{l}\text { Other infrastructure } \\
\text { (e.g., water) }\end{array}$ & NT & $\sqrt{ }$ & $\sqrt{ }$ & $\sqrt{ }$ & $\sqrt{ }$ & $\sqrt{ }$ \\
\hline
\end{tabular}

Note: $T=$ tradable, NT= nontradable. 
ment. The government balance is financed by external ODA "cash," separate from ODA for agricultural inputs. The endogeneity of ODA differs from similar models that typically frame official foreign savings as fixed. This approach is taken to inform the ground-up comparison of various potential public finance priorities in terms of both total cost and resulting medium-term macroeconomic dynamics.

Capital is immobile across regions, although foreign investment is possible in the manufacturing sector. Labor is fully mobile from rural to urban regions, although not across rural regions, and responds to relative real incomes. Total labor is fixed. Prices are free variables playing market clearing functions. In allocating their labor, rural households not directly hired by the public sector can choose between four sectors: staple foods, cash crops, rural services or migration to the urban area.

Real incomes, net of food, are equilibrated instantaneously in the rural sectors and over time between rural and urban sectors. Thus the most fundamental impulses driving labor markets are productivity in staple foods, relative food prices between rural and urban areas, and real income differences between rural and urban areas. Food prices are affected by transport costs, which are in turn determined by the scale of the road network. As the road network increases, transport costs decrease and less total food production is required to feed the population.

\section{On Soil Nutrient Dynamics}

The model contains 13 blocks of equations, the first of which includes rural agricultural production functions and soil nutrient balances as productivity determinants within those functions. In light of the evidence on soil nutrient losses in Uganda and throughout Africa, the agricultural production function needs to address two key soil nutrient issues. First, what will happen to the stock of soil nutrients if fertilizer is used at a large scale? For example, will soil organic matter simply level off at a new steady state; will it follow a linear upward trajectory, as in the paper by Aune and Lal (1995); or will it begin to increase over some period and then level off at a higher equilibrium? Algebraically speaking, the functional form of $\theta(\circ)$ in the following equation needs to be defined:

$$
S O_{i, t}=\theta\left(S O_{i, t-1}, F E R T_{i, t-1}\right)
$$

where $S O$ is soil organic matter and FERT is fertilizer use. The $i$ subscript indicates a geographic index, and $t$ indicates the time period (i.e., a year or a growing season).

Second, what will be the long-run yield implications of a leveling off or increase of soil organic matter (SOM) in the presence of long-term fertilizer use, and what are the marginal effects of fertilizer in relation to SOM over time? In other words, what is the functional form of $\Gamma\left({ }^{\circ}\right)$ in equation (S.2),

$$
F_{i, t}=\Gamma\left(S O_{i, t}, F E R T_{i, t}, \boldsymbol{Z}_{i, t}\right)
$$

where $F$ represents food output and $\boldsymbol{Z}$ represents a vector of other related inputs. A Cobb-Douglas agricultural production function in equation (S.3) adds specificity to equation (S.2): 


$$
F_{i, t}=A_{i, t}\left(K_{i, t}\right)^{\alpha}\left(L_{i, t}\right)^{\beta}\left(H_{i, t}\right)^{(1-\alpha-\beta)}
$$

where $A$ is a productivity term, $K$ is physical capital, $L$ is labor, and $H$ is land area. The terms $\alpha$ and $\beta$ represent factor shares. The main commodity-based green revolution technologies-seeds and fertilizer-enter directly through the $A$ term, which is defined in equation (S.4) to be a function of baseline germplasm-defined crop yields $(Y)$, the agrozone potential $(A Z)$, available soil nutrient stock, and a green revolution package of inputs $(G)$ :

$$
A_{i, t}=\mathrm{f}\left(Y_{i, t}, A Z_{i}, S O_{i, t}, G_{i, t}\right)
$$

The agrozone potential includes both climate factors $\left(\Omega_{i}^{c l i m}\right)$, such as temperature and precipitation, and soil water carrying capacity $\left(\Omega_{i}^{\text {wat }}\right)$, which is defined by soil type:

$$
A Z_{i}=\Omega_{i}^{c l i m} \Omega_{i}^{\text {wat }}
$$

Setting $\Omega_{\mathrm{i}}^{\text {clim }}$ equal to 1 for high-potential climates allows for downward-scaled values for medium or low potential, with $1 \geq \Omega_{\mathrm{i}}^{\text {clim }}>0$. A similar indexing approach can be applied to $\Omega_{\mathrm{i}}{ }^{\text {wat }}$.

The soil nutrient stock acts like a capital stock that is adjusted by net nutrient flows per season. For the purposes of exposition here, this is described as nitrogen (available rather than total nitrogen), although in reality it includes a more complex array of macro and micronutrients. Equation (S.6) reflects how nutrient flows are affected by the soil take-up rate $(l)$ in fertilizer inputs, a crop-specific nutrient extraction rate $(\pi)$, erosion $(R)$ and nitrogen accumulated through natural fixation and lying fallow $(E):^{4}$

$$
N_{i, t}=\mathbf{\imath}\left(F E R T_{i, t-1}\right)-\pi\left(F_{i, t-1}\right)-R_{i, t-1}+E_{i, t-1}
$$

Soil nutrient stocks are bounded by upper and lower thresholds in a confined piece of land, so the nutrient accumulation and depletion processes can be represented in the logistic function of equation (S.7). The $N$ variable is the key intermediate input, and the level of soil nutrients in time $t$ is a function of the average net inflows per period. A negative average $N$ value or a large value of $\psi$, the geographically indexed constant, imply a large denominator and a small total value of available nutrients. The value of $\psi$ can be estimated as the ratio of current versus maximum soil nutrient levels, which thus indicate the current value of the $S$-intercept on the logistic function. In this equation, $\Theta$ represents the maximum available soil nutrient level in a location, and $\psi$ represents a geographically specific constant parameter. The initial $S O$ value can be defined as per equation (S.8):

$$
\begin{aligned}
& S O_{\mathrm{i}, \mathrm{t}}=\frac{\Theta_{i}}{1+\psi_{i} e^{-\sum_{t} N_{i, t}}} \\
& S O_{\mathrm{i}, 0}=\frac{\Theta_{i}}{1+\psi_{i}}
\end{aligned}
$$


The final $G$ term in equation (S.4) captures permutations pertaining to the introduction of a green revolution package of technologies, including the adoption of high-yield variety seeds (HYV), agricultural extension services (EXT) and fertilizer use (McArthur 2013). For simplicity, one can assume that $H Y V$ and EXT are binary variables because farmers will generally either adopt seeds or not, and extension is either present or not. The formulation in equation (S.9a) allows for four basic permutations to address the presence of extension services and high-yield varieties. The "nn" subscript on the $\sigma$ multiplier indicates no extension and no HYVs; " $n y$ " indicates no extension and yes to the presence of HYVs, and so forth. In most of rural Africa, there is almost no history of rural small holders using inorganic fertilizer, so it is assumed that fertilizer is only used in the presence of a policy decision to provide agricultural extension services. Because successful green revolution programs have typically relied on packages of inputs, equation (S.9b) presents the operative reduced form of equation (S.9a). Of particular importance, the functional form allows convexity at all levels of fertilizer input and a nonzero productivity term in the absence of fertilizer, while also allowing a large and immediate productivity boost when fertilizer is introduced. The $\delta$ exponent on fertilizer can be set to equal 1 in an assumption of constant returns, or to equal less than 1 under an assumption of decreasing returns:

$$
\begin{aligned}
G_{i, t}= & {\left[\sigma_{i, n n}\left(1-E X T_{i, t}\right)\left(1-H Y V_{i, t}\right)+\sigma_{i, n y}\left(1-E X T_{i, t}\right)\left(H Y V_{i, t}\right)\right.} \\
& \left.+\sigma_{i, y n}\left(E X T_{i, t}\right)\left(1-H Y V_{i, t}\right)\left(1+F E R T_{i, t}\right)^{\delta}+\sigma_{i, y y}\left(E X T_{i, t}\right)\left(H Y V_{i, t}\right)\left(1+F E R T_{i, t}\right)^{\delta}\right]
\end{aligned}
$$

\section{Key Model Equations}

\section{Agriculture}

Equations (S.1) through (S.9b) capture the basic dynamics of soil nutrient accumulation in a manner that allows soil-relevant estimation of yields with relative simplicity while focusing on key policy decision variables for a green revolution. In the CGE model, equation block 1 (EQ.1.1 through EQ.1.8) applies the core elements of these equations to a broader computational model. This paper adopts the notation convention that model variables are listed

in CAPITAL letters and parameters are listed in small letters (e.g., theta). The full listing of equations, variables and parameters is presented in Appendices A, B and C, respectively.

The agricultural production functions for food, $F$, and cash crops, $C C$, are Cobb-Douglas and are indexed to each rural region, with no production in the urban region:

$$
F_{i, t}=S_{i, t}{ }^{*} \text { thetaf }_{i}^{*} \operatorname{land}_{i} *\left(1+F E R T_{i, t}\right) * E L F_{i, t} \text { alphaf }^{*} k f_{i}^{\text {betaf }}
$$

$$
C C_{i, t}=S_{i, t}{ }^{*} \text { thetacc }_{i}{ }^{*} \operatorname{land}_{i} *\left(1+F E R T_{i, t}\right) * E L C C_{i, t}^{\text {alphac }} *\left(\text { kcscale }^{*} K C C_{i, t}\right) \text { betac }
$$


There are five key elements to note in this equation structure. The first is the introduction of a soil productivity parameter, $S$. The second is that land is considered a fixed parameter in the immediate term and thus is presented without an exponent. The coefficients on capital and labor therefore sum to less than 1, and labor serves as the marketclearing factor in the economy. The third element is the introduction of fertilizer as a linear multiplier in production. ${ }^{5}$ Fertilizer enters the equation as $(1+F E R T)$ in order to accommodate the common African scenario of zero initial fertilizer use. Conceptually, the fertilizer term represents the package of green revolution technologies, including modern-variety seeds and agricultural extension, rather than fertilizer alone. The fourth item to note is the kcscale term in (EQ.1.3), which is inserted to facilitate parameterization of the capital stocks in the sectors other than staple foods. The fifth element to note is the use of "effective labor" (EL) rather than pure units of labor, allowing human capital to be indexed by the presence of health services, clean water and education. Unlike the MAMS approach, we do not pursue these human capital issues in detail in the context of this paper, but note their overarching importance as evidenced in the growth literature (e.g., Sala-i-Martin, Doppelhofer and Miller 2004), and also the model's potential scope for extension in this area.

In equations (EQ1.4) through (EQ.1.8), the soil productivity parameter follows the logic of equations (S.6) through (S.8), with the numerator defined as uppersoil, the upper-bound level of soil productivity, and NUTSUM the cumulative flow of soil nutrients inflows, NETIN, up to time $t$. To facilitate solubility in the numerical model, equation (EQ.1.8) presents a shorthand calculation for NETIN in each period, subtracting a fixed proportion, nlossrate, from the level of fertilizer used. A more precise formulation would also include losses through erosion and food extraction alongside gains through nitrogen fixation, but these feedback loops prove difficult for the model to solve computation-wise, and add very little to the core dynamics of the model. NETIN decreases by nlossrate per year in the absence of fertilizer. The rho parameter in (EQ.1.4) (equivalent to the $\psi$ parameter in equation S.7), is set such that the absence of fertilizer leads to a 14 percent decrease in soil productivity over 10 years, and the presence of fertilizer leads to a 27 percent increase during the same amount of time:

$$
\begin{aligned}
& S_{i, t}=\frac{\text { uppersoil }_{i}}{1+\text { rho }^{*} \operatorname{EXPNUT}_{i, t}} \\
& \operatorname{EXPNUT}_{i, t}=e^{- \text {NUTSUM }_{i, t}} \\
& \operatorname{NUTSUM}_{i, t+1}=\operatorname{NUTSUM}_{i, t}+\operatorname{NETIN~}_{i, t} \\
& \operatorname{NUTSUM}_{i, t 0}=\text { nutriento }_{i} \\
& \operatorname{NETIN~}_{i, t}=\text { FERT }_{i, t}-\text { nlossrate }
\end{aligned}
$$

Equation (EQ.1.9) on fertilizer use is central to the model. The amount of fertilizer is top-coded at an index value of one. Below that level, fertilizer use is restricted by a minimum capital requirement in cash crops. The simplified capital requirement reflects a wealth level required to afford fertilizer and bear the risk of adverse weather outcomes. It also reflects a collateral requirement for borrowing. A small capital accumulation increment, khurdle, must 
be passed in order to initiate fertilizer use, and the capital response function is inversely related to fertilizer prices. Other income-based constraints to purchasing fertilizer could easily be substituted into the model:

$$
F E R T_{i, t}=\min \left(1, \max \left(0,\left(\text { kcscale }^{*} \frac{K C C_{i, t}-\left(\left(1+\text { khurdle } * k c c 0_{i}\right)\right.}{\operatorname{PFERTR}_{i, t}}\right)+\operatorname{grpoda}_{t}\right)\right)
$$

The market-based purchases of fertilizer in (EQ.1.9) are bolstered by an ODA-financed "green revolution package" $\left(\operatorname{grpod}_{\mathrm{t}}\right)$ of fertilizer and improved seeds. This ODA package is set as an exogenous policy parameter for each period, reflecting the policy decision to support inputs over time. The vector of grpoda $a_{\mathrm{t}}$ parameters are programmed as a critical choice for the model scenarios, as discussed in more detail below.

\section{Other Productive Sectors}

Equation block 2 includes the production functions for the other key productive sectors: urban manufacturing, urban services and rural services. These again take a normal Cobb-Douglas form and use effective labor rather than nominal labor. Manufacturing and urban services are modeled to take place only in the urban area (Kampala in Uganda) so their production functions are not indexed by region. The rural service sector is meanwhile present in each rural region $i$. Equation block 3 outlines a simple process through which effective labor can be determined by progress on public service delivery, in particular the health and water sectors, which are both simple inputs to overall health and productivity progress.

\section{Market-Clearing Conditions}

Block 4 introduces food market-clearance conditions. Equation (EQ.4.1) describes urban food demand (FKAMP) as the product of urban labor $(L U)$ and food requirements per capita (phi). Equation (EQ.4.2) then defines the urban food supply, which equals the urban food demand, as the sum of all rural areas' food surpluses minus the losses (TLOSS) incurred in transporting food from the rural areas to the urban areas. Each rural region's food surplus is defined in (EQ.4.3) as its food production minus the product of the region's labor size and food requirements per capita:

$$
\begin{aligned}
& \text { FKAMP }_{t}=p h i^{*} L U_{t} \\
& \text { FKAMP }_{t}=\sum_{i} \text { FSURP }_{i, t}^{*}\left(1-\operatorname{TLOSS}_{i, t}\right) \\
& \text { FSURP }_{i, t}=F_{i, t}-p h i^{*} L R_{i, t}
\end{aligned}
$$

\section{Transport Costs and Prices}

Block 5 introduces the transport cost adjustments that are central to the model's allocation of labor and production both across sectors and across rural and urban areas. Equation (EQ.5.1) sets transport losses between urban and rural areas as an inverse function of the road stock, with initial transport losses indexed to each region and a lower asymptote of zero as roads increase. In (EQ.5.2), the urban price of food is more expensive than the rural price of food, due to the costs of transporting food from rural areas to urban areas. The farmgate price of fertilizer, an inter- 
nationally priced good, is also inversely related to transport costs. Meanwhile, the farmgate price of cash crops is scaled down by the transport costs as well. The manufactured good is assumed to have a sufficiently high value per weight that domestic transport costs are insignificant, and the international price holds equally in both rural and urban areas. Equations (EQ.5.7) and (EQ.5.8) define the respective urban and rural nonfood consumer price indexes (CPINFU and CPINFR) based on the weighted share of service and imported goods in consumption:

$$
\operatorname{TLOSS}_{i, t}=\frac{\text { tfirst }_{i}}{\operatorname{KROAD}_{i, t}}
$$

$$
\begin{aligned}
& \text { PFR }_{i, t}=\text { PFU }_{t}^{*}\left(1-\text { TLOSS }_{i, t}\right) \\
& \text { PFERTR }_{i, t}=\frac{\text { pworldfert }}{1-\text { TLOSS }_{i, t}}
\end{aligned}
$$

\section{Real Wages and Income}

Block 6 outlines the labor income per sector. The manufacturing wage is set as the marginal product of effective labor, multiplied by the numeraire price. The urban service wage is also set equal to effective labor's marginal product, multiplied by the price of urban services, $P S U$. The rural service wage is set similarly, although with a separate wage rate for each rural region. Both urban and rural government wages are set at a fixed premium over the respective service wages. Equations (EQ.6.4) and (EQ.6.5) set the marginal productivities of labor in food production and cash crop production, respectively. The on-farm crop choice optimization occurs by equilibrating the marginal product of cash crops and the marginal product of staple food.

The remainder of equation block 6 outlines the real wages net of food consumption. The real manufacturing wage is set in (EQ.6.9) as the manufacturing wage minus the cost of urban food requirements, all adjusted for the nonfood urban consumer price index (CPINFU). The urban service wage is set analogously in (EQ.6.10). The real rural service wage is set through a similar approach in (EQ.6.11), but using each rural region's local food price and nonfood consumer price index:

$\begin{array}{ll}\text { (EQ.6.10) } & Y S U_{t}=\frac{W S U_{t}-p h i * P F U_{t}}{C P I N F U_{t}} \\ \text { (EQ.6.11) } & Y S R_{i, t}=\frac{W S R_{i, t}-p h i * P F R_{i, t}}{C P I N F R_{i, t}}\end{array}$ 
The real per capita farm income (EQ.6.12) is somewhat more layered in its construction, given that it includes the sum of rural households' food crop income plus cash crop income, minus the equivalent cost of the minimum food need, minus the cost of market-purchased fertilizer. Each region's real income is then adjusted for the regional nonfood price index and divided by the size of the farm labor force:

$$
\operatorname{YFARM}_{i, t}=\frac{\text { PFR }_{i, t} * F_{i, t}+\text { PCCR }_{i, t} * C C_{i, t}-\text { phi } * \operatorname{PFR}_{i, t} * \operatorname{LFARM}_{i, t}-\left(\text { FERT }_{i, t}-\operatorname{grpoda}_{t}\right) * \operatorname{PFERTR}_{i, t}}{\text { CPINFR }_{i, t} * \operatorname{LFARM}_{i, t}}
$$

\section{Labor Market Clearing and Migration}

Block 7 outlines the real income conditions for labor market equilibrium and the determinants of rural to urban migration. The urban labor equilibrium is set by equating the real wage in manufacturing with the real wage in urban services. In rural regions, real service wages are equated with real farm incomes, and mobility is instantaneous across sectors. This perfect mobility is recognized as a limitation of the model and an area for future research and refinements. Migration is nonetheless a function of rural-urban wage differentials, which are minimized over time as a result of migration.

Total rural labor, $L R$, is the sum of farm labor (cash crop plus staple food), rural service labor and rural government labor. Total urban labor, $L U$, is the sum of manufacturing labor, urban service labor and urban government labor. Implicit in the model is an assumption that all labor has a home rural region and that each rural region has a fixed total implicit population of origin, $\operatorname{pop}_{i}$, so even the labor present in the urban area in the first period is linked to one of the four rural areas:

(EQ.7.1) $\quad Y S U_{t}=Y M A N_{t}$

(EQ.7.2) $\quad Y S R_{i, t}=Y F A R M_{i, t}$

(EQ.7.3) $\quad \operatorname{MIGRATE}_{i, t}=$ migtheta $^{*}\left(Y S U_{t}-Y S R_{i, t}\right)$

(EQ.7.4) $\quad L R_{i, t+1}=L R_{i, t}-M_{I G R A T E}$

(EQ.7.6) $\quad L R_{i, t}=L F A R M_{i, t}+L S R_{i, t}+L G R_{i, t}$

(EQ.7.7) $\quad \operatorname{LFARM}_{i, t}=L F_{i, t}+L C C_{i, t}$

(EQ.7.8) $\quad L U_{t}=L M_{t}+L S U_{t}+L G U_{t}$

(EQ.7.9) $L U_{t}=\sum_{i} p p_{i}-\sum_{i} L R_{i, t}$

\section{Aggregate Income, Savings and Consumption}

Block 8 establishes the broader macroeconomic aggregates. Disposable urban income, $Y U$, is set as the sum of urban value added net of food and taxes and measured relative to the numeraire (EQ.8.1). Disposable rural income is set similarly. Total disposable income is then set as the sum of urban disposable income and the four rural regions' 
disposable income levels. Cumulative disposable income is set as the (undiscounted) sum of total disposable income over the period:

(EQ.8.1)

$$
Y U_{t}=\left(V S U_{t}+M_{t}+W G U_{t}^{*} L G U_{t}-p h i^{*} P F U_{t}^{*} L U_{t}\right) *(1-\operatorname{taxr})
$$

(EQ.8.2)

$$
Y R_{i, t}=\left(V F_{i, t}+V C C_{i, t}+V S R_{i, t}+W G R_{i, t} * L G R_{i, t}-p h i * P F R_{i, t} * L R_{i, t}\right) *(1-\text { taxr })
$$

(EQ.8.3) $\quad$ YRTOT $_{t}=\sum_{i} Y R_{i, t}$

$$
Y D I S_{t}=Y U_{t}+\sum_{i} Y R_{i, t}
$$

The saving dynamics are important and are set in equations (EQ.8.6) and (EQ.8.7), with different fixed savings rates assumed for urban and rural areas, and set as a fraction of disposable income. The model assumes a minimum level of nonfood consumption, cmin, which includes services and imported goods. If disposable incomes are below $\mathrm{cmin}$, then saving is zero. Consistent with a savings-based poverty trap, the net savings rate therefore increases as households cross an average income threshold that pays for both minimum food needs and the minimum consumption basket:

$$
S A V U_{t}=\max \left(0,\left(Y U_{t}-\left(C P I N F U_{t}^{*} \operatorname{cmin} * L U_{t}\right)\right) * s a v u r b\right)
$$

Both urban consumption and rural consumption are set equal to real disposable income minus savings (EQ.8.9 and EQ.8.10). Demand for urban and rural services (EQ.8.11 and EQ.8.12) takes a fixed share of consumption and follows a standard downward-sloping form with respect to prices, with the remainder of consumption fulfilled by the imported good:

(EQ.8.9)

(EQ.8.10)

$$
\operatorname{SAVR}_{i, t}=\max \left(0,\left(Y R_{i, t}-\left(\operatorname{CPINFR}_{i, t}{ }^{2} \operatorname{cmin}^{*} L R_{i, t}\right)\right) *_{\text {savrur }}\right)
$$

$$
S A V T O T_{t}=S A V U_{t}+\sum_{i} S A V R_{i, t}
$$

(EQ.8.11) $\quad S U_{t}=\frac{\operatorname{gammas}^{*} C U_{t}}{P S U_{t}}$

(EQ.8.12) $\quad S R_{i, t}=\frac{\operatorname{gammas}^{*} C R_{t}}{P S R_{i, t}}$

\section{External Balance}

Block 9 defines the trade balances. Imports for consumption goods are defined in (EQ.9.1) and (EQ.9.2). Because all capital investment goods are imported, urban private investment imports are equal to the sum of urban saving 
plus all foreign direct investment. Rural private investment imports are equal only to rural savings. Total exports are equal to total cash crop production net of domestic transport losses plus total manufacturing production (EQ.9.5). Public investment goods for roads and other social sectors are imported, so total imports are then given in (EQ.9.6) as the sum of total fertilizer use, imported consumption goods, imported investment goods and imported goods for government consumption (TOTIMPG, defined in EQ.11.23). The trade balance of exports minus imports (EQ.9.7) is equal to the sum of total ODA plus foreign direct investment:

(EQ.9.5)

$$
\begin{aligned}
& \operatorname{EXPORT}_{t}=\sum_{i}\left(C C_{i, t} *\left(1-\operatorname{tloss}_{i, t}\right)\right)+M_{t} \\
& I M P O R T_{t}=\sum_{i} F_{E R T_{i, t}}+\sum_{i} I M P R C_{i, t}+I M P U C_{t}+I M P U I_{t}+\sum_{i} I M P R I_{i, t} \\
& + \text { PUBINV }+ \text { ROADINV }+ \text { TOTIMPG }
\end{aligned}
$$

Block 10 presents the basic capital accumulation equations. In equation (EQ.10.1), foreign direct investment (FDI) is determined by the difference between the local rate of return, $R$, and the global rate of return, rworld, and is only greater than zero when the former is greater than the latter. The global rate is exogenous to the model, and the local rate is set by the manufacturing sector's gross rate of return on capital before depreciation (EQ.10.2):

$$
\begin{aligned}
& F D I_{t}=\max \left(0, \text { fdimult }^{*}\left(R_{t}-\text { rworld }\right)\right) \\
& R_{t}=\frac{(1-\text { alpham }) * M_{t}}{K M_{t}}
\end{aligned}
$$

\section{Private Capital Accumulation}

Rural savings are allocated in fixed proportions to investment in cash crops (at share rsavcc) and in rural services (at share 1-savcc). The cash crop sector is assumed to have its own rate of capital depreciation. Capital stocks in staple foods are assumed to be fixed and receive no investment. Urban savings are divided between manufacturing (at share savm) and urban services (at share 1-usavm), with the former being supplemented by FDI. All investment goods are assumed to be imported at fixed international prices:

$$
\begin{aligned}
& K C C_{i, t+1}=K C C_{i, t} *(1-\text { depcc })+\operatorname{rsavcc} * S A V R_{i, t} \\
& K M_{t+1}=K M_{t}^{*}(1-\text { dep })+F D I_{t}+\text { usavm }^{*} S A V U_{t}
\end{aligned}
$$

\section{Public Sector and Government Balance}

Block 11 presents the public sector. The first subsection defines the public sector balance. Tax revenues are set by an average tax rate collected across all sectors on after-food incomes (EQ.11.1). Total public expenditures are financed by tax revenues and cash ODA (EQ.11.2). Note that cash ODA is accounted for independently from the ODA provided to finance the green revolution package of inputs. The green revolution package is structured as 
distinct from total public expenditures and can thus be considered its own separate, fully externally funded public account. Total ODA is therefore the sum of cash ODA plus the green revolution ODA:

$$
\begin{aligned}
T A X_{t}= & \left(V S U_{t}+M_{t}+W G U_{t}{ }^{*} L G U_{t}-p h i^{*} P F U_{t}^{*} L U_{t}\right) *(\text { taxr }) \\
& +\sum_{i}\left(V F_{i, t}+V C C_{i, t}+V S R_{i, t}+W G R_{i, t}{ }^{*} L G R_{i, t}-p h i{ }^{*} P F R_{i, t}{ }^{*} L R_{i, t}\right) *(\text { taxr })
\end{aligned}
$$

$$
\begin{aligned}
& \text { TOTEXP }_{t}=\text { TAX } X_{t}+\text { CASHODA }_{t} \\
& \text { TOTODA }_{t}=\text { CASHODA } A_{t}+\text { grpoda }_{t}
\end{aligned}
$$

Total public expenditure is defined as the sum of expenditures across service sectors and road building (EQ.11.6). The government module is scalable to include any number of service sectors or ministry-type accounts. Further to the fiscal modeling work of Sachs and colleagues (2004), it can include the urban investment costs, rural investment costs and recurrent costs in a straightforward manner. The model can include as many public sectors as desired, with explicit allocations between rural and urban regions. The simulations presented below include roads, health, education, general infrastructure (e.g., for water) and public administration. Uganda's public administration is overwhelmingly based in Kampala, so this public sector is only located in the urban region, while the others are spread across both rural and urban regions:

$$
\text { TOTEXP }_{t}=\sum_{p} \text { PEXP }_{p, t}+R_{\text {OADCOST }}
$$

Public expenditures and staffing levels for roads, schools, hospitals and other elements of infrastructure are planned over multiyear periods and taken as planned inputs to the model, in line with true multiyear government budgeting. Each service sector's expenditures are the sum of investment costs and recurrent costs. Recurrent public service costs are defined as the sum of labor costs and commodity inputs and are assumed to include operations and maintenance. Labor costs are determined by the staffing needs identified in a public sector plan and the relative wage as determined by service sector wages. Commodity inputs can also be easily specified to a particular year; for example, if a malaria bed net distribution campaign required a major spike in imported bed nets in a single season. The import composition of each sector's commodities can then be specified in EQ.11.24:

$$
\begin{aligned}
& \operatorname{PEXP}_{p, t}=\operatorname{inv}_{p, t}+\sum_{i} \operatorname{invr}_{p, i, t}+\operatorname{RECCOST} T_{p, t} \\
& \operatorname{RECCOST}_{p, t}=\sum_{r e g} \operatorname{commod}_{p, r e g, t}+\operatorname{LABCOST}_{p, t} \\
& \operatorname{LABCOST}_{p, t}=\operatorname{lpu_{p,t}}{ }^{*} W G U_{t}+\sum_{i}\left(\operatorname{lpr}_{p, i, t} * W G R_{i, t}\right) \\
& I M P G_{p, t}=\sum_{r e g}\left(\text { impcontc }_{p} * \operatorname{commod}_{p, r e g, t}\right)
\end{aligned}
$$

The road sector's investments are similarly pursued in equations (EQ.11.11) through (EQ.11.14). Its labor requirements in a particular period are assumed to be proportional to the amount of road being paved and to the existing road stock, the latter being important for maintenance. 


\section{Total Output}

Block 12 presents economic aggregates for output, value added and savings. Gross national product (GNP) net of food production is defined in (EQ.12.5), and GNP inclusive of food production is defined in (EQ.12.6). Gross national savings is then defined in (EQ.12.7) as total savings divided by $G N P$, inclusive of food production:

(EQ.12.5)

$$
\begin{aligned}
G N P N F_{t} & =V S U_{t}+M_{t}+W G U_{t}^{*} L G U_{t}-p h i * P F U_{t}^{*} L U_{t} \\
& +\sum_{i}\left(V F_{i, t}+V C C_{i, t}+V S R_{i, t}+W G R_{i, t}{ }^{*} L G R_{i, t}-p h i * P F R_{i, t} * L R_{i, t}\right)
\end{aligned}
$$

(EQ.12.6) $\quad G N P W F_{t}=V S U_{t}+M_{t}+W G U_{t} * L G U_{t}+\sum_{i}\left(V F_{i, t}+V C C_{i, t}+V S R_{i, t}+W G R_{i, t}{ }^{*} L G R_{i, t}\right)$

(EQ.12.7) $\quad S A V G N P W F_{t}=\frac{S A V T O T_{t}}{G N P W F_{t}}$

\section{Labor Scaling}

Block 13, then, presents a final set of simple equations to permit feedback effects from public sector investments in health and water to or in the production function. The model allows indexed progress in health and education as a straightforward linear function based on service delivery targets (e.g., AIDS treatment, malaria control, safe water access) over a total of $T$ periods. As mentioned above, the topic of effective labor is not pursued in the current paper, but the model's flexibility for incorporating such dynamics is noted:

(EQ.13.3) $\quad$ WATERPROG ${ }_{t}=(t / T) *($ waterlast - waterfirst $)$

$$
H_{W P R O G}=H_{t} A L T H P R O G_{t}+\text { WATERPROG }_{t}
$$$$
\text { HEALTHPROG }_{t}=(t / T) *(\text { healthlast }- \text { healthfirst })
$$ 


\section{DATA}

$\mathbf{T}$

o illustrate its basic dynamics, the model is applied to the general structure of the Ugandan economy as of the

mid-2000s. This paper's main focus is to present the core model as a flexible framework for parameterization, so more detailed country-specific refinements are not pursued here. Nonetheless, the model captures Uganda's administrative division into four main regions: Central, Eastern, Northern and Western. This is the most reliable level of decentralized poverty data collection in the country, although with adequate data the model could be equally applied to all 111 of the country's current districts. Kampala is located within the Central region, so Central aggregates are adjusted to subtract Kampala aggregates where needed. Other baseline data and key parameters are described in Appendix $\mathrm{C}$.

One of the most important parameters in the model is phi, the minimum food requirement per person. This is presented as an amalgam measure of physical units because families consume different staple foods in different parts of Uganda. The value of 0.55 was set as a reasonable first approximation for the broader dynamics of the model. Future research could provide more precision on staple crop volume needs differentiated by region. With the benefit of emerging geographic information system-based technologies, soil nutrient mapping and census data could be used to develop location-specific and crop-specific farm productivity thresholds. 


\section{SCENARIOS}

T

he model is applied using GAMS software and the CONOPT nonlinear solver. Six scenarios are presented to illustrate the model's core dynamics. Table 4 summarizes the interventions implemented under each scenario:

Scenario 1: Baseline. This establishes the reference point for the subsequent scenarios. It includes no external support for agriculture.

Scenario 2: Baseline with Soil Productivity. This scenario introduces the basic soil productivity and net nutrient flow parameter into the agricultural production functions. Otherwise, it mirrors the baseline.

Scenario 3: Green Revolution Package. This scenario maintains the soil productivity function from scenario 2 and adds a major agricultural input support program in year 3, backed by ODA. The program lasts five years, but is reduced over time. Year 4 support is 14 percent less than year 3 , and year 5 is 50 percent less again. The support level is held constant in years 5 through 7 , and then decreased to zero as of year 8 .

Scenario 4: Expanded Road Investment Program. The only adjustment compared with scenario 2 is a doubling of annual investment in rural road construction, with corollary increases in government labor for road building. The government accounts are backed by ODA for budget support. There is no agricultural support program.

Scenario 5: Expanded Social Sector Expenditure Package. This scenario differs from scenario 2 through a doubling of commodity inputs, labor force and investment rates in all nonroad public service sectors. The services are assumed to provide no direct effects on labor productivity via human capital accumulation Government accounts are again backed by ODA for budget support. There is no agricultural support program.

Scenario 6: Soil Productivity + Integrated Public Support Package. This scenario integrates the elements of scenarios 2, 3, 4, and 5 with an agricultural support package, expanded road investment and expanded social sector expenditures.

\section{Table 4: Mapping of Key Model Components, by Scenario}

\begin{tabular}{|c|c|c|c|c|c|c|}
\hline Key Model Component & $\begin{array}{c}1 \\
\text { Baseline }\end{array}$ & $\begin{array}{c}2 \\
\text { Soil } \\
\text { Productivity }\end{array}$ & $\begin{array}{c}3 \\
\text { Green } \\
\text { Revolution }\end{array}$ & $\begin{array}{c}4 \\
\text { Roads }\end{array}$ & $\begin{array}{c}5 \\
\text { Public } \\
\text { Service }\end{array}$ & $\begin{array}{c}6 \\
\text { Integrated }\end{array}$ \\
\hline $\begin{array}{l}\text { Soil productivity term in } \\
\text { agriculture production } \\
\text { functions }\end{array}$ & & $\sqrt{ }$ & $\sqrt{ }$ & $\sqrt{ }$ & $\sqrt{ }$ & $\sqrt{ }$ \\
\hline $\begin{array}{l}\text { Green revolution input } \\
\text { package introduced }\end{array}$ & & & $\sqrt{ }$ & & & $\sqrt{ }$ \\
\hline $\begin{array}{l}\text { Doubling of road } \\
\text { construction }\end{array}$ & & & & $\sqrt{ }$ & & $\sqrt{ }$ \\
\hline $\begin{array}{l}\text { Doubling of other public } \\
\text { services }\end{array}$ & & & & & $\sqrt{ }$ & $\sqrt{ }$ \\
\hline
\end{tabular}




\section{RESULTS}

or each scenario, Tables 5 through 10 report values for labor movements, prices, fertilizer use, savings, value added, external balances and government aggregates, respectively. Again, the results present general dynamics rather than precise point estimates for Uganda.

\section{Scenario 1: The Baseline}

The baseline scenario shows the poverty-trap-type stagnation of a low-productivity rural economy in the absence of soil productivity dynamics. In the first period, rural labor is 16.9 million out of the total labor force of 19.6 million, with more than 9 million in subsistence farming. More than 4 million are engaged in cash crops, and roughly 3.5 million are in rural services. In the small urban labor force, roughly one-third are engaged in services and twothirds in manufacturing. The government sector accounts for roughly 430,000 jobs throughout the economy, or approximately 2 percent of the labor force. Total urban-to-rural migration adds up to nearly 90,000 people in the first period.

The fertilizer block of Table 5 is telling, because it shows no fertilizer use in the economy. As indicated earlier in the paper, this is a good general approximation of the situation in Uganda. At the same time, there is variation in the price of fertilizer across regions. The Central region is closest to Kampala and has a stronger transportation network, so fertilizer is nearly 10 percent cheaper there than in the Eastern and Western regions. Meanwhile, the Northern region has a weaker road network, so fertilizer is more than 10 percent more expensive there, compared with the Eastern and Central regions.

The price block indicates both the price of food in rural and urban areas, and the corresponding nonfood consumer price index (CPI) values. Food is twice as expensive in urban areas compared with rural areas because of transport costs. And although fertilizer is cheaper in the Central region compared with other regions, food is more expensive because the lower transport costs mean that the region's producers can charge at a level closer to the ultimate demand-defining price in the urban area. Meanwhile, the urban nonfood CPI is only approximately 30 percent higher than the rural counterpart because services are provided locally without transport costs and imported consumption goods are assumed to have no transport costs due to their high value-to-weight ratios.

The "real wage" section of Table 5 only indicates real incomes in the rural and urban service sectors because wages are set to equilibrate across sectors within rural and urban areas, respectively. The table shows a considerable real income differential, with urban service laborers earning three times as much as their rural counterparts, much more than the 30 percent difference in CPIs.

The "total income" section then shows the variations in aggregate income across regions. The populations differ in each region, so these figures should not be considered in per capita terms, but they show the relative ordering of aggregate income in the Central, Western, Eastern and Northern regions. Urban income is much higher, despite the much smaller population. 


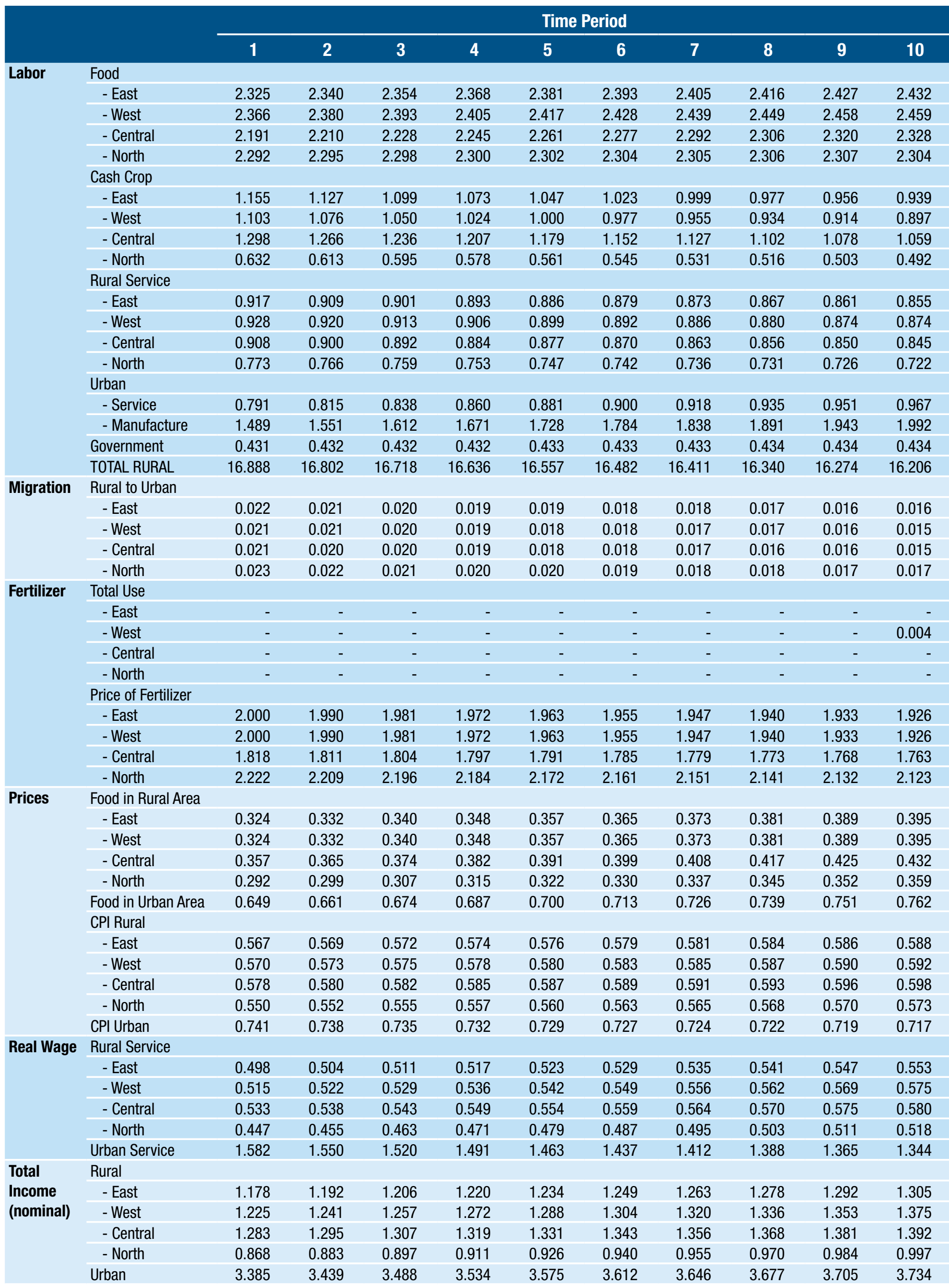




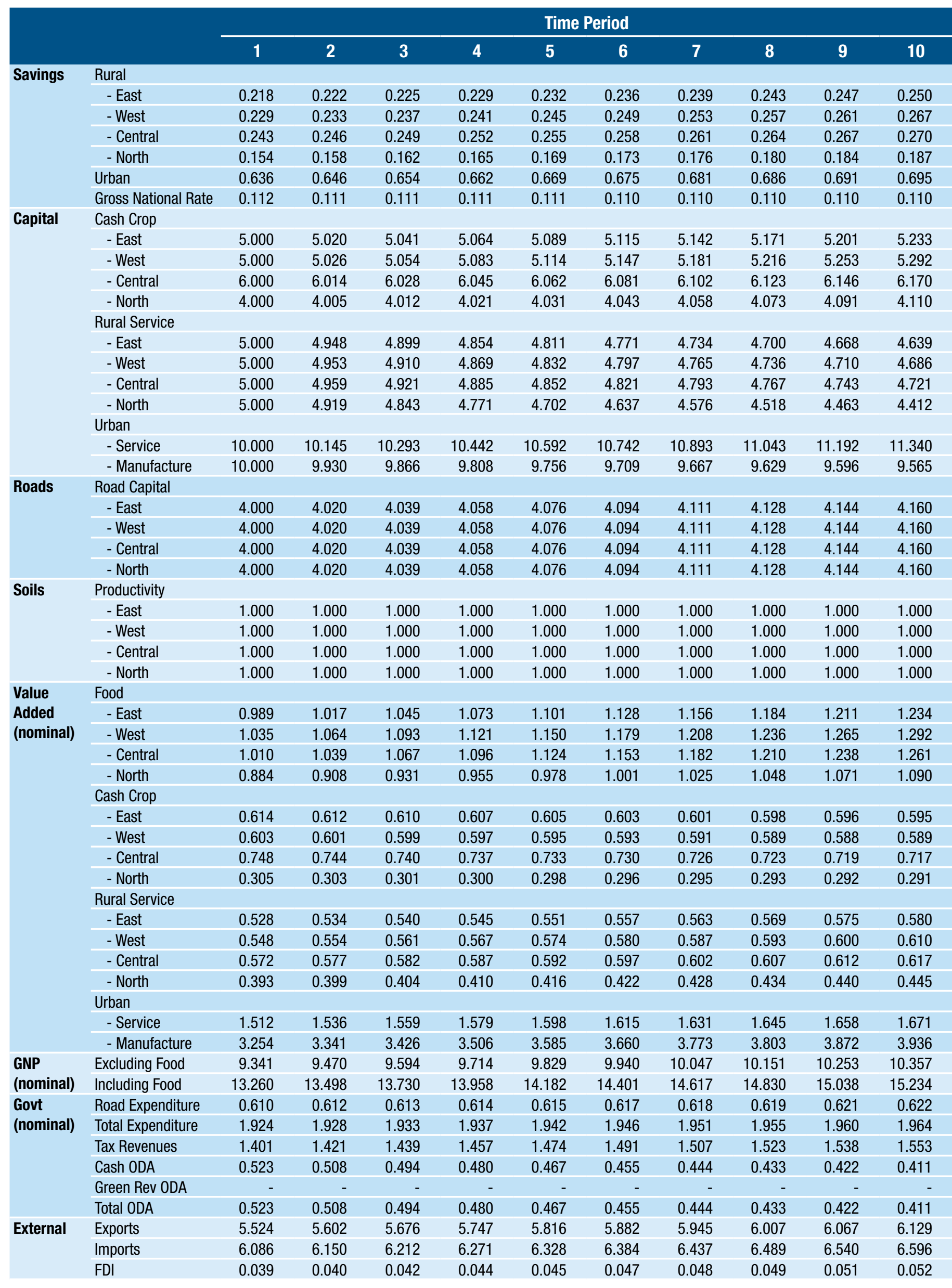


The savings section shows nominal savings levels in each region. Not surprisingly, in light of total incomes, the urban region has much higher savings levels than the rural regions, followed by the Central region. The gross national savings rate as a share of total output (including food production) is 11 percent.

Capital stocks are shown for each productive sector. Looking at initial dynamics across time periods, the low levels of rural savings feed into investment, with a slight majority directed toward cash crops over services, and are just enough to outweigh depreciation and lead to very slow capital accumulation. In the rural service sector, depreciation outweighs investment. In the urban area, a slight majority of urban savings is directed toward services over manufacturing. Thus, we see nearly 1.5 percent annual capital stock growth but nearly 1 percent annual capital stock loss in manufacturing, where depreciation outpaces investment. The indexed road stock also grows very slowly.

The value-added section shows variation in food production value across rural areas and slightly lower values for cash crops. Units can be interpreted as billions of U.S. dollars, noting the approximation of parameters as discussed above. Notably, the Northern region has less than half the cash crop value added as the Central region, reflective of the North's low starting capital stock and productivity in this sector. Value added for rural services is slightly lower than for cash crops in all regions except the North, where it is slightly higher. The more advanced urban service and manufacturing sectors then again have considerably higher output values. GNP is shown both with and without the value of the subsistence food production.

The penultimate section of the table shows the government accounts. Road expenditures amount to nearly one-third of total government expenditures. Nearly three-quarters of the budget is covered by domestic tax revenues, and the remainder is financed by cash ODA. There is no green revolution package in this scenario, so there is no other ODA to count.

The external balances mirror the government balance, with a trade deficit equal to one-tenth of total imports. Exports are equivalent to 42 percent of GNP, which is significantly higher than Uganda's actual share of less than 30 percent. Foreign direct investment is, meanwhile, very small, which is reflective of the low return on capital in the country and the low level of investment in the manufacturing sector.

The intertemporal dimensions of the baseline scenario reflect economic stagnation. The majority of farm families remain stuck on farms, and labor moves out of service and cash crops over time, with small increases in food labor and otherwise migration to urban areas. Manufacturing substitutes a growing workforce for its declining capital stock over time. Real wage equilibration between rural and urban areas occurs primarily through urban decline rather than through significant rural climbs. Aggregate rural income growth is approximately 1 percent per year in all regions. Even the capital deepening in cash crops is not enough to support an increase in fertilizer use, so only one region is able to start using even the smallest amount of fertilizer in year 10.

The price of food climbs more than 20 percent in all rural regions over the 10-year period and 17 percent in the urban area. The rural price of services remains almost stagnant, while it declines slightly in the urban areas, linked to the decline in urban service wages as its labor force increases. These price changes fuse with output level changes to yield a 20 percent increase in food value added over the period and approximately a 15 percent increase across rural services. Nominal value added in the urban sector increases gradually over the period. 


\section{Scenario 2: The Baseline with Soil Productivity}

The only adjustment between scenarios 1 and 2 is the addition of a soil productivity factor in the food and cash crop production functions. As shown in Table 6, the poverty trap dynamics are worsened dramatically in the process. By introducing a very small annual loss function that adds up to a cumulative 14 percent soil productivity loss over 10 years, the model shows tremendous adverse effects in the rural economy, with labor shifting to food crops in large number in order to maintain minimum food production for the economy, and cash crop labor decreasing by approximately 60 to 70 percent over the period. The rural and urban service sectors also experience significant labor declines over the same period. Only manufacturing absorbs a slightly larger amount of labor than in scenario 1 , although rural to urban migration nearly stops by year 10 in scenario 2.

The other major implication for the rural economy is a major increase in food prices. Rural food prices now increase more than 250 percent over 10 years and, by year 10, are more than twice as high in scenario 2 compared with the baseline. Urban food prices in year 10 are also double those of the baseline scenario. The rural CPI is only slightly increased, but the urban CPI is slightly lower. However, the urban real wage is cut in half in scenario 2 due to the higher food price, even as the rural real wage adjusts only slightly. Nominal savings are slightly increased but, amid higher prices, the final period's national savings rate is only 7.8 percent, compared with 11.0 percent in the baseline, a considerable drop.

In the government accounts, the road-building and service delivery plans are unchanged, but labor costs increase marginally due to the increased service sector wages. Tax collections also decrease, so the need for cash ODA is more than 60 percent higher than in the baseline by year 10 , covering nearly 32 percent of the full budget. Exports are also 11 percent lower by year 10, due to decreased cash crop production. In this scenario, exports are equivalent to only 28 percent of GNP, a much closer proportion to the case of Uganda. Scenario 2 therefore highlights the extent to which a small loss in soil productivity can have a devastating overall effect for both rural and

urban households in a low-income economy. This scenario might therefore provide a more accurate snapshot of Uganda's current economic situation than the baseline, consistent with the findings of Marenya and Barrett (2009) and Matsumoto and Yamano (2009).

\section{Scenario 3: The Green Revolution Package}

This scenario introduces the first major policy experiment, a major green revolution input package, including fertilizer. The results are presented in Table 7 . The agricultural package is introduced in year 3, with phaseout by year 8 , and the result is starkly different from the previous scenarios. The boost in staple food productivity frees up labor for cash crops and services in rural areas, and boosts migration into urban areas. Even when the package is withdrawn entirely in year 8 , there is a temporary shift upward in staple food labor. However, then the downward trend is resumed as labor continues to move into the higher-paying urban sectors.

Of particular importance, fertilizer use jumps from zero in years 1 and 2 to more than 0.3 in all regions in year 3. The phasing out of fertilizer support is completed by year 8 , but by that point farmers have been able to generate 
Table 6: Scenario 2 - Baseline with Soil Productivity

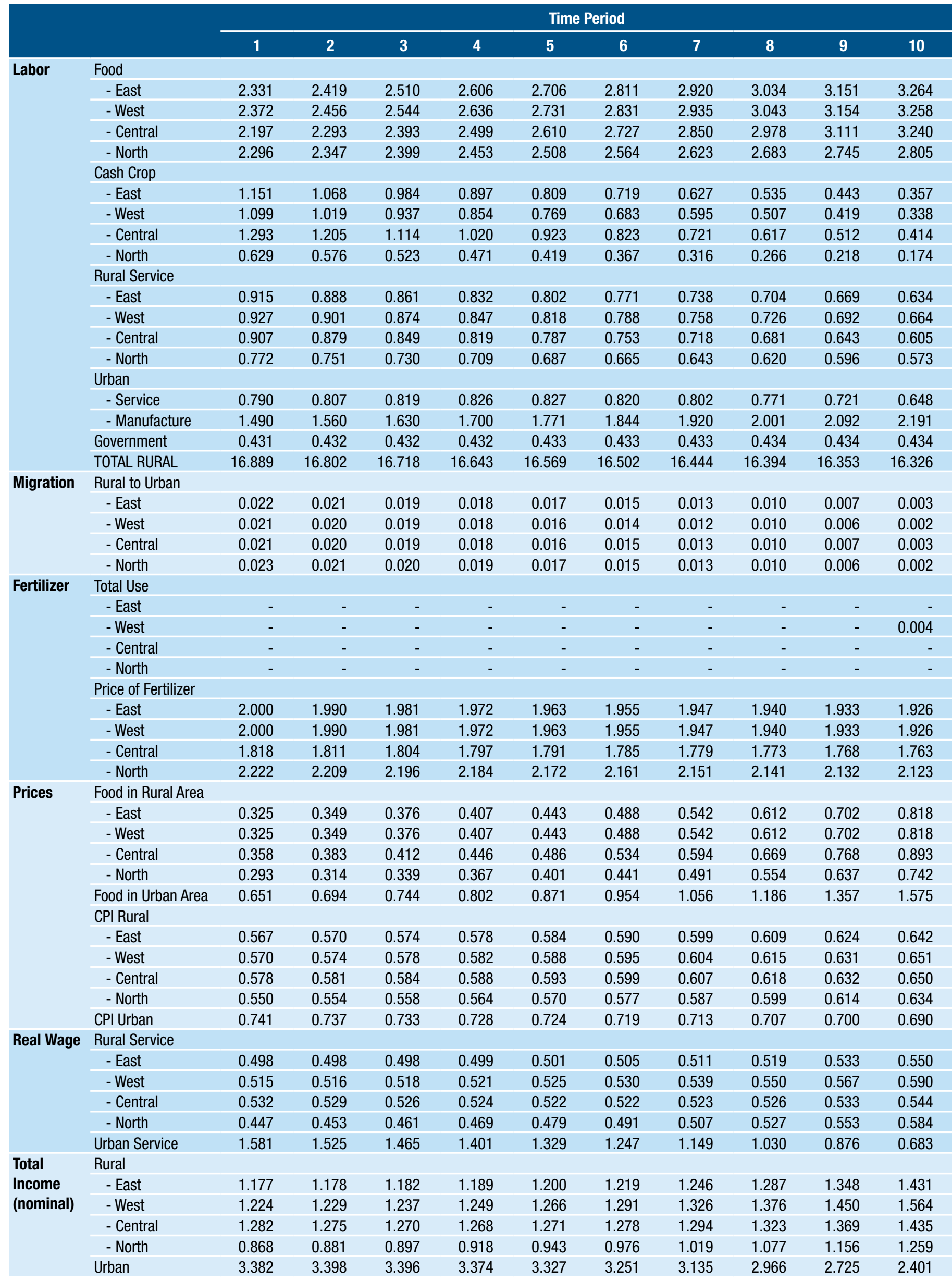




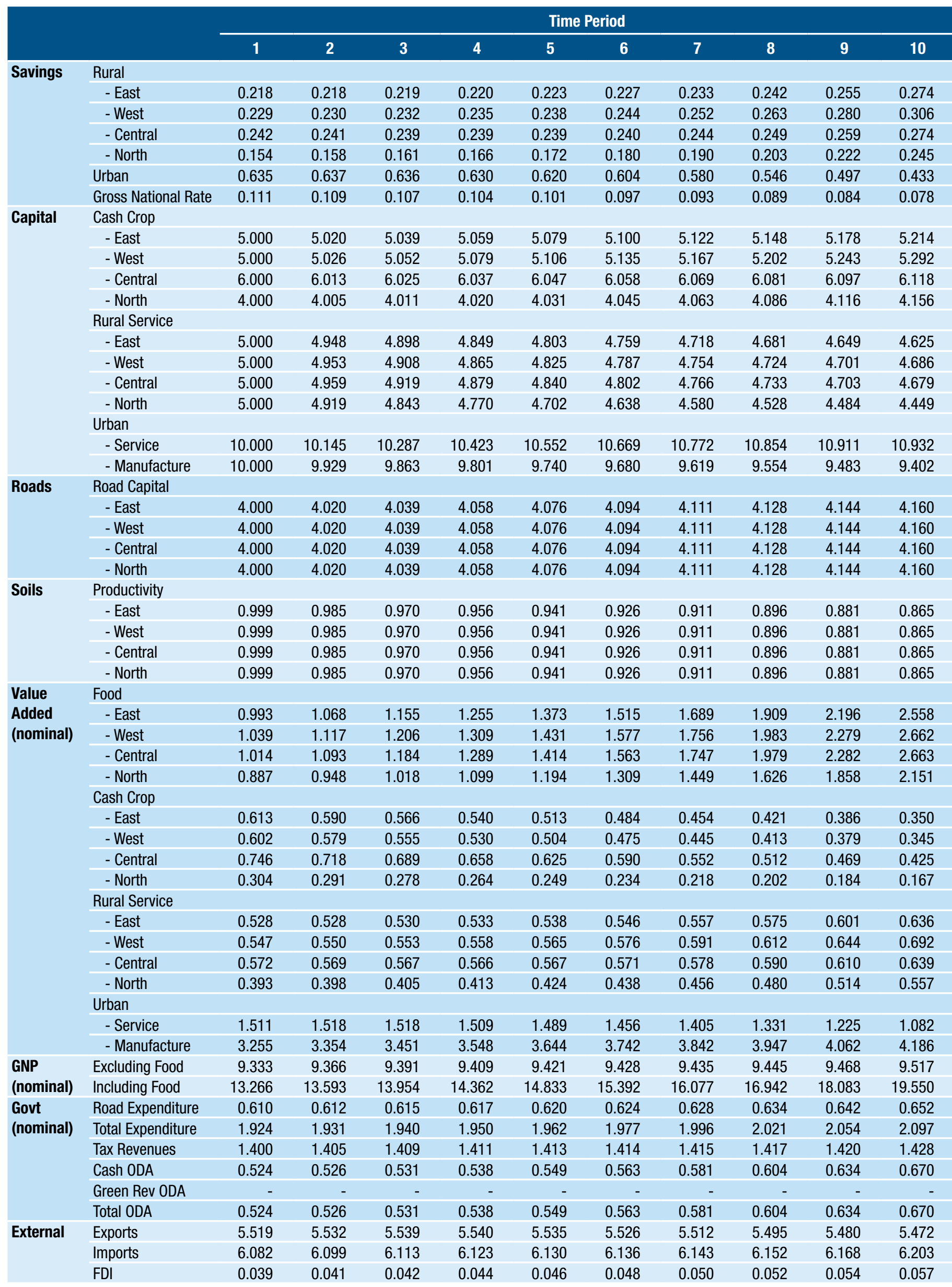


Table 7: Scenario 3 - Green Revolution

\begin{tabular}{|c|c|c|c|c|c|c|c|c|c|c|c|}
\hline & \multicolumn{10}{|c|}{ Time Period } \\
\hline & & 1 & 2 & 3 & 4 & 5 & 6 & 7 & 8 & 9 & 10 \\
\hline \multirow[t]{20}{*}{ Labor } & Food & & & & & & & & & & \\
\hline & - East & 2.331 & 2.419 & 1.377 & 1.209 & 1.229 & 1.126 & 1.036 & 1.394 & 1.393 & 1.387 \\
\hline & - West & 2.372 & 2.456 & 1.427 & 1.257 & 1.276 & 1.172 & 1.079 & 1.440 & 1.438 & 1.431 \\
\hline & - Central & 2.197 & 2.293 & 1.238 & 1.078 & 1.099 & 1.003 & 0.919 & 1.266 & 1.266 & 1.263 \\
\hline & - North & 2.296 & 2.347 & 1.579 & 1.431 & 1.448 & 1.356 & 1.272 & 1.589 & 1.586 & 1.581 \\
\hline & Cash Crop & & & & & & & & & & \\
\hline & - East & 1.151 & 1.068 & 1.864 & 1.974 & 1.935 & 1.993 & 2.043 & 1.734 & 1.715 & 1.698 \\
\hline & - West & 1.099 & 1.019 & 1.809 & 1.922 & 1.883 & 1.944 & 1.995 & 1.682 & 1.663 & 1.647 \\
\hline & - Central & 1.293 & 1.205 & 2.010 & 2.113 & 2.074 & 2.127 & 2.171 & 1.877 & 1.856 & 1.839 \\
\hline & - North & 0.629 & 0.576 & 1.154 & 1.251 & 1.217 & 1.272 & 1.320 & 1.048 & 1.033 & 1.020 \\
\hline & Rural Service & & & & & & & & & & \\
\hline & - East & 0.915 & 0.888 & 1.113 & 1.150 & 1.148 & 1.171 & 1.193 & 1.123 & 1.125 & 1.127 \\
\hline & - West & 0.927 & 0.901 & 1.119 & 1.155 & 1.154 & 1.177 & 1.198 & 1.131 & 1.133 & 1.137 \\
\hline & - Central & 0.907 & 0.879 & 1.108 & 1.145 & 1.142 & 1.166 & 1.188 & 1.117 & 1.118 & 1.121 \\
\hline & - North & 0.772 & 0.751 & 0.920 & 0.946 & 0.940 & 0.955 & 0.968 & 0.901 & 0.897 & 0.893 \\
\hline & Urban & & & & & & & & & & \\
\hline & - Service & 0.790 & 0.807 & 0.917 & 0.958 & 0.986 & 1.022 & 1.057 & 1.057 & 1.083 & 1.110 \\
\hline & - Manufacture & 1.490 & 1.560 & 1.532 & 1.579 & 1.635 & 1.683 & 1.729 & 1.808 & 1.861 & 1.912 \\
\hline & Government & 0.431 & 0.432 & 0.432 & 0.432 & 0.433 & 0.433 & 0.433 & 0.434 & 0.434 & 0.434 \\
\hline & TOTAL RURAL & 16.889 & 16.802 & 16.718 & 16.631 & 16.545 & 16.462 & 16.382 & 16.302 & 16.223 & 16.144 \\
\hline \multirow[t]{5}{*}{ Migration } & Rural to Urban & & & & & & & & & & \\
\hline & - East & 0.022 & 0.021 & 0.022 & 0.021 & 0.021 & 0.020 & 0.019 & 0.020 & 0.019 & 0.019 \\
\hline & - West & 0.021 & 0.020 & 0.022 & 0.021 & 0.020 & 0.020 & 0.019 & 0.019 & 0.019 & 0.018 \\
\hline & - Central & 0.021 & 0.020 & 0.021 & 0.020 & 0.019 & 0.019 & 0.018 & 0.018 & 0.018 & 0.018 \\
\hline & - North & 0.023 & 0.021 & 0.024 & 0.023 & 0.023 & 0.023 & 0.022 & 0.022 & 0.021 & 0.021 \\
\hline \multirow[t]{10}{*}{ Fertilizer } & Total Use & & & & & & & & & & \\
\hline & - East & - & - & 0.329 & 0.286 & 0.194 & 0.203 & 0.213 & 0.024 & 0.031 & 0.039 \\
\hline & - West & - & - & 0.330 & 0.287 & 0.196 & 0.205 & 0.216 & 0.027 & 0.035 & 0.044 \\
\hline & - Central & - & - & 0.320 & 0.278 & 0.188 & 0.198 & 0.209 & 0.022 & 0.031 & 0.040 \\
\hline & - North & - & - & 0.333 & 0.285 & 0.189 & 0.192 & 0.196 & 0.0001 & 0.003 & 0.005 \\
\hline & Price of Fertilizer & & & & & & & & & & \\
\hline & - East & 2.000 & 1.990 & 1.981 & 1.972 & 1.963 & 1.955 & 1.947 & 1.940 & 1.933 & 1.926 \\
\hline & - West & 2.000 & 1.990 & 1.981 & 1.972 & 1.963 & 1.955 & 1.947 & 1.940 & 1.933 & 1.926 \\
\hline & - Central & 1.818 & 1.811 & 1.804 & 1.797 & 1.791 & 1.785 & 1.779 & 1.773 & 1.768 & 1.763 \\
\hline & - North & 2.222 & 2.209 & 2.196 & 2.184 & 2.172 & 2.161 & 2.151 & 2.141 & 2.132 & 2.123 \\
\hline \multirow[t]{11}{*}{ Prices } & Food in Rural Area & & & & & & & & & & \\
\hline & - East & 0.325 & 0.349 & 0.190 & 0.173 & 0.178 & 0.169 & 0.161 & 0.209 & 0.211 & 0.214 \\
\hline & - West & 0.325 & 0.349 & 0.190 & 0.173 & 0.178 & 0.169 & 0.161 & 0.209 & 0.211 & 0.214 \\
\hline & - Central & 0.358 & 0.383 & 0.208 & 0.190 & 0.195 & 0.185 & 0.177 & 0.228 & 0.231 & 0.234 \\
\hline & - North & 0.293 & 0.314 & 0.171 & 0.156 & 0.161 & 0.153 & 0.146 & 0.189 & 0.192 & 0.194 \\
\hline & $\begin{array}{l}\text { Food in Urban Area } \\
\text { CPI Rural }\end{array}$ & 0.651 & 0.694 & 0.376 & 0.341 & 0.350 & 0.331 & 0.314 & 0.405 & 0.409 & 0.412 \\
\hline & - East & 0.567 & 0.570 & 0.580 & 0.586 & 0.587 & 0.592 & 0.597 & 0.585 & 0.587 & 0.588 \\
\hline & - West & 0.570 & 0.574 & 0.582 & 0.588 & 0.589 & 0.594 & 0.599 & 0.588 & 0.590 & 0.591 \\
\hline & - Central & 0.578 & 0.581 & 0.594 & 0.601 & 0.602 & 0.607 & 0.613 & 0.599 & 0.600 & 0.602 \\
\hline & - North & 0.550 & 0.554 & 0.553 & 0.557 & 0.558 & 0.560 & 0.563 & 0.558 & 0.558 & 0.559 \\
\hline & CPI Urban & 0.741 & 0.737 & 0.744 & 0.743 & 0.740 & 0.738 & 0.737 & 0.732 & 0.729 & 0.727 \\
\hline \multirow[t]{6}{*}{ Real Wage } & Rural Service & & & & & & & & & & \\
\hline & - East & 0.498 & 0.498 & 0.664 & 0.707 & 0.706 & 0.736 & 0.766 & 0.677 & 0.681 & 0.686 \\
\hline & - West & 0.515 & 0.516 & 0.674 & 0.716 & 0.716 & 0.746 & 0.776 & 0.690 & 0.695 & 0.701 \\
\hline & - Central & 0.532 & 0.529 & 0.726 & 0.772 & 0.769 & 0.803 & 0.836 & 0.735 & 0.739 & 0.745 \\
\hline & - North & 0.447 & 0.453 & 0.558 & 0.589 & 0.589 & 0.609 & 0.628 & 0.564 & 0.564 & 0.564 \\
\hline & Urban Service & 1.581 & 1.525 & 1.751 & 1.760 & 1.737 & 1.737 & 1.737 & 1.654 & 1.639 & 1.625 \\
\hline Total & Rural & & & & & & & & & & \\
\hline \multirow{5}{*}{$\begin{array}{l}\text { Income } \\
\text { (nominal) }\end{array}$} & - East & 1.177 & 1.178 & 1.548 & 1.672 & 1.678 & 1.772 & 1.869 & 1.636 & 1.656 & 1.679 \\
\hline & - West & 1.224 & 1.229 & 1.579 & 1.703 & 1.712 & 1.807 & 1.904 & 1.681 & 1.705 & 1.731 \\
\hline & - Central & 1.282 & 1.275 & 1.727 & 1.866 & 1.867 & 1.975 & 2.088 & 1.810 & 1.831 & 1.856 \\
\hline & - North & 0.868 & 0.881 & 1.040 & 1.104 & 1.104 & 1.147 & 1.189 & 1.061 & 1.062 & 1.061 \\
\hline & Urban & 3.382 & 3.398 & 3.878 & 4.010 & 4.082 & 4.192 & 4.297 & 4.238 & 4.305 & 4.373 \\
\hline
\end{tabular}




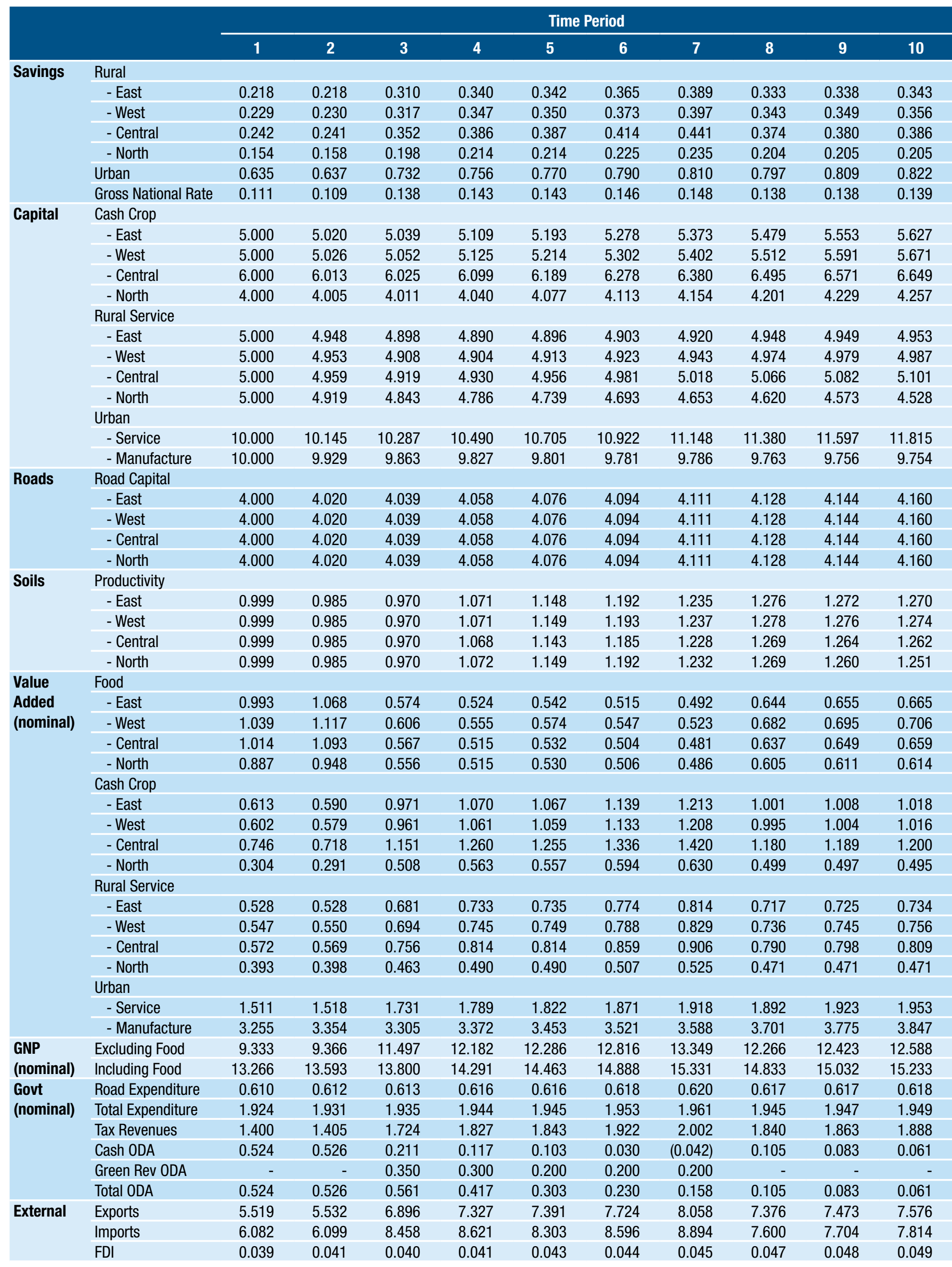


enough capital in cash crops to start purchasing fertilizer on their own terms. The result is a growing and selfsustaining fertilizer market from year 8 onward. In other words, a temporary boost in input-targeted ODA leads to a permanent boost in agricultural productivity.

The most prominent other difference in this scenario is the overall tendency of decreased local prices and hence real exchange rate depreciation. By period 7, food prices drop by half in all regions. By period 10, real wages in rural services increase by 26 to 38 percent, and in urban services by 2 percent. This is a key result, because it suggests that the ODA support package can have clear anti-Dutch disease effects, contrary to the concerns of Rajan and Subramanian and others.

Meanwhile, savings receives a considerable boost from the increase in disposable income, with the gross savings rate equal to 13.9 percent of GNP by year 10. Capital stocks are able to reverse the declines of the pre-green revolution support years. Soil nutrients are also being replenished from year to year thanks to the infusion of fertilizer and higher yields, so soil productivity jumps more than 25 percent in all regions, with a plateau effect when the package is removed.

The effect on the government balance comes through the revenue side but not the expenditure side. The latter is preprogrammed, and the wage effects are minimal in the scenario, but the tax revenues are significantly boosted. In the final year of the green revolution package, year 7 , the government actually runs a cash surplus (i.e., excluding the ODA for the inputs). After an adjustment in year 8, the revenue growth trajectory reinitiates, and by year 10 the government is almost fully domestically financed again. In this scenario, the nominal value of total GNP is smaller (only $\$ 15.2$ billion in approximate dollar terms), and exports account for nearly half the output (at approximately $\$ 7.6$ billion).

\section{Scenario 4: The Expanded Road Investment Program}

This scenario singles out an expanded road-building program, with the results presented in Table 8. The only dynamic effects here are through decreased transport costs and slightly increased government labor. Compared with the reference point in scenario 2 , fertilizer prices are approximately 15 percent lower in year 10 , contributing to the adoption of market-based fertilizer use in two regions by the end of the period.

More generally, scenario 4 reflects something of a midpoint between the economic stagnation of scenario 1 and the highly negative dynamics of scenario 2. Even with a 30 percent increase in road stock over 10 years, the effort is not enough to support the introduction of market-based fertilizers by year 3 , nor is it enough to countervail the pull of labor into staple production. (As an aside, this scenario demonstrates the perils of expanding infrastructure relative to a low baseline, rather than investing to target specific needs, which might be much greater.) In scenario 4 real rural wages are almost exactly the same as in scenario 2, but real urban wages are significantly higher, at 1.05 compared with 0.68 . In addition, the gross savings rate still drops to 8.9 percent by year 10 .

For the public accounts, the road-building program is costly. It boosts revenues, but not enough to compensate for the overall expenditure need. By year 10, the cash ODA need is 1.12 , up from 0.67 in scenario 2 . On the positive side, exports are 8 percent higher in scenario 4 , accounting for 32 percent of total output. 


\section{Scenario 5: Expanded Social Sector Expenditures}

This scenario's public service delivery expansion has no direct productivity effects within the model's given parameters, so it is only expected to affect outcomes through a tightened labor market and government balance. This happens as shown in Table 9, wherein government labor amounts to 0.77 , compared with 0.43 in the scenario 2 reference case. The result is slightly fewer workers in every other sector, but little difference to relative allocations of labor. There is no boost in fertilizer use.

The scenario presents a clear case of Dutch disease. Labor scarcity results in even more inflationary pressures on both food and nonfood prices, with all food prices increasing by more than 100 percent and the rural CPI increasing by approximately 15 percent. The reallocation of labor produces a slight increase in the real wage for rural services and a significant decrease for urban services.

Not surprisingly, the government's budget suffers most in this scenario, with a near-stagnant tax base alongside a nearly doubled expenditure program. Cash ODA is more than threefold as big as in scenario 2 and amounts to 58 percent of the government's budget, funding a dramatically expanded trade deficit. Unlike the green revolution scenario, where a temporary effect provides a permanent welfare boost, here ODA provides a welfare boost but no permanent growth effects.

In reality, it is likely that a soundly implemented public service expansion to double nonroad expenditures would have medium- and long-term effects on human capital accumulation and labor productivity, particularly through spending on health, water and education. In unreported results, the model was used to test the effects of linear improvements in labor productivity over the period as social services are expanded. If labor productivity improves by 2 percentage points per year, the labor allocations and relative prices remain essentially unchanged over the period. In that instance, cash ODA also declines to 1.4 by the 10 th period, much less than the 2.09 in scenario 5 , but still considerably more than in scenarios 2 through 4 . These positive productivity spillovers, similar to those covered by the MAMS models, form an important area for separate estimation.

\section{Scenario 6: The Integrated Public Support Package}

This final scenario jointly implements the segmented dynamics from scenarios 2 through 5 with the results presented in Table 10. The progress is even more dramatic than the free-standing green revolution implementation in scenario 3. In scenario 6, even less labor remains in food production at the end of year 10 and even more is in cash crops and rural services. The urban service labor force is equivalent in scenarios 3 and 6 , and the manufacturing labor force is slightly smaller in the latter. Government is nearly twice the size, at 0.81 compared with 0.43 . Migration is slightly slower in scenario 6, too, because the real wage differentials are slightly less.

Fertilizer use picks up even more strongly after the agricultural ODA package is cut in year 8, because the higher real incomes are boosting more capital accumulation in cash crops and the price of fertilizer also comes down to scenario 4 levels amid the road construction. Rural food prices are very similar in scenarios 3 and 6 , but urban food prices are lower in scenario 6 due to the improved roads. Overall real wages in scenario 6 are also higher, especially in rural areas. The savings rate reaches 14.7 percent in year 10 . Soil productivity is again up nearly 30 percent, and exports jump to 8.67 . The need for cash ODA is considerably greater in scenario 6 than scenario 3 , but is less than in scenario 5 and is still decreasing over time. 
TABLE 8: Scenario 4 - Road Building

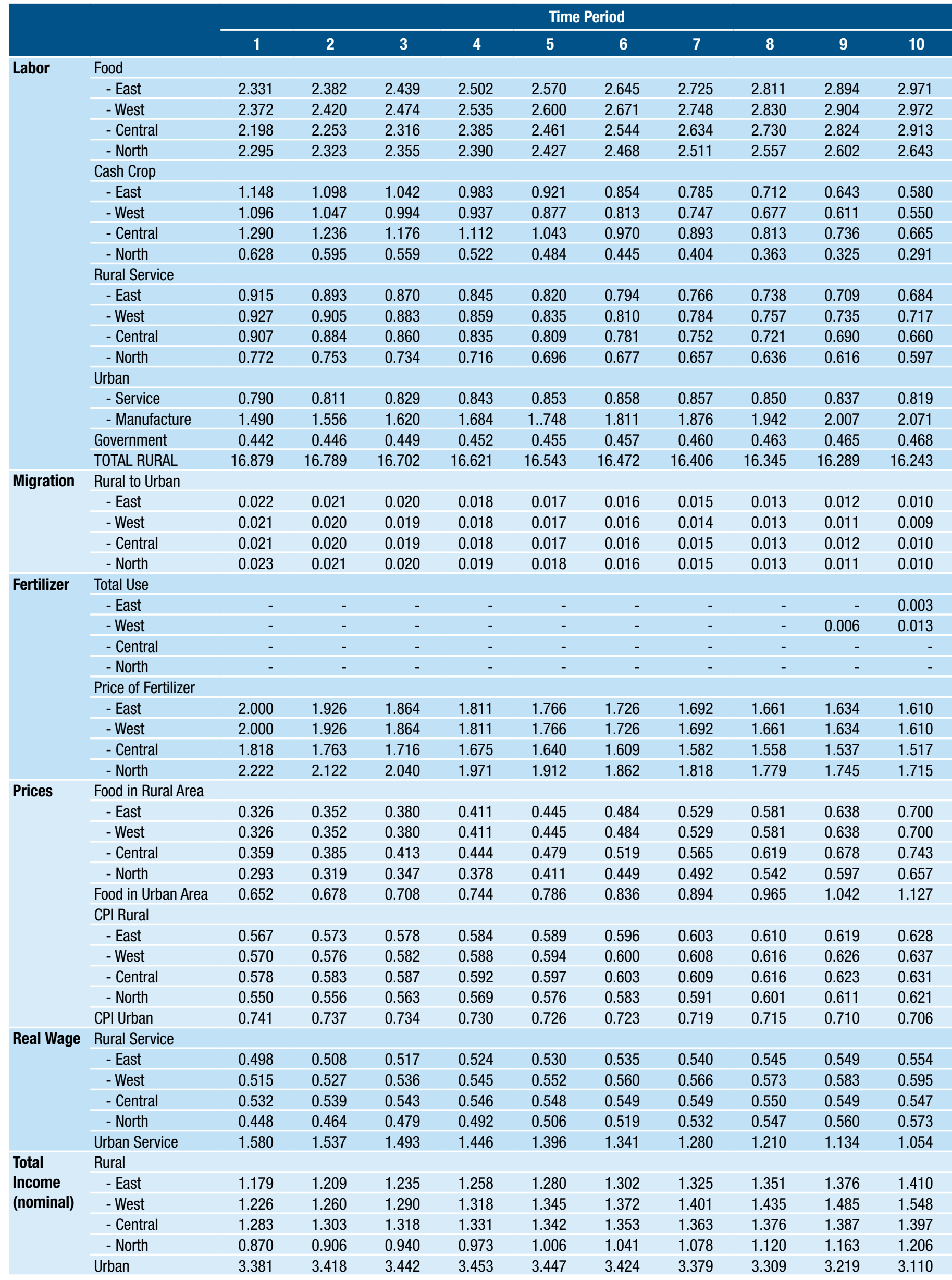




\begin{tabular}{|c|c|c|c|c|c|c|c|c|c|c|c|}
\hline & \multicolumn{10}{|c|}{ Time Period } \\
\hline & & 1 & 2 & 3 & 4 & 5 & 6 & 7 & 8 & 9 & 10 \\
\hline \multirow{7}{*}{ Savings } & Rural & & & & & & & & & & \\
\hline & - East & 0.218 & 0.225 & 0.231 & 0.237 & 0.242 & 0.247 & 0.252 & 0.258 & 0.263 & 0.271 \\
\hline & - West & 0.230 & 0.238 & 0.245 & 0.251 & 0.258 & 0.264 & 0.270 & 0.278 & 0.289 & 0.304 \\
\hline & - Central & 0.243 & 0.247 & 0.251 & 0.254 & 0.256 & 0.258 & 0.261 & 0.263 & 0.265 & 0.267 \\
\hline & - North & 0.155 & 0.163 & 0.172 & 0.179 & 0.187 & 0.195 & 0.204 & 0.214 & 0.224 & 0.234 \\
\hline & Urban & 0.635 & 0.641 & 0.645 & 0.646 & 0.644 & 0.638 & 0.628 & 0.614 & 0.595 & 0.573 \\
\hline & Gross National Rate & 0.111 & 0.110 & 0.108 & 0.107 & 0.104 & 0.102 & 0.099 & 0.096 & 0.093 & 0.089 \\
\hline \multirow[t]{13}{*}{ Capital } & Cash Crop & & & & & & & & & & \\
\hline & - East & 5.000 & 5.020 & 5.043 & 5.070 & 5.099 & 5.130 & 5.163 & 5.198 & 5.236 & 5.276 \\
\hline & - West & 5.000 & 5.026 & 5.056 & 5.090 & 5.126 & 5.165 & 5.207 & 5.252 & 5.299 & 5.353 \\
\hline & - Central & 6.000 & 6.014 & 6.029 & 6.047 & 6.066 & 6.085 & 6.106 & 6.127 & 6.149 & 6.172 \\
\hline & - North & 4.000 & 4.005 & 4.015 & 4.029 & 4.047 & 4.069 & 4.095 & 4.126 & 4.161 & 4.201 \\
\hline & Rural Service & & & & & & & & & & \\
\hline & - East & 5.000 & 4.948 & 4.901 & 4.858 & 4.819 & 4.783 & 4.751 & 4.722 & 4.696 & 4.674 \\
\hline & - West & 5.000 & 4.953 & 4.912 & 4.874 & 4.841 & 4.812 & 4.786 & 4.764 & 4.746 & 4.734 \\
\hline & - Central & 5.000 & 4.959 & 4.922 & 4.887 & 4.855 & 4.825 & 4.796 & 4.770 & 4.745 & 4.722 \\
\hline & - North & 5.000 & 4.920 & 4.846 & 4.777 & 4.715 & 4.658 & 4.606 & 4.560 & 4.519 & 4.484 \\
\hline & Urban & & & & & & & & & & \\
\hline & - Service & 10.000 & 10.145 & 10.289 & 10.432 & 10.571 & 10.705 & 10.830 & 10.945 & 11.046 & 11.132 \\
\hline & - Manufacture & 10.000 & 9.929 & 9.864 & 9.804 & 9.748 & 9.694 & 9.642 & 9.590 & 9.537 & 9.482 \\
\hline \multirow[t]{5}{*}{ Roads } & Road Capital & & & & & & & & & & \\
\hline & - East & 4.000 & 4.160 & 4.315 & 4.466 & 4.612 & 4.753 & 4.891 & 5.024 & 5.153 & 5.279 \\
\hline & - West & 4.000 & 4.160 & 4.315 & 4.466 & 4.612 & 4.753 & 4.891 & 5.024 & 5.153 & 5.279 \\
\hline & - Central & 4.000 & 4.160 & 4.315 & 4.466 & 4.612 & 4.753 & 4.891 & 5.024 & 5.153 & 5.279 \\
\hline & - North & 4.000 & 4.160 & 4.315 & 4.466 & 4.612 & 4.753 & 4.891 & 5.024 & 5.153 & 5.279 \\
\hline \multirow[t]{5}{*}{ Soils } & Productivity & & & & & & & & & & \\
\hline & - East & 0.999 & 0.985 & 0.970 & 0.956 & 0.941 & 0.926 & 0.911 & 0.896 & 0.881 & 0.865 \\
\hline & - West & 0.999 & 0.985 & 0.970 & 0.956 & 0.941 & 0.926 & 0.911 & 0.896 & 0.881 & 0.868 \\
\hline & - Central & 0.999 & 0.985 & 0.970 & 0.956 & 0.941 & 0.926 & 0.911 & 0.896 & 0.881 & 0.865 \\
\hline & - North & 0.999 & 0.985 & 0.970 & 0.956 & 0.941 & 0.926 & 0.911 & 0.896 & 0.881 & 0.865 \\
\hline Value & Food & & & & & & & & & & \\
\hline \multirow{17}{*}{$\begin{array}{l}\text { Added } \\
\text { (nominal) }\end{array}$} & - East & 0.994 & 1.070 & 1.152 & 1.242 & 1.343 & 1.458 & 1.590 & 1.745 & 1.912 & 2.095 \\
\hline & - West & 1.040 & 1.118 & 1.203 & 1.297 & 1.401 & 1.520 & 1.656 & 1.816 & 1.999 & 2.200 \\
\hline & - Central & 1.016 & 1.087 & 1.166 & 1.254 & 1.354 & 1.467 & 1.599 & 1.753 & 1.921 & 2.099 \\
\hline & - North & 0.888 & 0.959 & 1.034 & 1.116 & 1.206 & 1.306 & 1.421 & 1.554 & 1.698 & 1.850 \\
\hline & Cash Crop & & & & & & & & & & \\
\hline & - East & 0.612 & 0.616 & 0.615 & 0.610 & 0.601 & 0.589 & 0.572 & 0.553 & 0.531 & 0.511 \\
\hline & - West & 0.601 & 0.605 & 0.604 & 0.600 & 0.591 & 0.578 & 0.563 & 0.543 & 0.526 & 0.509 \\
\hline & - Central & 0.745 & 0.745 & 0.740 & 0.731 & 0.717 & 0.699 & 0.678 & 0.652 & 0.626 & 0.599 \\
\hline & - North & 0.304 & 0.307 & 0.307 & 0.305 & 0.301 & 0.294 & 0.286 & 0.276 & 0.265 & 0.254 \\
\hline & Rural Service & & & & & & & & & & \\
\hline & - East & 0.528 & 0.541 & 0.552 & 0.562 & 0.571 & 0.580 & 0.590 & 0.601 & 0.612 & 0.627 \\
\hline & - West & 0.548 & 0.562 & 0.575 & 0.587 & 0.598 & 0.610 & 0.622 & 0.636 & 0.658 & 0.684 \\
\hline & - Central & 0.572 & 0.580 & 0.587 & 0.593 & 0.597 & 0.602 & 0.606 & 0.612 & 0.617 & 0.622 \\
\hline & - North & 0.393 & 0.408 & 0.422 & 0.436 & 0.450 & 0.465 & 0.481 & 0.498 & 0.517 & 0.535 \\
\hline & Urban & & & & & & & & & & \\
\hline & - Service & 1.510 & 1.527 & 1.539 & 1.544 & 1.542 & 1.532 & 1.513 & 1.483 & 1.443 & 1.396 \\
\hline & - Manufacture & 3.255 & 3.348 & 3.437 & 3.525 & 3.612 & 3.697 & 3.783 & 3.869 & 3.953 & 4.034 \\
\hline \multirow{8}{*}{$\begin{array}{l}\text { GNP } \\
\text { (nominal) } \\
\text { Govt } \\
\text { (nominal) }\end{array}$} & Excluding Food & 9.340 & 9.524 & 9.677 & 9.804 & 9.907 & 9.990 & 10.056 & 10.106 & 10.154 & 10.202 \\
\hline & Including Food & 13.279 & 13.758 & 14.232 & 14.713 & 15.211 & 15.741 & 16.321 & 16.974 & 17.683 & 18.446 \\
\hline & Road Expenditure & 1.177 & 1.181 & 1.186 & 1.191 & 1.197 & 1.203 & 1.210 & 1.217 & 1.225 & 1.234 \\
\hline & Total Expenditure & 2.491 & 2.504 & 2.517 & 2.531 & 2.547 & 2.563 & 2.582 & 2.603 & 2.626 & 2.651 \\
\hline & Tax Revenues & 1.401 & 1.429 & 1.452 & 1.471 & 1.486 & 1.499 & 1.508 & 1.516 & 1.523 & 1.530 \\
\hline & Cash ODA & 1.090 & 1.075 & 1.066 & 1.061 & 1.060 & 1.065 & 1.073 & 1.087 & 1.103 & 1.121 \\
\hline & Green Rev ODA & - & - & - & - & - & - & - & - & - & - \\
\hline & Total ODA & 1.090 & 1.075 & 1.066 & 1.061 & 1.060 & 1.065 & 1.073 & 1.087 & 1.103 & 1.121 \\
\hline \multirow[t]{3}{*}{ External } & Exports & 5.517 & 5.621 & 5.705 & 5.771 & 5.822 & 5.858 & 5.882 & 5.893 & 5.901 & 5.907 \\
\hline & Imports & 6.646 & 6.737 & 6.813 & 6.876 & 5.928 & 6.970 & 7.004 & 7.031 & 7.062 & 7.098 \\
\hline & FDI & 0.039 & 0.041 & 0.042 & 0.044 & 0.046 & 0.047 & 0.049 & 0.051 & 0.052 & 0.054 \\
\hline
\end{tabular}


TABLE 9: Scenario 5 - Public service expansion

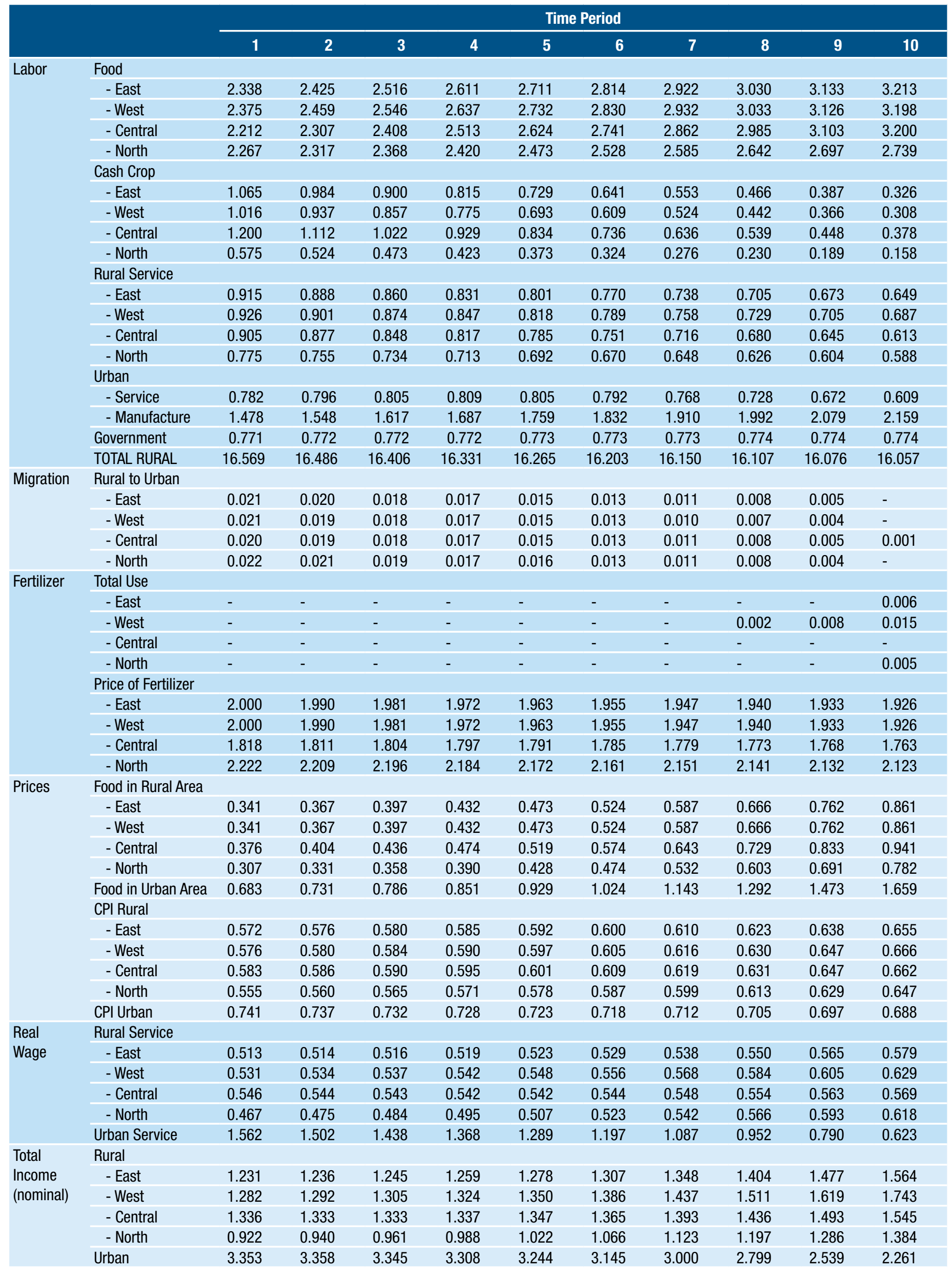




\begin{tabular}{|c|c|c|c|c|c|c|c|c|c|c|c|}
\hline & \multicolumn{10}{|c|}{ Time Period } \\
\hline & & 1 & 2 & 3 & 4 & 5 & 6 & 7 & 8 & 9 & 10 \\
\hline \multirow[t]{7}{*}{ Savings } & Rural & & & & & & & & & & \\
\hline & - East & 0.230 & 0.232 & 0.234 & 0.237 & 0.241 & 0.247 & 0.257 & 0.269 & 0.285 & 0.305 \\
\hline & - West & 0.243 & 0.245 & 0.248 & 0.252 & 0.258 & 0.266 & 0.278 & 0.295 & 0.320 & 0.348 \\
\hline & - Central & 0.255 & 0.254 & 0.254 & 0.255 & 0.257 & 0.261 & 0.267 & 0.276 & 0.288 & 0.299 \\
\hline & - North & 0.167 & 0.171 & 0.177 & 0.183 & 0.191 & 0.201 & 0.214 & 0.231 & 0.252 & 0.275 \\
\hline & Urban & 0.630 & 0.630 & 0.626 & 0.617 & 0.604 & 0.583 & 0.554 & 0.513 & 0.461 & 0.406 \\
\hline & Gross National Rate & 0.111 & 0.109 & 0.106 & 0.104 & 0.100 & 0.097 & 0.093 & 0.088 & 0.084 & 0.079 \\
\hline \multirow[t]{13}{*}{ Capital } & Cash Crop & & & & & & & & & & \\
\hline & - East & 5.000 & 5.027 & 5.054 & 5.081 & 5.110 & 5.140 & 5.173 & 5.211 & 5.255 & 5.307 \\
\hline & - West & 5.000 & 5.034 & 5.068 & 5.103 & 5.140 & 5.179 & 5.222 & 5.270 & 5.327 & 5.396 \\
\hline & - Central & 6.000 & 6.020 & 6.040 & 6.059 & 6.078 & 6.098 & 6.119 & 6.143 & 6.172 & 6.207 \\
\hline & - North & 4.000 & 4.012 & 4.026 & 4.043 & 4.062 & 4.086 & 4.115 & 4.151 & 4.195 & 4.250 \\
\hline & Rural Service & & & & & & & & & & \\
\hline & - East & 5.000 & 4.954 & 4.909 & 4.867 & 4.828 & 4.791 & 4.759 & 4.732 & 4.711 & 4.698 \\
\hline & - West & 5.000 & 4.959 & 4.921 & 4.885 & 4.852 & 4.823 & 4.798 & 4.779 & 4.768 & 4.769 \\
\hline & - Central & 5.000 & 4.965 & 4.930 & 4.897 & 4.865 & 4.834 & 4.807 & 4.782 & 4.763 & 4.750 \\
\hline & - North & 5.000 & 4.925 & 4.855 & 4.788 & 4.727 & 4.671 & 4.622 & 4.580 & 4.546 & 4.523 \\
\hline & Urban & & & & & & & & & & \\
\hline & - Service & 10.000 & 10.141 & 10.277 & 10.407 & 10.527 & 10.634 & 10.723 & 10.788 & 10.824 & 10.822 \\
\hline & - Manufacture & 10.000 & 9.927 & 9.859 & 9.793 & 9.729 & 9.664 & 9.596 & 9.524 & 9.445 & 9.354 \\
\hline \multirow[t]{5}{*}{ Roads } & Road Capital & & & & & & & & & & \\
\hline & - East & 4.000 & 4.020 & 4.039 & 4.058 & 4.076 & 4.094 & 4.111 & 4.128 & 4.144 & 4.160 \\
\hline & - West & 4.000 & 4.020 & 4.039 & 4.058 & 4.076 & 4.094 & 4.111 & 4.128 & 4.144 & 4.160 \\
\hline & - Central & 4.000 & 4.020 & 4.039 & 4.058 & 4.076 & 4.094 & 4.111 & 4.128 & 4.144 & 4.160 \\
\hline & - North & 4.000 & 4.020 & 4.039 & 4.058 & 4.076 & 4.094 & 4.111 & 4.128 & 4.144 & 4.160 \\
\hline \multirow[t]{5}{*}{ Soils } & Productivity & & & & & & & & & & \\
\hline & - East & 0.999 & 0.985 & 0.970 & 0.956 & 0.941 & 0.926 & 0.911 & 0.896 & 0.881 & 0.866 \\
\hline & - West & 0.999 & 0.985 & 0.970 & 0.956 & 0.941 & 0.926 & 0.911 & 0.896 & 0.882 & 0.869 \\
\hline & - Central & 0.999 & 0.985 & 0.970 & 0.956 & 0.941 & 0.926 & 0.911 & 0.896 & 0.881 & 0.865 \\
\hline & - North & 0.999 & 0.985 & 0.970 & 0.956 & 0.941 & 0.926 & 0.911 & 0.896 & 0.881 & 0.865 \\
\hline Value & Food & & & & & & & & & & \\
\hline \multirow{17}{*}{$\begin{array}{l}\text { Added } \\
\text { (nominal) }\end{array}$} & - East & 1.043 & 1.126 & 1.222 & 1.334 & 1.467 & 1.628 & 1.829 & 2.078 & 2.377 & 2.689 \\
\hline & - West & 1.091 & 1.176 & 1.275 & 1.390 & 1.527 & 1.693 & 1.900 & 2.161 & 2.483 & 2.820 \\
\hline & - Central & 1.068 & 1.155 & 1.255 & 1.373 & 1.513 & 1.683 & 1.895 & 2.158 & 2.473 & 2.788 \\
\hline & - North & 0.925 & 0.992 & 1.069 & 1.159 & 1.266 & 1.396 & 1.557 & 1.758 & 1.999 & 2.250 \\
\hline & Cash Crop & & & & & & & & & & \\
\hline & - East & 0.594 & 0.571 & 0.547 & 0.521 & 0.493 & 0.464 & 0.432 & 0.400 & 0.367 & 0.341 \\
\hline & - West & 0.583 & 0.560 & 0.536 & 0.511 & 0.484 & 0.455 & 0.425 & 0.393 & 0.364 & 0.340 \\
\hline & - Central & 0.724 & 0.696 & 0.666 & 0.634 & 0.601 & 0.565 & 0.527 & 0.487 & 0.447 & 0.412 \\
\hline & - North & 0.293 & 0.280 & 0.267 & 0.253 & 0.239 & 0.223 & 0.208 & 0.191 & 0.175 & 0.162 \\
\hline & Rural Service & & & & & & & & & & \\
\hline & - East & 0.550 & 0.553 & 0.556 & 0.562 & 0.570 & 0.583 & 0.600 & 0.624 & 0.655 & 0.692 \\
\hline & - West & 0.572 & 0.576 & 0.581 & 0.589 & 0.601 & 0.616 & 0.637 & 0.669 & 0.715 & 0.767 \\
\hline & - Central & 0.594 & 0.593 & 0.593 & 0.595 & 0.600 & 0.607 & 0.620 & 0.638 & 0.663 & 0.685 \\
\hline & - North & 0.415 & 0.422 & 0.432 & 0.443 & 0.457 & 0.476 & 0.500 & 0.531 & 0.569 & 0.610 \\
\hline & Urban & & & & & & & & & & \\
\hline & - Service & 1.498 & 1.501 & 1.495 & 1.480 & 1.452 & 1.409 & 1.345 & 1.257 & 1.143 & 1.020 \\
\hline & - Manufacture & 3.237 & 3.336 & 3.433 & 3.529 & 3.626 & 3.723 & 3.825 & 3.931 & 4.040 & 4.137 \\
\hline \multirow{8}{*}{$\begin{array}{l}\text { GNP } \\
\text { (nominal) } \\
\text { Govt } \\
\text { (nominal) }\end{array}$} & Excluding Food & 9.557 & 9.599 & 9.635 & 9.667 & 9.696 & 9.727 & 9.756 & 9.820 & 9.899 & 9.994 \\
\hline & Including Food & 13.683 & 14.048 & 14.456 & 14.922 & 15.469 & 16.128 & 16.947 & 17.974 & 19.232 & 20.542 \\
\hline & Road Expenditure & 0.613 & 0.615 & 0.617 & 0.620 & 0.624 & 0.628 & 0.634 & 0.641 & 0.649 & 0.658 \\
\hline & Total Expenditure & 3.257 & 3.271 & 3.288 & 3.309 & 3.334 & 3.366 & 3.407 & 3.458 & 3.523 & 3.589 \\
\hline & Tax Revenues & 1.434 & 1.440 & 1.445 & 1.450 & 1.454 & 1.459 & 1.465 & 1.473 & 1.485 & 1.499 \\
\hline & Cash ODA & 1.823 & 1.831 & 1.843 & 1.859 & 1.880 & 1.907 & 1.942 & 1.986 & 2.038 & 2.090 \\
\hline & Green Rev 0DA & - & - & - & - & - & - & - & - & - & - \\
\hline & Total ODA & 1.823 & 1.831 & 1.843 & 1.859 & 1.880 & 1.907 & 1.942 & 1.986 & 2.038 & 2.090 \\
\hline \multirow[t]{3}{*}{ External } & Exports & 5.431 & 5.443 & 5.449 & 5.448 & 5.442 & 5.431 & 5.416 & 5.402 & 5.393 & 5.391 \\
\hline & Imports & 7.293 & 7.315 & 7.334 & 7.351 & 7.368 & 7.386 & 7.408 & 7.442 & 7.493 & 7.563 \\
\hline & FDI & 0.039 & 0.040 & 0.042 & 0.044 & 0.046 & 0.048 & 0.050 & 0.052 & 0.054 & 0.056 \\
\hline
\end{tabular}


TABLE 10: Scenario 6 - Integrated Public Sector Program

\begin{tabular}{|c|c|c|c|c|c|c|c|c|c|c|c|}
\hline & \multicolumn{10}{|c|}{ Time Period } \\
\hline & & 1 & 2 & 3 & 4 & 5 & 6 & 7 & 8 & 9 & 10 \\
\hline \multirow[t]{20}{*}{ Labor } & Food & & & & & & & & & & \\
\hline & - East & 2.338 & 2.388 & 1.339 & 1.156 & 1.153 & 1.035 & 0.930 & 1.210 & 1.171 & 1.126 \\
\hline & - West & 2.375 & 2.423 & 1.388 & 1.202 & 1.198 & 1.078 & 0.971 & 1.253 & 1.214 & 1.168 \\
\hline & - Central & 2.212 & 2.268 & 1.204 & 1.030 & 1.029 & 0.919 & 0.822 & 1.090 & 1.055 & 1.014 \\
\hline & - North & 2.266 & 2.293 & 1.526 & 1.366 & 1.363 & 1.255 & 1.156 & 1.414 & 1.380 & 1.341 \\
\hline & Cash Crop & & & & & & & & & & \\
\hline & - East & 1.062 & 1.012 & 1.811 & 1.933 & 1.913 & 1.984 & 2.044 & 1.799 & 1.808 & 1.822 \\
\hline & - West & 1.013 & 0.965 & 1.758 & 1.883 & 1.863 & 1.936 & 2.000 & 1.750 & 1.760 & 1.775 \\
\hline & - Central & 1.197 & 1.143 & 1.952 & 2.066 & 2.045 & 2.108 & 2.161 & 1.930 & 1.936 & 1.948 \\
\hline & - North & 0.573 & 0.541 & 1.116 & 1.224 & 1.207 & 1.274 & 1.334 & 1.111 & 1.120 & 1.134 \\
\hline & Rural Service & & & & & & & & & & \\
\hline & - East & 0.915 & 0.892 & 1.122 & 1.161 & 1.164 & 1.191 & 1.216 & 1.163 & 1.174 & 1.186 \\
\hline & - West & 0.926 & 0.905 & 1.127 & 1.166 & 1.169 & 1.196 & 1.221 & 1.170 & 1.182 & 1.195 \\
\hline & - Central & 0.905 & 0.883 & 1.117 & 1.157 & 1.159 & 1.186 & 1.212 & 1.158 & 1.169 & 1.182 \\
\hline & - North & 0.775 & 0.757 & 0.928 & 0.957 & 0.954 & 0.972 & 0.989 & 0.933 & 0.937 & 0.941 \\
\hline & Urban & & & & & & & & & & \\
\hline & - Service & 0.781 & 0.800 & 0.913 & 0.954 & 0.982 & 1.018 & 1.052 & 1.056 & 1.083 & 1.111 \\
\hline & - Manufacture & 1.479 & 1.543 & 1.510 & 1.554 & 1.606 & 1.650 & 1.692 & 1.760 & 1.805 & 1.849 \\
\hline & Government & 0.782 & 0.786 & 0.789 & 0.792 & 0.795 & 0.797 & 0.800 & 0.803 & 0.805 & 0.808 \\
\hline & TOTAL RURAL & 16.557 & 16.470 & 16.388 & 16.301 & 16.217 & 16.134 & 16.056 & 15.981 & 15.906 & 15.832 \\
\hline \multirow[t]{5}{*}{ Migration } & Rural to Urban & & & & & & & & & & \\
\hline & - East & 0.021 & 0.020 & 0.021 & 0.020 & 0.019 & 0.019 & 0.018 & 0.018 & 0.017 & 0.017 \\
\hline & - West & 0.021 & 0.019 & 0.021 & 0.020 & 0.019 & 0.018 & 0.017 & 0.018 & 0.017 & 0.017 \\
\hline & - Central & 0.020 & 0.019 & 0.020 & 0.019 & 0.018 & 0.017 & 0.016 & 0.017 & 0.016 & 0.016 \\
\hline & - North & 0.022 & 0.021 & 0.023 & 0.022 & 0.022 & 0.021 & 0.021 & 0.021 & 0.020 & 0.020 \\
\hline \multirow[t]{10}{*}{ Fertilizer } & Total Use & & & & & & & & & & \\
\hline & - East & - & - & 0.329 & 0.288 & 0.201 & 0.214 & 0.230 & 0.049 & 0.065 & 0.082 \\
\hline & - West & - & - & 0.331 & 0.291 & 0.203 & 0.217 & 0.234 & 0.054 & 0.070 & 0.088 \\
\hline & - Central & - & - & 0.320 & 0.280 & 0.194 & 0.209 & 0.226 & 0.048 & 0.064 & 0.082 \\
\hline & - North & - & - & 0.333 & 0.287 & 0.193 & 0.199 & 0.206 & 0.016 & 0.023 & 0.030 \\
\hline & Price of Fertilizer & & & & & & & & & & \\
\hline & - East & 2.000 & 1.926 & 1.864 & 1.811 & 1.766 & 1.726 & 1.692 & 1.661 & 1.634 & 1.610 \\
\hline & - West & 2.000 & 1.926 & 1.864 & 1.811 & 1.766 & 1.726 & 1.692 & 1.661 & 1.634 & 1.610 \\
\hline & - Central & 1.818 & 1.763 & 1.716 & 1.675 & 1.640 & 1.609 & 1.582 & 1.558 & 1.537 & 1.517 \\
\hline & - North & 2.222 & 2.122 & 2.040 & 1.971 & 1.912 & 1.862 & 1.818 & 1.779 & 1.745 & 1.715 \\
\hline \multirow[t]{12}{*}{ Prices } & Food in Rural Area & & & & & & & & & & \\
\hline & - East & 0.342 & 0.370 & 0.202 & 0.187 & 0.194 & 0.185 & 0.177 & 0.224 & 0.225 & 0.224 \\
\hline & - West & 0.342 & 0.370 & 0.202 & 0.187 & 0.194 & 0.185 & 0.177 & 0.224 & 0.225 & 0.224 \\
\hline & - Central & 0.376 & 0.404 & 0.220 & 0.202 & 0.209 & 0.199 & 0.189 & 0.239 & 0.239 & 0.238 \\
\hline & - North & 0.308 & 0.336 & 0.185 & 0.172 & 0.179 & 0.172 & 0.165 & 0.209 & 0.211 & 0.211 \\
\hline & Food in Urban Area & 0.684 & 0.713 & 0.377 & 0.339 & 0.343 & 0.320 & 0.300 & 0.372 & 0.367 & 0.361 \\
\hline & CPI Rural & & & & & & & & & & \\
\hline & - East & 0.572 & 0.578 & 0.590 & 0.600 & 0.604 & 0.613 & 0.622 & 0.610 & 0.615 & 0.619 \\
\hline & - West & 0.576 & 0.582 & 0.592 & 0.602 & 0.606 & 0.615 & 0.624 & 0.613 & 0.618 & 0.623 \\
\hline & - Central & 0.583 & 0.588 & 0.604 & 0.615 & 0.618 & 0.627 & 0.637 & 0.623 & 0.627 & 0.632 \\
\hline & - North & 0.555 & 0.562 & 0.563 & 0.570 & 0.573 & 0.578 & 0.584 & 0.578 & 0.580 & 0.581 \\
\hline & CPI Urban & 0.741 & 0.737 & 0.746 & 0.744 & 0.741 & 0.740 & 0.738 & 0.734 & 0.732 & 0.730 \\
\hline Real & Rural Service & & & & & & & & & & \\
\hline \multirow{5}{*}{ Wage } & - East & 0.513 & 0.524 & 0.706 & 0.765 & 0.777 & 0.825 & 0.873 & 0.788 & 0.808 & 0.830 \\
\hline & - West & 0.532 & 0.544 & 0.717 & 0.775 & 0.788 & 0.835 & 0.884 & 0.803 & 0.824 & 0.847 \\
\hline & - Central & 0.547 & 0.554 & 0.764 & 0.825 & 0.835 & 0.884 & 0.935 & 0.840 & 0.861 & 0.884 \\
\hline & - North & 0.468 & 0.485 & 0.603 & 0.648 & 0.659 & 0.692 & 0.725 & 0.658 & 0.666 & 0.674 \\
\hline & Urban Service & 1.561 & 1.516 & 1.756 & 1.768 & 1.750 & 1.754 & 1.757 & 1.689 & 1.681 & 1.676 \\
\hline Total & Rural & & & & & & & & & & \\
\hline \multirow{5}{*}{$\begin{array}{l}\text { Income } \\
\text { (nominal) }\end{array}$} & - East & 1.233 & 1.267 & 1.690 & 1.871 & 1.925 & 2.082 & 2.250 & 2.023 & 2.100 & 2.186 \\
\hline & - West & 1.284 & 1.322 & 1.724 & 1.906 & 1.963 & 2.123 & 2.293 & 2.076 & 2.158 & 2.250 \\
\hline & - Central & 1.338 & 1.361 & 1.865 & 2.059 & 2.105 & 2.276 & 2.459 & 2.189 & 2.270 & 2.361 \\
\hline & - North & 0.924 & 0.964 & 1.156 & 1.259 & 1.290 & 1.372 & 1.454 & 1.316 & 1.340 & 1.363 \\
\hline & Urban & 3.352 & 3.381 & 3.880 & 4.014 & 4.089 & 4.200 & 4.305 & 4.268 & 4.346 & 4.425 \\
\hline
\end{tabular}




\begin{tabular}{|c|c|c|c|c|c|c|c|c|c|c|c|}
\hline & \multicolumn{10}{|c|}{ Time Period } \\
\hline & & 1 & 2 & 3 & 4 & 5 & 6 & 7 & 8 & 9 & 10 \\
\hline \multirow[t]{7}{*}{ Savings } & Rural & & & & & & & & & & \\
\hline & - East & 0.231 & 0.239 & 0.344 & 0.388 & 0.401 & 0.440 & 0.481 & 0.426 & 0.445 & 0.466 \\
\hline & - West & 0.243 & 0.252 & 0.352 & 0.396 & 0.410 & 0.450 & 0.491 & 0.439 & 0.459 & 0.482 \\
\hline & - Central & 0.256 & 0.261 & 0.385 & 0.433 & 0.444 & 0.486 & 0.531 & 0.466 & 0.485 & 0.508 \\
\hline & - North & 0.168 & 0.177 & 0.226 & 0.251 & 0.259 & 0.279 & 0.299 & 0.266 & 0.272 & 0.278 \\
\hline & Urban & 0.629 & 0.634 & 0.732 & 0.757 & 0.771 & 0.792 & 0.812 & 0.803 & 0.818 & 0.832 \\
\hline & Gross National Rate & 0.111 & 0.110 & 0.140 & 0.145 & 0.146 & 0.149 & 0.153 & 0.144 & 0.146 & 0.147 \\
\hline \multirow[t]{13}{*}{ Capital } & Cash Crop & & & & & & & & & & \\
\hline & - East & 5.000 & 5.027 & 5.058 & 5.146 & 5.256 & 5.372 & 5.506 & 5.660 & 5.781 & 5.910 \\
\hline & - West & 5.000 & 5.034 & 5.072 & 5.164 & 5.279 & 5.399 & 5.538 & 5.697 & 5.825 & 5.961 \\
\hline & - Central & 6.000 & 6.021 & 6.044 & 6.135 & 6.250 & 6.370 & 6.510 & 6.671 & 6.794 & 6.925 \\
\hline & - North & 4.000 & 4.012 & 4.030 & 4.073 & 4.130 & 4.189 & 4.259 & 4.338 & 4.398 & 4.459 \\
\hline & Rural Service & & & & & & & & & & \\
\hline & - East & 5.000 & 4.954 & 4.913 & 4.920 & 4.947 & 4.979 & 5.028 & 5.093 & 5.132 & 5.178 \\
\hline & - West & 5.000 & 4.959 & 4.924 & 4.935 & 4.965 & 5.001 & 5.053 & 5.123 & 5.166 & 5.218 \\
\hline & - Central & 5.000 & 4.965 & 4.934 & 4.959 & 5.005 & 5.055 & 5.122 & 5.207 & 5.260 & 5.321 \\
\hline & - North & 5.000 & 4.925 & 4.858 & 4.813 & 4.782 & 4.755 & 4.738 & 4.730 & 4.708 & 4.689 \\
\hline & Urban & & & & & & & & & & \\
\hline & - Service & 10.000 & 10.141 & 10.280 & 10.484 & 10.700 & 10.918 & 11.145 & 11.379 & 11.600 & 11.824 \\
\hline & - Manufacture & 10.000 & 9.927 & 9.860 & 9.824 & 9.797 & 9.777 & 9.764 & 9.759 & 9.753 & 9.753 \\
\hline \multirow[t]{5}{*}{ Roads } & Road Capital & & & & & & & & & & \\
\hline & - East & 4.000 & 4.160 & 4.315 & 4.466 & 4.612 & 4.753 & 4.891 & 5.024 & 5.153 & 5.279 \\
\hline & - West & 4.000 & 4.160 & 4.315 & 4.466 & 4.612 & 4.753 & 4.891 & 5.024 & 5.153 & 5.279 \\
\hline & - Central & 4.000 & 4.160 & 4.315 & 4.466 & 4.612 & 4.753 & 4.891 & 5.024 & 5.153 & 5.279 \\
\hline & - North & 4.000 & 4.160 & 4.315 & 4.466 & 4.612 & 4.753 & 4.891 & 5.024 & 5.153 & 5.279 \\
\hline \multirow[t]{5}{*}{ Soils } & Productivity & & & & & & & & & & \\
\hline & - East & 0.999 & 0.985 & 0.970 & 1.071 & 1.149 & 1.195 & 1.240 & 1.285 & 1.287 & 1.292 \\
\hline & - West & 0.999 & 0.985 & 0.970 & 1.071 & 1.150 & 1.196 & 1.243 & 1.288 & 1.291 & 1.297 \\
\hline & - Central & 0.999 & 0.985 & 0.970 & 1.068 & 1.144 & 1.188 & 1.233 & 1.277 & 1.279 & 1.284 \\
\hline & - North & 0.999 & 0.985 & 0.970 & 1.072 & 1.150 & 1.193 & 1.235 & 1.275 & 1.269 & 1.265 \\
\hline Value & Food & & & & & & & & & & \\
\hline \multirow{17}{*}{$\begin{array}{l}\text { Added } \\
\text { (nominal) }\end{array}$} & - East & 1.045 & 1.126 & 0.604 & 0.555 & 0.575 & 0.547 & 0.522 & 0.665 & 0.667 & 0.666 \\
\hline & - West & 1.093 & 1.177 & 0.639 & 0.588 & 0.610 & 0.581 & 0.555 & 0.706 & 0.710 & 0.710 \\
\hline & - Central & 1.070 & 1.147 & 0.591 & 0.537 & 0.554 & 0.523 & 0.497 & 0.639 & 0.640 & 0.637 \\
\hline & - North & 0.926 & 1.002 & 0.591 & 0.555 & 0.574 & 0.551 & 0.529 & 0.644 & 0.642 & 0.636 \\
\hline & Cash Crop & & & & & & & & & & \\
\hline & - East & 0.593 & 0.597 & 1.021 & 1.160 & 1.192 & 1.310 & 1.433 & 1.236 & 1.288 & 1.347 \\
\hline & - West & 0.582 & 0.586 & 1.011 & 1.152 & 1.185 & 1.304 & 1.430 & 1.232 & 1.287 & 1.349 \\
\hline & - Central & 0.723 & 0.723 & 1.198 & 1.345 & 1.375 & 1.500 & 1.633 & 1.413 & 1.467 & 1.530 \\
\hline & - North & 0.293 & 0.296 & 0.540 & 0.621 & 0.635 & 0.698 & 0.763 & 0.633 & 0.652 & 0.672 \\
\hline & Rural Service & & & & & & & & & & \\
\hline & - East & 0.551 & 0.565 & 0.741 & 0.816 & 0.838 & 0.903 & 0.973 & 0.878 & 0.910 & 0.946 \\
\hline & - West & 0.572 & 0.588 & 0.755 & 0.830 & 0.854 & 0.920 & 0.991 & 0.901 & 0.935 & 0.973 \\
\hline & - Central & 0.595 & 0.605 & 0.814 & 0.894 & 0.913 & 0.984 & 1.060 & 0.948 & 0.981 & 1.019 \\
\hline & - North & 0.416 & 0.433 & 0.512 & 0.555 & 0.567 & 0.601 & 0.635 & 0.578 & 0.587 & 0.597 \\
\hline & Urban & & & & & & & & & & \\
\hline & - Service & 1.497 & 1.511 & 1.731 & 1.791 & 1.825 & 1.874 & 1.921 & 1.905 & 1.940 & 1.976 \\
\hline & - Manufacture & 3.238 & 3.329 & 3.271 & 3.334 & 3.410 & 3.472 & 3.532 & 3.631 & 3.695 & 3.758 \\
\hline \multirow{8}{*}{$\begin{array}{l}\text { GNP } \\
\text { (nominal) } \\
\text { Govt } \\
\text { (nominal) }\end{array}$} & Excluding Food & 9.565 & 9.759 & 12.136 & 13.069 & 13.379 & 14.180 & 15.014 & 13.966 & 14.369 & 14.806 \\
\hline & Including Food & 13.698 & 14.211 & 14.561 & 15.304 & 15.691 & 16.382 & 17.117 & 16.620 & 17.028 & 17.455 \\
\hline & Road Expenditure & 1.179 & 1.184 & 1.188 & 1.194 & 1.198 & 1.204 & 1.210 & 1.207 & 1.211 & 1.215 \\
\hline & Total Expenditure & 3.824 & 3.847 & 3.862 & 3.891 & 3.905 & 3.932 & 3.961 & 3.932 & 3.946 & 3.961 \\
\hline & Tax Revenues & 1.435 & 1.464 & 1.820 & 1.960 & 2.007 & 2.127 & 2.252 & 2.095 & 2.155 & 2.221 \\
\hline & Cash ODA & 2.389 & 2.383 & 2.041 & 1.931 & 1.898 & 1.805 & 1.709 & 1.837 & 1.791 & 1.740 \\
\hline & Green Rev 0DA & - & - & 0.350 & 0.300 & 0.200 & 0.200 & 0.200 & - & - & - \\
\hline & Total ODA & 2.389 & 2.383 & 2.391 & 2.231 & 2.098 & 2.005 & 1.909 & 1.837 & 1.791 & 1.740 \\
\hline \multirow[t]{3}{*}{ External } & Exports & 5.429 & 5.530 & 7.042 & 7.612 & 7.797 & 8.284 & 8.791 & 8.145 & 8.389 & 8.655 \\
\hline & Imports & 7.857 & 7.953 & 10.437 & 10.730 & 10.527 & 10.971 & 11.442 & 10.194 & 10.449 & 10.726 \\
\hline & FDI & 0.039 & 0.040 & 0.040 & 0.041 & 0.042 & 0.043 & 0.044 & 0.046 & 0.047 & 0.048 \\
\hline
\end{tabular}




\section{DISCUSSION}

he scenarios outlined above illustrate many of the key dynamics that can be evaluated using the new model presented here. Figures 5 through 9 present some comparisons of key variables across the scenarios. The right side of Figure 5 shows labor in cash crops in the indicative Western region. Here, one sees that the baseline (scenario 1) has relatively stable, although slightly decreasing, labor in cash crops, and all but one scenario has an even faster rate of decline. Only the green revolution scenario shows a structural increase in cash crop labor over the period, and it is significantly greater. The left side of Figure 5 shows labor in urban services. Interestingly, all scenarios show an increase in service labor over the first few periods before divergence sets in. The public service delivery scenario and scenario 2 (baseline with soil) have the most rapid service labor drop off, while the road-building scenario stays relatively even. Again, the green revolution prompts the most dramatic increase in the service sector as its capital stock is bolstered through increased savings and labor is freed up through increased farm productivity.

Figure 6 outlines different trajectories for both urban and rural food prices. Two major trends emerge here. First, the incorporation of soil productivity initiates a major divergence in prices from the baseline of scenario 1. Road building tempers the price increase slightly, even more in urban than rural areas; but the core point is that a 15 percent decline in soil productivity over 10 periods is linked to roughly a doubling of rural food prices. The second major trend pertains again to the green revolution. This is the only scenario that leads to decreases in domestic food prices by roughly a third in both rural and urban scenarios.

Figure 7 shows the nonfood $\mathrm{CPI}$ in rural and urban areas. It is important to note that the vertical axes are truncated in these graphs, so the changes are smaller than they might first appear. All of the relevant scenarios have relative urban nonfood price stability, with decreased demand leading to a 7 percent drop in the most extreme case of scenario 5 (public services). In the rural areas, nonfood prices increase by no more than 16 percent in the worst case and

\section{Figure 5: Labor Movements across the Scenarios}

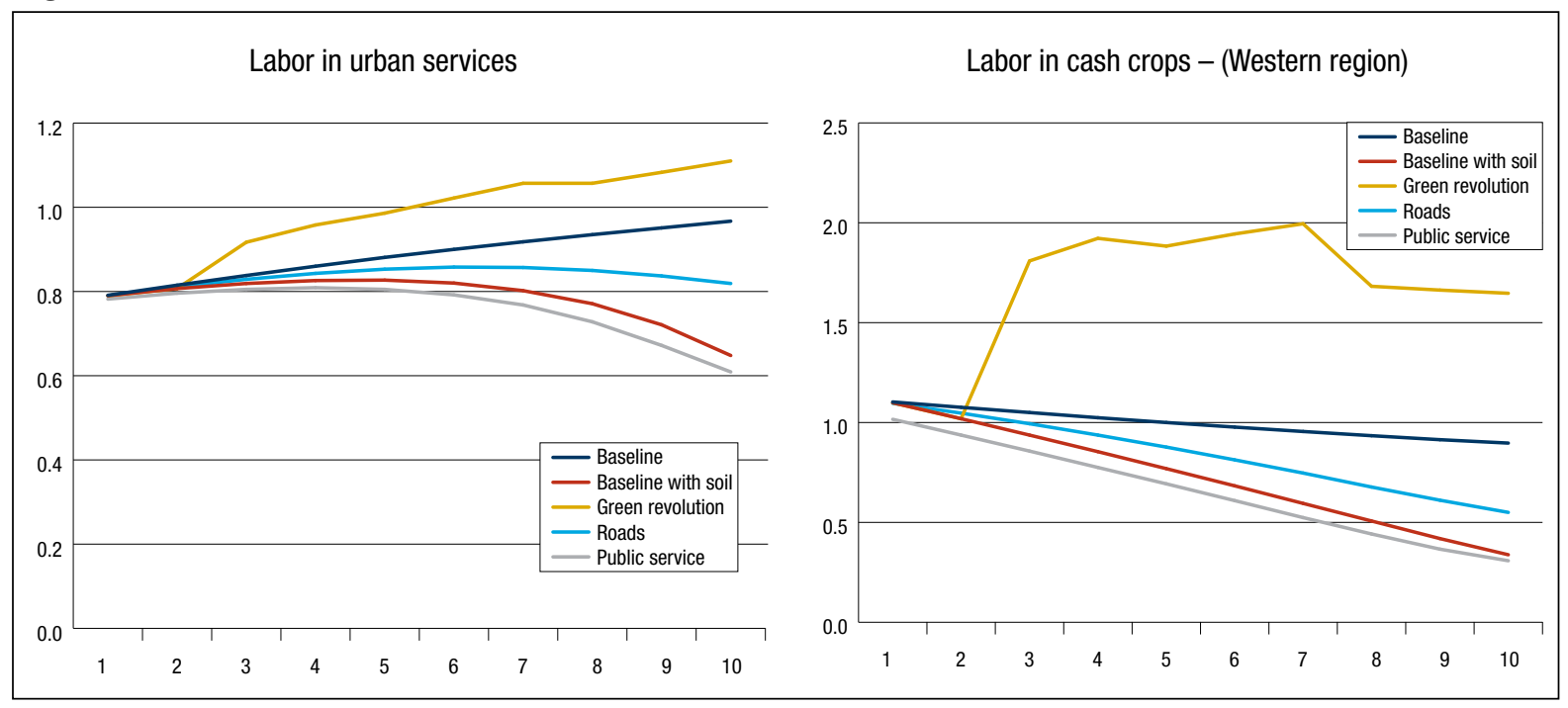


Figure 6: Food Prices across the Scenarios

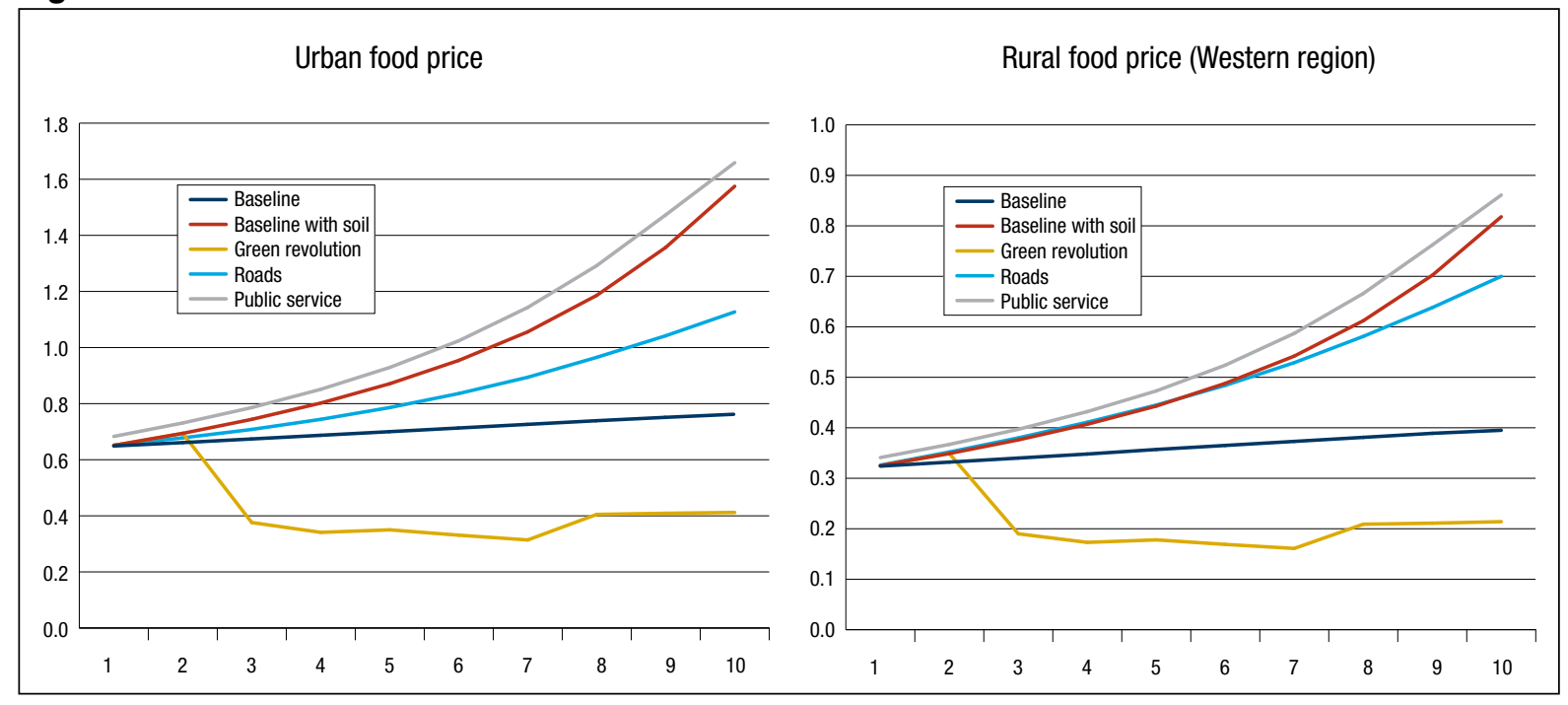

\section{Figure 7: Food Prices across the Scenarios}

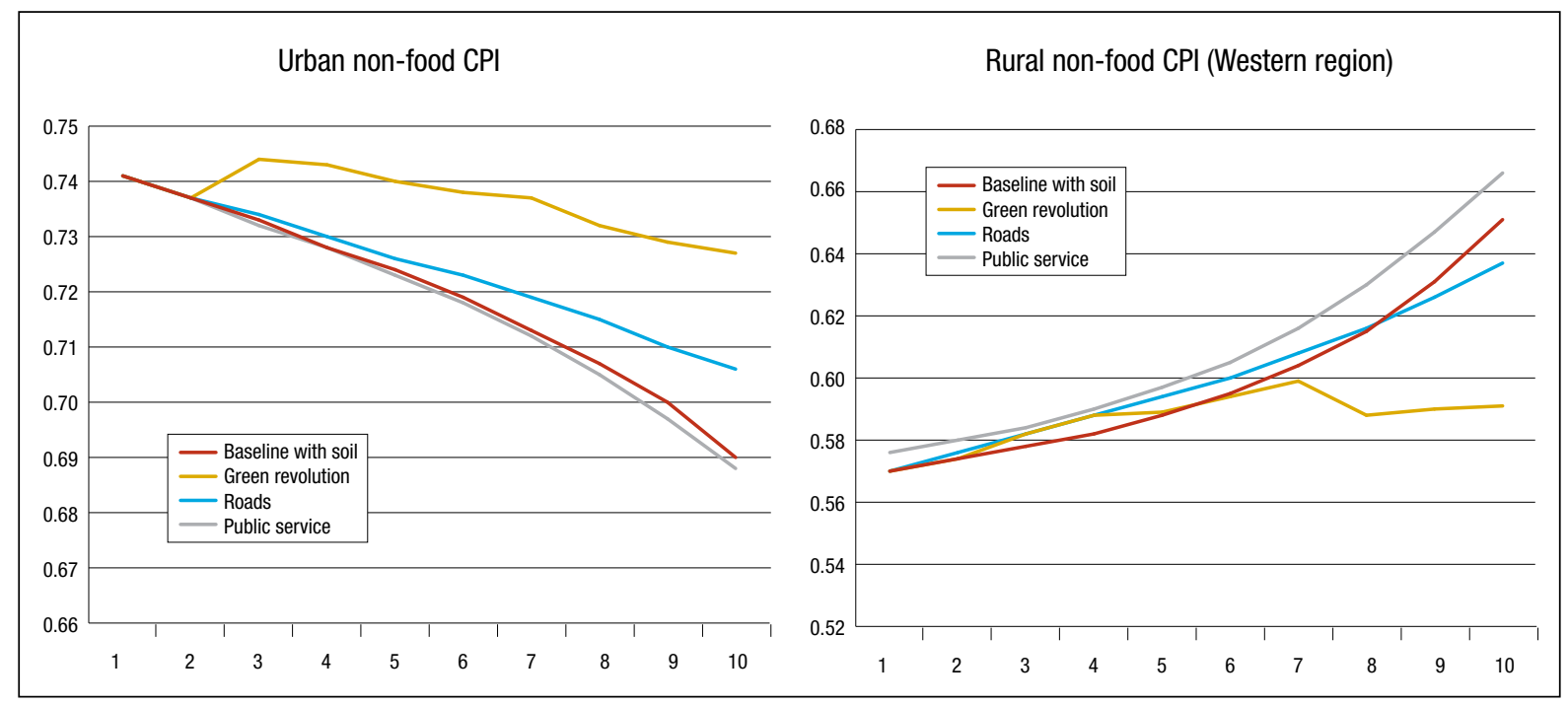

increase by only 4 percent in the green revolution scenario. The rural-urban and food-CPI mix of prices is different in each scenario, but it is clear that a Dutch disease dynamic can take hold even in the road-building scenario, although it clearly does not take place in the green revolution scenario.

Figure 8 shows the real wages in the urban and rural service sectors. In the urban areas, the low demand and productivity in non-green revolution scenarios lead to enormous declines in real wages. The baseline with soil degradation (scenario 2) sees the real wage drop 57 percent by period 10 . The road-building scenario mitigates the losses, such that wages drop only 33 percent. In the green revolution scenario, urban wages are nearly 3 percent 
Figure 8: Real Service Wages across the Scenarios

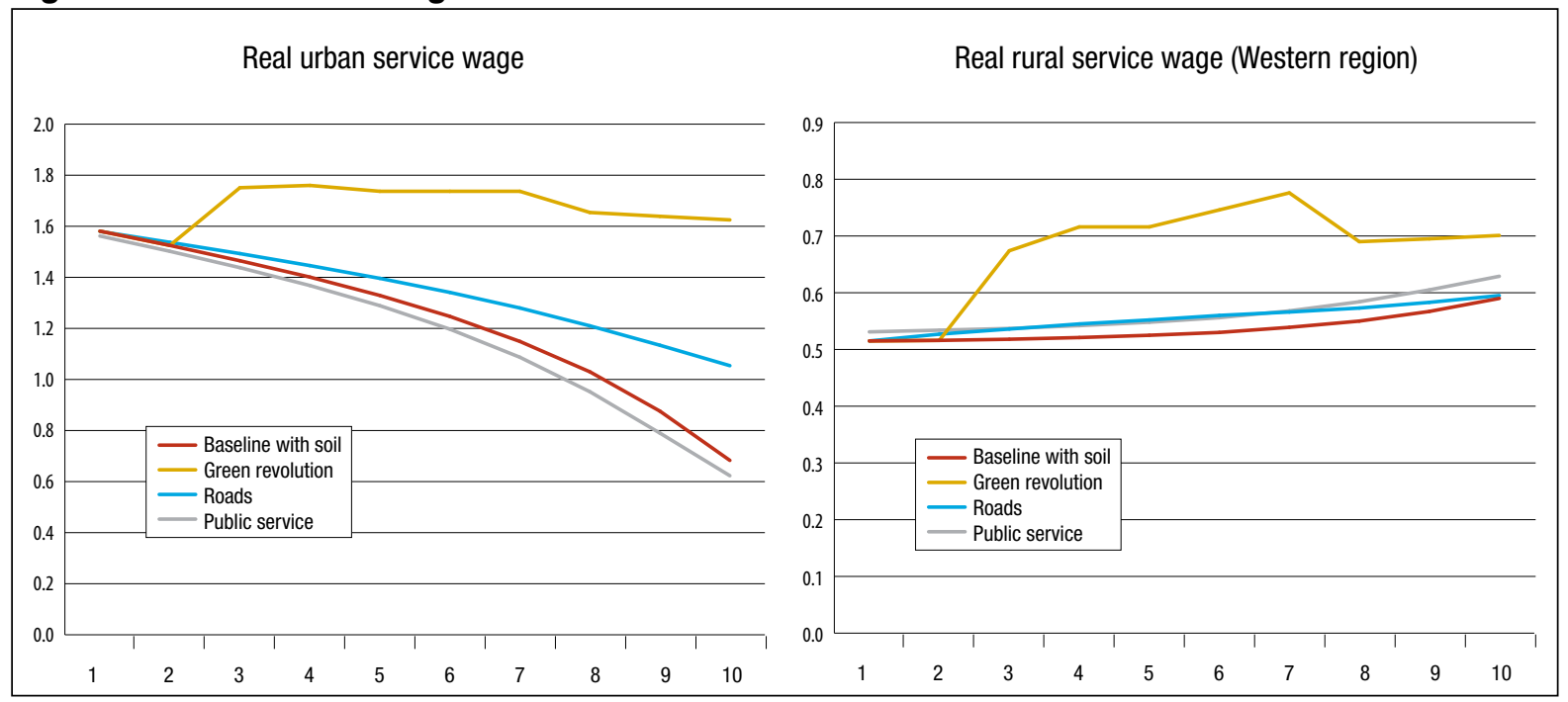

Figure 9: Total ODA Costs across the Scenarios

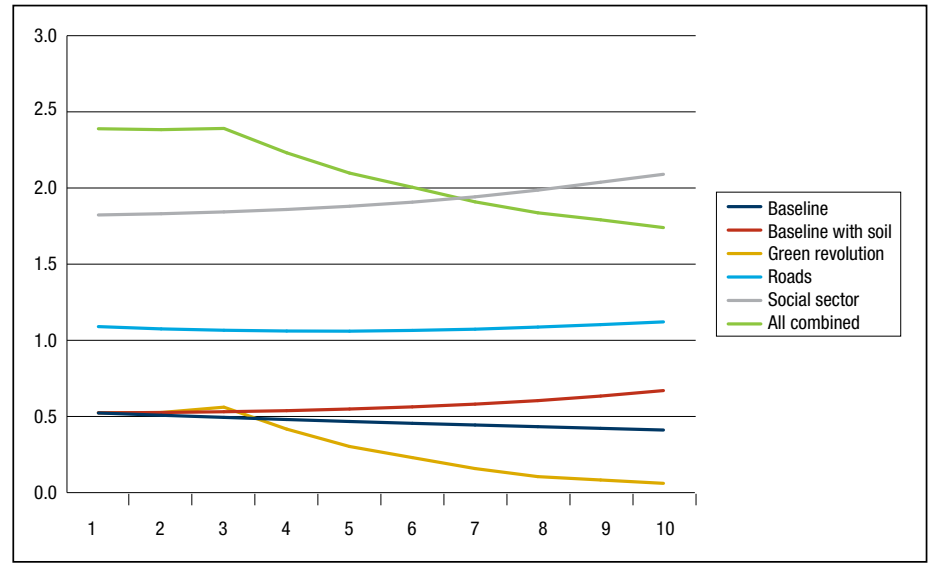

higher by the final period. Meanwhile, the rural wage dynamics are better across the board. Wages increase by approximately 15 percent in each of the non-green revolution paths and by 36 percent in the green revolution path.

The figures given above show a pattern in which the green revolution scenario is clearly the preferred outcome across a range of variables. The key remaining variable is therefore cost. Figure 9 presents a graph of the ODA required to finance all six scenarios. Several key points can be made here. It is clear that the social sector investments are the most expensive from an ODA vantage point. As noted above, scenario 5 is presented with no supplyside productivity effects here, so the result is not to be overinterpreted. However, in unreported results, even with a 20 percent productivity improvement during the period and a downward ODA trend over time, the social sector 
ODA is still estimated to be 24 percent higher than the road-building scenario as of period 10 . The roads sector requires nearly twice as much ODA as the baseline-with-soil scenario, but the productivity effects are not enough to decrease the need for external finance by period 10.

The green revolution scenario has strong productivity effects that represent a targeted boost in ODA but require even less ODA than the baseline (scenario 1), or the baseline with soil scenario (scenario 2), from period 4 onward. Indeed, by the final period, the green revolution scenario is clearly the least expensive approach from the vantage of total ODA. This suggests that temporary public finance for agricultural inputs might be the most efficient path to long-term growth and graduation from foreign aid. 


\section{CONCLUSIONS}

T

his paper uses plausible parameters to confer important insights regarding the different channels through

which aid might support economic growth in Africa. Although the results are not presented as precise point estimates, the key dynamics pertain to the equilibrium impact of introducing a broadly scaled small-holder agricultural support strategy. The model also provides a mechanism for evaluating the growth implications suggested by Christiaensen, Demery and Kuhl (2011) and the macroeconomic consequences of agricultural productivity declines caused by soil nutrient depletion. Scenario 2 demonstrates the dramatically different outcomes that occur when only subtle changes in soil productivity are incorporated into the analysis. This suggests that soil productivity alone might have tremendous consequences for aggregate economic growth and poverty traps in Africa.

The model also provides a mechanism for evaluating different public support strategies, financed by both foreign and domestic sources, for rural African economies. Scenario 4 shows a sizable positive effect for infrastructure, but not enough in scale to overcome the other capital-widening aspects of the economy. In terms of boosts to real wages, scenario 3's green revolution package remains the cheapest option due to the deflationary effect on prices and a boom in output. It frees up labor to move into higher value-added tradable sectors, especially cash crops, and also higher value-added nontradable service sectors. In addition, the green revolution strategy provides a strong result in which the temporary boost in targeted ODA yields permanent productivity and welfare effects. Within the parameters of the scenarios presented, this result is achieved at lower cost than ODA programs focused on road building, health and education. We stress that this observation should not be interpreted as argument for prioritizing aid to agriculture over complementary aid for roads, health and education. It merely serves to highlight the very different general equilibrium pathways that can result from different forms of aid allocation.

While labor is parameterized to migrate fairly gradually between the rural and urban sectors, rapid mobility between the food and cash crop sectors is fundamental to the model's dynamics and to the positive general outcomes in the green revolution scenario. In reality, most farmers have a high degree of mobility between these two sectors in making planting choices on their own farms. However, switching costs are likely nonzero, and a considerable literature on farmer adoption patterns suggests that the instantaneous assumption is a simplification. Mobility from the farm to rural service sectors is also less than immediate in reality, although this is less of a core dynamic in the model.

In light of much of the macroeconomic literature's emphasis on Dutch disease and the related effects of ODA, the model's evaluations of real exchange rate dynamics under different forms of aid targeting are informative. Rural inflation and real exchange rate appreciation are much worse in the presence of soil productivity loss than in scenarios with constant soil fertility, even while urban prices remain relatively stable. A public service expansion amplifies this challenge in the absence of productivity-boosting consequences, while also stretching public accounts and ODA budgets.

Conversely, a foreign-financed green revolution package shows a clear anti-Dutch disease result where imported inputs have strong deflationary consequences for the rural populations, again even while urban prices remain fairly 
constant. Road building helps to mitigate inflation among staple food as a primary consumption good that is dramatically affected by transport costs, but it does not play a major role in determining nonfood price indexes in an economy with no intermediate goods. The ODA-related discussions of Dutch disease might need to introduce new jargon for the countervailing relative price effects caused by agriculture-focused ODA_-agro-ease"?

It is notable that, when the various dynamics are merged in scenario 6, the agricultural productivity effect dominates as both rural and urban food prices drop and nonfood prices remain fairly stagnant. An African green revolution strategy would appear to have strong positive competitiveness effects, even in the presence of a non-productivityboosting public service delivery strategy. The agricultural intervention package is the only one that leads to adequate growth in rural tradable sector capital stocks to allow the market-based financing of related inputs.

Although the model provides considerable range for scenario building and a further empirical analysis based on more refined parameterization, at least six structural dimensions can be noted for future research and refinements. First, instantaneous labor mobility remains quantitatively significant within regions during the same period as when the green revolution input package is introduced. A more gradual labor mobility function would be a useful addition to the model. Second, the model represents fertilizer as purely labor-saving, which is not necessarily the case in real life because the introduction of fertilizer requires additional weeding and land management. A more nuanced labor function is required to capture this.

Third, the model includes very simple assumptions around human capital, with only one labor skill type. As in recent evolutions of the MAMS model, an important differentiation could be added for various skill and productivity levels, in addition to a deeper consideration of linkages between government services, aid, and long-term supplyside productivity effects through investments in education and health. Fourth, the model uses only a capital constraint to fertilizer use. Other constraints could usefully be added, including income constraints or credit market constraints.

Fifth, the model excludes any demographic effects, which are important both due to the importance of shrinking land/labor ratios in many African countries and because investments in health, education and agricultural productivity are all likely to lead to increases in life expectancy and decreases in fertility rates. Sixth, future models could integrate explicit emphasis on the domestic and external factors affecting the growth of manufacturing. These are all important issues that would improve the model's ability to illustrate key dynamics in African economies. 


\section{APPENDIX A: MODEL EQUATION LISTING}

\section{Block 1: Agricultural Production Functions}

(EQ.1.1)

$$
F_{i, t}=S_{i, t} \text { thetaf }_{i}^{*} \operatorname{land}_{i} *\left(1+F E R T_{i, t}\right) * E L F_{i, t} \text { alphaf } * k f_{i}^{\text {betaf }}
$$

(EQ.1.2)

$$
V F_{i, t}=F_{i, t}{ }^{*} P F R_{i, t}
$$

$$
C C_{i, t}=S_{i, t}{ }^{*} \text { thetacc }_{i}{ }^{*} \operatorname{land}_{i} *\left(1+F E R T_{i, t}\right) * E L C C_{i, t}^{\text {alphacc } *}\left(\text { kcscale }^{*} K C C_{i, t}\right) \text { betacc }
$$

(EQ.1.4)

$$
S_{i, t}=\frac{\text { uppersoil }_{i}}{1+r h o^{*} \text { EXPNUT }_{i, t}}
$$

$$
E X P N U T_{i, t}=e^{-N U T S U M_{i, t}}
$$

$$
\operatorname{NUTSUM}_{i, t+1}=\operatorname{NUTSUM}_{i, t}+\operatorname{NETIN}_{i, t}
$$

$$
\text { NUTSUM }_{i, t 0}=\text { nutrient }_{i}
$$

(EQ.1.8) $\quad$ NETIN $_{i, t}=F E R T_{i, t}-$ nlossrate

$$
F E R T_{i, t}=\min \left(1, \max \left(0,\left(k c s c a l e * \frac{K C C_{i, t}-\left(\left(1+\text { khurdle }^{*} k c c 0_{i}\right)\right.}{\operatorname{PFERTR}_{i, t}}\right)+\text { grpoda }_{t}\right)\right)
$$

(EQ.1.10) $\quad V C C_{i, t}=C C_{i, t} * P C C R_{i, t}$

\section{Block 2: Nonagricultural Production Functions}

$$
M_{t}=\operatorname{thetam}_{t} * \operatorname{ELM}_{t}^{\text {alpham } *}\left(\text { kmscale }^{*} K M_{t}\right)^{(1-\text { alpham })}
$$

$$
S U_{t}=\operatorname{thetasu}_{t}{ }^{*} \operatorname{LSU} U_{t}^{\text {alphas } *}\left(k s s c a l e * K S U_{t}\right)^{(1-a l p h a s)}
$$

(EQ.2.3)

$$
V S U_{t}=S U_{t}^{*} P S U_{t}
$$

$$
S R_{i, t}=\text { thetasr }_{i}^{*} \operatorname{ELSR}_{i, t} \text { alphas*}\left(\operatorname{ksscale}^{*} \operatorname{KSR}_{i, t}\right)^{(1-a \text { aphas })}
$$

$$
V S R_{i, t}=S R_{i, t} * P S R_{i, t}
$$

\section{Block 3: Effective Labor}

$$
E L F_{i, t}=L F_{i, t} * L A B S C A L E_{t}
$$

$$
E L C C_{i, t}=L C C_{i, t} * L A B S C A L E_{t}
$$

$$
E L M_{t}=L M_{t}^{*} L A B S C A L E_{t}
$$

$$
E L S R_{i, t}=L S R_{i, t}{ }^{*} L A B S C A L E_{t}
$$

$$
\begin{aligned}
& E L S U_{t}=L S U_{t}^{*}{ }^{*} A B S C A L E_{t} \\
& L A B S C A L E_{t}=\frac{10+H W P R O G_{t}}{10}
\end{aligned}
$$




\section{Block 4: Food Market Clearance}

(EQ.4.1) $\quad F K A M P_{t}=p h i{ }^{*} L U_{t}$

(EQ.4.2) $\quad F K A M P_{i}=\sum_{i} F S U R P_{i, t} *\left(1-\operatorname{TLOSS}_{i, t}\right)$

(EQ.4.3) $\quad$ FSURP $_{i, t}=F_{i, t}-p h i * L R_{i, t}$

\section{Block 5: Transport Costs and Prices}

(EQ.5.1)

$$
\operatorname{TLOSS}_{i, t}=\frac{{ }_{\text {first }} 0_{i}}{\operatorname{KROAD}_{i, t}}
$$

$$
P F R_{i, t}=P F U_{t}^{*}\left(1-\operatorname{TLOSS}_{i, t}\right)
$$

(EQ.5.3)

$$
\text { PFERTR }_{i, t}=\frac{\text { pworldfert }}{1-\text { TLOSS }_{i, t}}
$$

(EQ.5.4) $\quad$ PCCR $_{i, t}=1-$ TLOSS $_{i, t}$

(EQ.5.5) $\quad$ PIMPR $_{t}=1$

(EQ.5.6) $\quad \operatorname{PIMPU}_{t}=1$

(EQ.5.7) $\quad$ CPINFU $U_{t}=P S U_{t}^{*}$ gammas $+P I M P U_{t}^{*}(1-$ gammas $)$

(EQ.5.8) $\quad$ CPINFR $_{i, t}=$ PSR $_{i, t}{ }^{*}$ gammas + PIMPR $_{t}^{*}(1-$ gammas $)$

\section{Block 6: Labor Income By Sector}

$$
\begin{aligned}
& \text { (EQ.6.1) } \quad W M A N_{t}=\text { thetam }_{t}^{*} \text { alpham }^{*}\left(\text { kmscale }^{*} K M_{t} / E L M_{t}\right)^{1-\text { alpham }} \\
& \text { (EQ.6.2) } \quad W S U_{t}=P S U_{t}^{*} \text { thetasu }_{t}^{*} \text { alphas }^{*}\left(\text { ksscale }^{*} K S U_{t} / \text { ELSU }_{t}\right)^{\text {I-alphas }} \\
& \text { (EQ.6.3) } \quad \operatorname{WSR}_{i, t}=P S R_{i, t}{ }^{*} \text { alphas }^{*} \text { thetasr }_{i}{ }^{*}\left(\text { ksscale }^{*} \operatorname{KSR}_{i, t} / \operatorname{ELSR}_{i, t}\right)^{1-\text { alphas }} \\
& \text { (EQ.6.4) } \quad M P F_{i, t}=\frac{P F R_{i, t}{ }^{*} F_{i, t}{ }^{*} \text { alphaf }}{E L F_{i, t}} \\
& \text { (EQ.6.5) } \quad M P C C_{i, t}=\frac{P C C R_{i, t}{ }^{*} C C_{i, t}{ }^{*} \text { alphacc }}{E L C C_{i, t}} \\
& \text { (EQ.6.6) } \quad W G R_{i, t}=\text { pwageprem } * W S R_{i, t} \\
& \text { (EQ.6.7) } \quad W G U_{t}=\text { pwageprem } * W S U_{t}
\end{aligned}
$$




$$
\begin{aligned}
& \text { (EQ.6.8) } \quad M P C C_{i, t}=M P F_{i, t} \\
& \text { (EQ.6.9) } \quad Y M A N_{t}=\frac{W M A N_{t}-p h i^{*} P F U_{t}}{C P I N F U_{t}} \\
& \text { (EQ.6.10) } \quad Y S U_{t}=\frac{W S U_{t}-p h i^{*} P F U_{t}}{C P I N F U_{t}} \\
& \text { (EQ.6.11) } \quad Y S R_{i, t}=\frac{W S R_{i, t}-p h i^{*} P F R_{i, t}}{C P I N F R_{i, t}}
\end{aligned}
$$

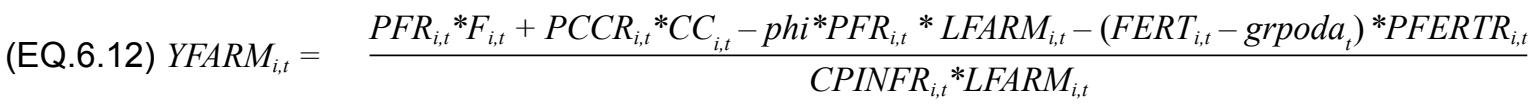

$$
\begin{aligned}
& \text { (EQ.6.13) } \quad Y G O V U_{t}=\frac{W G U_{t}-p h i^{*} P F U_{t}}{C P I N F U_{t}} \\
& \text { (EQ.6.14) } \quad Y G O V R_{i, t}=\frac{W G R_{i, t}-p h i * P F R_{t}}{C P I N F R_{i, t}}
\end{aligned}
$$

Block 7: Labor Migration And Market Equilibrium (optimal allocation of labor)

$$
\begin{aligned}
& \text { (EQ.7.1) } \quad Y S U_{t}=Y M A N_{t} \\
& \text { (EQ.7.2) } \quad Y S R_{i, t}=Y F A R M_{i, t} \\
& \text { (EQ.7.3) } \quad \text { MIGRATE }_{i, t}=\text { migtheta } *\left(Y S U_{t}-Y S R_{i, t}\right) \\
& \text { (EQ.7.4) } \quad L R_{i, t+1}=L R_{i, t}-\text { MIGRATE }_{i, t} \\
& \text { (EQ.7.5) } \quad L R_{i, t 0}=\operatorname{lr} O_{i} \\
& \text { (EQ.7.6) } \quad L R_{i, t}=L F A R M_{i, t}+L S R_{i, t}+L G R_{i, t} \\
& \text { (EQ.7.7) } \quad \operatorname{LFARM}_{i, t}=L F_{i, t}+L C C_{i, t} \\
& \text { (EQ.7.8) } \quad L U_{t}=L M_{t}+L S U_{t}+L G U_{t} \\
& \text { (EQ.7.9) } \quad L U_{t}=\sum_{i} p o p_{i}-\sum_{i} L R_{i, t} \\
& \text { (EQ.7.10) } \quad L G_{t}=\sum_{i} L G R_{i, t}+L G U_{t} \\
& \text { (EQ.7.11) } \quad \operatorname{LTOT}_{t}=\sum_{i} L R_{i, t}+L U_{t}
\end{aligned}
$$




\section{Block 8: Disposable Income, Taxation, Consumption and Saving}

(EQ.8.1) $\quad Y U_{t}=\left(V S U_{t}+M_{t}+W G U_{t}^{*} L G U_{t}-p h i * P F U_{t}^{*} L U_{t}\right) *(1-$ taxr $)$

(EQ.8.2) $\quad Y R_{i, t}=\left(V F_{i, t}+V C C_{i, t}+V S R_{i, t}+W G R_{i, t}{ }^{*} L G R_{i, t}-p h i * P F R_{i, t}{ }^{*} L R_{i, t}\right) *(1-$ taxr $)$

(EQ.8.3) $\quad$ YRTOT $_{i}=\sum_{i} Y R_{i, t}$

(EQ.8.4) $\quad Y D I S_{t}=Y U_{t}+\sum_{i} Y R_{i, t}$

(EQ.8.5) $\quad C U M Y D I S=\sum_{t} Y D I S_{t}$

(EQ.8.6) $\quad S A V U_{t}=\max \left(0,\left(Y U_{t}-\left(C P I N F U_{t}^{*}{ }^{2 m i n} * L U_{t}\right)\right) *_{\text {savurb })}\right.$

(EQ.8.7) $\quad \operatorname{SAVR}_{i, t}=\max \left(0,\left(\right.\right.$ YR $\left._{i, t}-\left(\operatorname{CPINFR}_{i, t}{ }^{*} \mathrm{cmin} * L R_{i, t}\right)\right) *$ savrur $)$

(EQ.8.8) $\quad$ SAVTOT $_{t}=S A V U_{t}+\sum_{i} S A V R_{i, t}$

(EQ.8.9) $\quad C U_{t}=Y U_{t}-S A V U_{t}$

(EQ.8.10) $\quad C R_{i, t}=Y R_{i, t}-S A V R_{i, t}$

(EQ.8.11) $\quad S U_{t}=\frac{\operatorname{gammas}^{*} C U_{t}}{P S U_{t}}$

(EQ.8.12) $\quad S R_{i, t}=\frac{\operatorname{gammas}^{*} C R_{i, t}}{P S R_{i, t}}$

\section{Block 9: Trade Balance}

(EQ.9.1) $\quad$ IMPUC $_{t}=(1-$ gammas $) * C U_{t}$

(EQ.9.2) $\quad \operatorname{IMPRC}_{i, t}=(1-$ gammas $) * C R_{i, t}$

(EQ.9.3) $\quad I M P U I_{t}=S A V U_{t}+F D I_{t}$

(EQ.9.4) IMPRI $=S A V R_{i, t}$

(EQ.9.5) $\quad$ EXPORT $_{t}=\sum_{i}\left(C C_{i, t} *\left(1-\right.\right.$ tloss $\left.\left._{i, t}\right)\right)+M_{t}$

(EQ.9.6) $\quad I M P O R T_{t}=\sum_{i} F E R T_{i, t}+\sum_{i} I M P R C_{i, t}+I M P U C_{t}+I M P U I_{t}+\sum_{i} I M P R I_{i, t}$

+ PUBINV $_{t}+R O A D I N V_{t}+$ TOTIMPG $_{t}$

(EQ.9.7) $\quad T B_{t}=E X P O R T_{t}-I M P O R T_{t}$ 


\section{Block 10: Investment And Capital Accumulation}

$(\mathrm{EQ} .10 .1) \quad F D I_{t}=\max \left(0, \operatorname{fdimult}^{*}\left(R_{t}-r\right.\right.$ world $\left.)\right)$

(EQ.10.2) $\quad R_{t}=\frac{(1-\text { alpham }) * M_{t}}{K M_{t}}$

(EQ.10.3) $\quad K C C_{i, t+1}=K C C_{i, t} *(1-\operatorname{depcc})+\operatorname{rsavcc} * S A V R_{i, t}$

(EQ.10.4) $\quad K M_{t+1}=K M_{t}^{*}(1-$ dep $)+F D I_{t}+$ usavm $^{*} S A V U_{t}$

(EQ.10.5) $\quad K C C_{i, t 0}=k c c O_{i}$

(EQ.10.6) $\quad K M_{t 0}=k m 0$

(EQ.10.7) $\quad K S U_{t 0}=k s u 0$

(EQ.10.8) $\quad K S R_{i, t 0}=k s r O_{i}$

(EQ.10.9) $\quad K S U_{t+1}=K S U_{t}^{*}(1-d e p)+(1-r s a v c c) * S A V U_{t}$

(EQ.10.10) $\quad K S R_{i, t+1}=\operatorname{KSR}_{i, t} *(1-$ dep $)+(1-$ usavm $) * S A V R_{i, t}$

\section{Block 11: Public Sector}

a) Public balances

(EQ.11.1) $\quad T A X_{t}=\left(V S U_{t}+M_{t}+W G U_{t}^{*} L G U_{t}-p h i * P F U_{t}^{*} L U_{t}\right) *($ taxr $)$

$$
+\sum_{i}\left(V F_{i, t}+V C C_{i, t}+V S R_{i, t}+W G R_{i, t} * L G R_{i, t}-p h i * P F R_{i, t} * L R_{i, t}\right) *(\operatorname{taxr})
$$

(EQ.11.2) $\quad$ TOTEXP $_{t}=$ TAX $_{t}+$ CASHODA $_{t}$

(EQ.11.3) $\quad$ TOTODA $_{t}=$ CASHODA $_{t}+\operatorname{grpoda}_{t}$

(EQ.11.4) $\quad C O D A=\sum_{t}{ }_{t} A S H O D A_{t}$

(EQ.11.5) $\quad C E X P=\sum_{t} T_{T O T E X P_{t}}$

(EQ.11.6) $\quad$ TOTEXP $_{t}=\sum_{p}$ PEXP $_{p, t}+$ ROADCOST $_{t}$

(EQ.11.7) $\quad P E X P_{p, t}=i n v u_{p, t}+\sum_{i} i n v r_{p, i, t}+R E C C O S T_{p, t}$

(EQ.11.8) $\quad$ PUBINV $_{t}=\sum_{p} i n v u_{p, t}+\sum_{p} \sum_{i} i n v r_{p, i, t}$ 
b) Roads

(EQ.11.9) $\quad \operatorname{KROAD}_{i, t+1}=\operatorname{KROAD}_{i, t} *(1-$ dep $)+$ invroad $_{i, t}$

(EQ.11.10) $\quad \operatorname{KROAD}_{i, t 0}=\operatorname{road}_{i}$

(EQ.11.11) $\quad$ LROAD $_{i, t}=$ invroad $_{i, t}{ }^{*}$ klroad $_{i}+$ maintlabor $^{*}$ KROAD $_{i, t}$

(EQ.11.12) ROADWAGE $E_{i, t}=L R O A D_{i, t}{ }^{*} W G R_{i, t}$

(EQ.11.13) $\quad$ ROADINV $_{t}=\sum_{i}$ invroad $_{i, t}$

(EQ.11.14) $R O A D C O S T_{t}=R O A D I N V_{t}+\sum_{i} R O A D W A G E_{i, t}$

c) Other Public Capital Equations

(EQ.11.15) $\quad K P U_{p, t+1}=K P U_{p, t} *(1-d e p)+i n v u_{p, t}$

(EQ.11.16) $\quad K P R_{p, i, t+1}=K P R_{p, i, t} *(1-d e p)+i n v r_{p, i, t}$

(EQ.11.17) $\quad K P U_{p, \text { tfirst }}=k p u 0_{p}$

(EQ.11.18) $\quad K P R_{p, i, \text { tfirst }}=k p r O_{i, p}$

d) Public Service Recurrent Expenditures

(EQ.11.19) $\quad R E C C O S T_{p, t}=\sum_{\text {reg }} \operatorname{commod}_{p, \text { reg }, t}+\operatorname{LABCOST}_{p, t}$

(EQ.11.20) $\quad L A B C O S T_{p, t}=l p u_{p, t} * W G U_{t}+\sum_{i}\left(l p r_{p, i, t}^{*} W G R_{i, t}\right)$

(EQ.11.21) $\quad L G U_{t}=\sum_{p} l p u_{p, t}$

(EQ.11.22) $\quad L G R_{i, t}=\sum_{p} l p r_{p, i, t}+L R O A D_{i, t}$

e) Public Service Import Content

(EQ.11.23) $\quad$ TOTIMPG $G_{t}=\sum_{p} I M P G_{p, t}$

(EQ.11.24) $\quad I M P G_{p, t}=\sum_{\text {reg }}\left(\right.$ impcontc $_{p}{ }^{*}$ commod $\left._{p, \text { reg }, t}\right)$

A GENERAL EQUILIBRIUM MODEL FOR ANALYZING AFRICAN RURAL SUBSISTENCE ECONOMIES AND AN AFRICAN GREEN REVOLUTION

55 


\section{Block 12: Economic Aggregates}

(EQ.12.1) $\quad F T O T_{t}=\sum_{i} F_{i, t}$

(EQ.12.2) $\quad V F T O T_{t}=\sum_{i} V F_{i, t}$

(EQ.12.3) $\quad C C T O T_{t}=\sum_{i} P C C R_{i, t}{ }^{*} C C_{i, t}$

(EQ.12.4) $\quad \operatorname{VSRTOT}_{t}=\sum_{i} V S R_{i, t}$

(EQ.12.5) $\quad G N P N F_{t}=V S U_{t}+M_{t}+W G U_{t}^{*} L G U_{t}-p h i * P F U_{t}^{*} L U_{t}$

$$
+\sum_{i}\left(V F_{i, t}+V C C_{i, t}+V S R_{i, t}+W G R_{i, t}{ }^{*} L G R_{i, t}-p h i * P F R_{i, t}{ }^{*} L R_{i, t}\right)
$$

(EQ.12.6) $\quad G N P W F_{t}=V S U_{t}+M_{t}+W G U_{t}^{*} L G U_{t}+\sum_{i}\left(V F_{i, t}+V C C_{i, t}+V S R_{i, t}+W G R_{i, t} * L G R_{i, t}\right)$

(EQ.12.7) $\quad$ SAVGNPWF $_{t}=\frac{\text { SAVTOT }_{t}}{G N P W F_{t}}$

\section{Block 13: Public Service Progress}

(EQ.13.1) $\quad H_{W P R O G}=$ HEALTHPROG $_{t}+$ WATERPROG $_{t}$

(EQ.13.2) $\quad$ HEALTHPROG $G_{t}=(t / T) *($ healthlast - healthfirst $)$

(EQ.13.3) $\quad$ WATERPROG $G_{t}=(t / T) *($ waterlast - waterfirst $)$ 


\section{APPENDIX B: LIST OF VARIABLES IN MODEL}

\section{Positive variables:}

$C C_{i, 1}$

CPINFU,

CPINFR $_{i, t}{ }^{t}$

$C R_{i, t}$

$C U_{t}$

$E^{E L C C_{i, t}}$
$E_{i, t}$
$\operatorname{ELM}_{t}$
$\operatorname{ELSR}_{i, t}$
$\operatorname{ELSU}_{t}$
$\operatorname{EXPNU}_{i, t}$
$\operatorname{EXPORT}_{t}$
EXTRACT

$F_{i, t}$

$F D I_{t}$

FERT $_{i, t}$

FSURP $_{i, t}$

FTOT $_{t}$

$G N P_{t}$
$G R P_{i, t}$

HEALTHPROG $H W P R O G_{t}$

IMPORT

$K C C_{i, t}$

$K M_{t}$

$K P R_{p, i, t}$

$K P U_{p, t}^{p, i, t}$

$K_{R O A D_{i, t}}$

$K S R_{i, t}$

$K S U_{t}$

$L A B C O S T_{p, t}$

$L C C_{i, t}$

$L F_{i, t}$

LFARM $_{i, t}$

$L G_{t}$

$L G R_{i, \text {, }}$

$L G U_{t}$

$L M_{t}$

$L R_{i, t}$

$L R O A D_{i, t}$

$L S R_{i, t}$

$L S U_{t}^{i, t}$

$L U_{t}$
Cash crop output

Nonfood consumer price index urban

Nonfood consumer price index rural

Rural consumption

Urban consumption

Effective labor in cash crop production

Effective labor in food production

Effective labor in manufacturing

Effective labor in rural service sector

Effective labor in urban service sector

Exponential of nutrient stock

Total exports

Crop extraction of nutrients

Food output

Foreign direct investment

Fertilizer use

Food surplus by region

Total food production

National output value

Regional output value

Health progress

Health and water progress

Total imports

Capital in cash crop production

Capital in manufacturing

Rural capital stock in sector in period

Urban capital stock in sector in period

Road length

Capital in rural service

Capital in urban service

Public labor force cost in sector $P$

Labor in cash crop production

Labor in food production

Farm labor

Total government labor

Rural government labor

Urban government labor

Labor in manufacturing

Labor in rural sector

Rural road building labor

Rural services labor

Urban services labor

Labor in urban sector
$M_{t}$

$M P C C_{i, t}$

$M P F_{i, t}$

PCCR

PFERTR $_{i, \text { }}$

$P F R_{i, t}$

$\mathrm{PFU}_{t}^{i, t}$

PIMPR $_{t}$

PIMPU $_{t}$

$P S R_{i, t}$

$\mathrm{PSU}_{t}$

$R_{t}$

$S_{i, t}$

$S R_{i, t}$

$S U_{t}^{i, t}$

$\operatorname{TLOSS}_{i, t}$

$V C C_{i, t}$

VCCTOT

$V F_{i, t}$

VFTOT $_{t}$

$V S R_{i,}$

VSRTOT $_{t}$

$\mathrm{VSU}_{t}$

WATERPROG $_{t}$

$W C C_{i, t}$

$W G R_{i, t}^{i, t}$

$W G U_{t}$

$W M A N_{t}$

$W S U_{t}$

$W_{\text {S }}{ }_{i, t}$

YFARM $_{i, t}$

$Y R_{i, t}$

YRTOT $_{t}$

$Y S R_{i, t}$

$Y S U_{t}{ }_{t}$
Manufacturing output

Marginal product of labor in cash

crop production

Marginal product of labor in food

production

Price of cash crop in rural area

Price of fertilizer in rural area

Price of food in rural area

Price of food in urban area

Price of manufactured good in rural

area

Price of manufactured good in

urban area

Price of services in rural area

Price of services in urban area

Marginal product of capital in

manufacturing

Soil productivity factor

Rural services output

Urban services output

Transport losses

Value added of cash crop

production

Value added of total cash crop

production

Value of food production

Total value of food production

Value of rural service production

Total value of rural service production

Value of urban service production

Water progress

Cash crop wage

Rural government salary

Urban government salary

Manufacturing wage

Urban service wage

Rural service wage

Real farm income

Rural income in region

Total rural income in region

Real rural service income in region

Real urban service income 


\section{Free variables:}

\begin{tabular}{|c|c|c|}
\hline $\begin{array}{l}\text { CASHODA } \\
\text { CEXP }\end{array}$ & $\begin{array}{l}\text { Cash ODA (i.e., nonfertilizer) } \\
\text { Cumulative expenditures over all } \\
\text { periods }\end{array}$ & $\begin{array}{l}\text { PEXP } \\
P U B I N V_{t}\end{array}$ \\
\hline CODA & Cumulative cash ODA & $R E C C O S T_{p, t}$ \\
\hline CUMYDIS & Cumulative disposable income & $R O A D C O S T_{t}$ \\
\hline $\operatorname{DISYRU}_{i, t}$ & $\begin{array}{l}\text { Rural income in excess of minimum } \\
\text { consumption }(\mathrm{cmin})\end{array}$ & $R O A D I N V_{t}$ \\
\hline$D I S Y U R_{t}$ & $\begin{array}{l}\text { Urban income in excess of } \\
\text { minimum consumption }(\mathrm{cmin})\end{array}$ & $R O A D W A G E_{i}$ \\
\hline$F K A M P_{t}$ & Food need in Kampala & $S A V G N P W F_{t}$ \\
\hline$G N P N F_{t}$ & $\begin{array}{l}\text { GNP excluding subsistence food } \\
\text { minimum }\end{array}$ & $\begin{array}{l}S A V R_{i, t} \\
S A V T O T_{t}\end{array}$ \\
\hline$G N P W F_{t}$ & GNP with food & $S A V U_{t}$ \\
\hline$I M P G_{p, t}$ & $\begin{array}{l}\text { Import content in public service } \\
\text { sector expenditures }\end{array}$ & $\begin{array}{l}T A X_{t} \\
T B_{t}\end{array}$ \\
\hline$I M P U C_{t}$ & Urban consumer good imports & TOTEXP \\
\hline $\operatorname{IMPRC}_{i, t}^{t}$ & Rural consumer good imports & TOTIMPG \\
\hline$I M P U I_{t}$ & Urban investment good imports & \\
\hline$I M P R I_{i, t}$ & Rural investment good imports & TOTODA $A_{t}$ \\
\hline$L A B S C A L E_{t}$ & $\begin{array}{l}\text { Labor scaling variable for effective } \\
\text { labor }\end{array}$ & $\begin{array}{l}Y D I S_{t} \\
Y G O V R_{i, t}\end{array}$ \\
\hline $\operatorname{MIGRATE}_{i, t}$ & $\begin{array}{l}\text { Rural to Urban migration from } \\
\text { region } i\end{array}$ & $Y G O V U_{t}$ \\
\hline $\operatorname{NETIN}_{i, t}$ & Nutrient flow & $Y M A N_{t}$ \\
\hline $\operatorname{NUTSUM}_{i, t}$ & $\begin{array}{l}\text { Indexed accumulation of nutrient } \\
\text { flows (initial =1) }\end{array}$ & $Y U_{t}$ \\
\hline$O A N D M_{p, t}$ & $\begin{array}{l}\text { Operations and maintenance } \\
\text { expenditures in public service sector }\end{array}$ & \\
\hline
\end{tabular}

Public service sector expenditures Total public investment

Recurrent public service expenditures in sector Total road investment and maintenance cost Total road investment cost across regions Road building wage across regions

Total saving as a share of GNP with food

Rural gross saving in region

Total gross saving

Urban gross saving

Total tax revenues

Trade balance

Total expenditures across sectors Total government public service sector imports

Total ODA (cash ODA + green revolution ODA)

Disposable income (total population) Real rural public sector wage net of food

Real urban public sector wage net of food

Real manufacturing sector wage net of food

Urban income net of food

consumption and taxes 


\section{APPENDIX C: MODEL PARAMETERS}

$\mathbf{T}$

his paper focuses on the presentation of a general economic model rather than precise point estimates.

Research to identify more precise subnational parameter values for Uganda is merited as follow-up research. The parameters used for this model are presented below and are set to a general baseline of the year 2002 . Factor shares in production functions are assumed at standard values (see Eberhardt 2006). The cost of capital, depreciation rates, the FDI multiplier, share of services in consumption and public sector service wage premiums are assumed. Capital stocks and productivity terms were estimated using the Uganda social accounting matrix for 2002 and then scaled. Public sector import contents were set at one for simplicity.

The labor force is set to match the approximate reality of 19.6 million workers as of 2002, and the population of origin from each region matches the approximate real distribution of populations. The distribution of roads and agricultural capital stocks across the four regions provides another approximate match of the reality in Uganda. The Northern region is poorest and therefore starts the first period with slightly higher transport losses, lower cash crop capital stock and lower cash crop productivity.

\section{Sets:}

$p$

reg

$i$

$t$

\section{Scalars:}

\begin{tabular}{lll} 
Label & Description & Value \\
\hline alphacc & labor share in cash crop production & 0.4 \\
alphaf & labor share in food production & 0.5 \\
alpham & labor share in manufacturing production & 0.7 \\
alphas & labor share in services & 0.8 \\
betacc & capital share in cash crop production & 0.3 \\
betaf & capital share in food production & 0.2 \\
cmin & minimum nonfood consumption & 0.12 \\
dep & depreciation & 0.03 \\
depcc & cash crop depreciation & 0.02 \\
fdimult & multiplier for FDI & 0.1 \\
gammas & share of services in the disposable income basket & 0.55 \\
healthfirst & initial health levels & 1 \\
healthlast & final health level & 1 \\
km0 & initial capital in manufacturing & 10 \\
ksu0 & initial capital in urban services & 10
\end{tabular}

Public service sectors [health, education, general infrastructure, public administration] Geographic divisions [East, West, Central, North, Kampala]

Rural regions [East, West, Central, North]

Time periods $[\mathrm{T}=10]$ 


\begin{tabular}{lll} 
Label & Description & Value \\
\hline kcscale & scaling parameter on CC capital stock & 0.2 \\
khurdle & hurdle parameter on household CC constraint & 0.04 \\
kmscale & scaling parameter on M capital stock & 0.2 \\
kroadscale & scaling parameter on road stock & 0.25 \\
ksscale & scaling parameter on SR capital stock & 0.2 \\
maintlabor & road maintenance labor-capital ratio & 0.005 \\
migtheta & rural-urban income migration parameter & 0.02 \\
nlossrate & nutrient loss rate in soil & 0.04 \\
phi & food requirement per person & 0.55 \\
pwageprem & public sector service wage premium & 1.2 \\
pworldfert & world price of fertilizer & 1 \\
rho & logistic function parameter & 1.5 \\
rworld & world cost of capital & 0.1 \\
rsavcc & share of rural saving to cash crop & 0.55 \\
savurb & urban saving rate out of disposable income & 0.2 \\
savrur & rural saving rate out of disposable income & 0.25 \\
taxr & tax rate on disposable income & 0.15 \\
usavm & share of urban saving to manufacturing \\
waterfirst & initial water level & 0.3 \\
waterlast & final water level & 1 \\
& & 1
\end{tabular}

\section{Parameters:}

\section{(A) Scenario-based}

grpoda $_{t} \quad$ ODA for green revolution package

Scenarios 1, 2, 4, 5: $\quad \operatorname{grpoda}_{t}=0$

Scenarios 3, 6: $\quad\{t=1,0 ; t=2,0 ; t=3,0.35 ; t=4,0.3 ; t=5,0.2 ; t=6,0.2 ; t=7,0.2 ; t=8,0 ; t=9,0 ; t=10,0\}$

invroad $_{i, t} \quad$ Investment in rural road I in period T

Scenario 1, 2, 3, 5: $\quad$ invroad $_{i, t}=0.14$

Scenario 4, 6: $\quad$ invroad $_{i, t}=0.28$

invr $r_{p, i, t} \quad$ Rural public investment in sector $\mathrm{P}$ in period $\mathrm{T}$

Scenario 1, 2, 3, 4: $\quad$ inv $r_{p, i, t}=0.04$

Scenario 5, 6: $\quad \quad \quad$ : $\quad v r_{p, i, t}=0.08$ 


$$
\begin{aligned}
& \text { invu } u_{p, t} \quad \text { Urban public investment in sector } \mathrm{P} \text { in period } \mathrm{T} \\
& \text { Scenario 1, 2, 3, 4: } \quad \text { invu } u_{p, t}=0.04 \\
& \text { Scenario 5, 6: } \quad \quad \quad i n v u_{p, t}=0.08 \\
& \operatorname{lpr}_{p, i, t} \quad \text { Skilled rural labor in public sector } \mathrm{P} \text { in period } \mathrm{T} \\
& \text { Scenario 1, 2, 3, 4: } \quad l p r_{p, i, t}=0.02 \\
& \text { Scenario 5, 6: } \quad l p r_{p, i, t}=0.04 \\
& l p u_{p, t} \quad \text { Urban labor in public sector } \mathrm{P} \text { in period } \mathrm{T} \\
& \text { Scenario 1, 2, 3, 4: } \quad l p u_{p, t}=0.005 \\
& \text { Scenario 5, 6: } \quad l p u_{p, t}=0.01 \\
& \text { commod }_{p, r e g, t} \quad \text { Commodity expenditures in sector } \mathrm{P} \text { in period } \mathrm{T} \\
& \text { Scenario 1, 2, 3, 4: } \quad \text { commod }_{p, \text { reg, }}=0.015 \\
& \text { Scenario 5, 6: } \quad \text { commod }_{p, \text { reg }, t}=0.03 \\
& \text { impcontc }_{p} \quad \text { Import content share in commodities for public sector } \mathrm{P} \\
& \text { impcontc }_{p}=1 \\
& \text { impcontk }_{p} \quad \text { Import content share in capital for public sector } \mathrm{P} \\
& \text { impcontk }_{p}=1 \\
& \text { impconto }_{p} \quad \text { Import content share in O\&M for public sector } \mathrm{P} \\
& \text { impconto }_{p}=1 \\
& \text { ltot } t_{t} \quad \text { Total labor } \\
& \text { ltot }_{t}=19.6
\end{aligned}
$$

\begin{tabular}{|c|c|}
\hline$k c c 0_{i}$ & $\begin{array}{l}\text { Initial capital in cash crops } \\
\qquad\{\text { east } 5 \text {, west } 5 \text {, north } 4 \text {, central } 6\}\end{array}$ \\
\hline$k f_{i}$ & $\begin{array}{l}\text { Capital in food production } \\
\qquad\{\text { east } 5 \text {, west } 6 \text {, north } 5 \text {, central } 4\}\end{array}$ \\
\hline$k s r 0_{i}$ & $\begin{array}{l}\text { Initial capital in rural services } \\
\qquad\{\text { east } 5 \text {, west } 5 \text {, north } 5 \text {, central } 5\}\end{array}$ \\
\hline klroad $_{i}$ & $\begin{array}{l}\text { K-L ratio for road building } \\
\qquad\{\text { east } .02 \text {, west } .02 \text {, north } .02 \text {, central } .02\}\end{array}$ \\
\hline$k p u 0_{p}$ & $\begin{array}{l}\text { Initial urban government capital stock in region i and sector } P \\
\qquad \text { health } 1, \text { prim } 1 \text {, infr } 1, \text { padmin } 1\}\end{array}$ \\
\hline$k p r 0_{i, p}$ & $\begin{array}{l}\text { Initial rural capital stock in sector } \mathrm{P} \\
\qquad \operatorname{kpr}_{i, p}=.1\end{array}$ \\
\hline
\end{tabular}

\section{(B) General}

\section{(C) Regional}




\begin{tabular}{|c|c|}
\hline land $_{i}$ & $\begin{array}{l}\text { Land area in each rural region - to exponent of } 0.3 \\
\qquad \text { east } 1.45, \text { west } 1.45, \text { north } 1.45 \text {, central } 1.45\}\end{array}$ \\
\hline $\operatorname{lr} 0_{i}$ & $\begin{array}{l}\text { Initial rural labor } \\
\qquad\{\text { east } 4.5 \text {, west } 4.5 \text {, north } 3.8 \text {, central } 4.5\}\end{array}$ \\
\hline nutrient $_{i}$ & $\begin{array}{l}\text { Initial soil nutrient value } \\
\qquad \text { (east } 1 \text {, west } 1 \text {, north } 1 \text {, central } 1\}\end{array}$ \\
\hline pop $_{i}$ & $\begin{array}{l}\text { Population of origin from each region } \\
\qquad \text { (east } 5.21 \text {, west } 5.17 \text {, north } 4.11 \text {, central } 5.11 \text { \} }\end{array}$ \\
\hline $\operatorname{road} 0_{i}$ & $\begin{array}{l}\text { Initial road value } \\
\qquad \text { (east } 4 \text {, west } 4 \text {, north } 4 \text {, central } 4\}\end{array}$ \\
\hline tlossfirst $_{i}$ & $\begin{array}{l}\text { Transport loss parameter } \\
\qquad \text { east } .5 \text {, west } .5 \text {, north } .55 \text {, central } .45\}\end{array}$ \\
\hline thetacc $_{i}$ & $\begin{array}{l}\text { Cash crop sector productivity term } \\
\qquad \text { (east } 0.8 \text {, west } 0.8 \text {, north } 0.6 \text {, central } 0.8\}\end{array}$ \\
\hline thetaf $_{i}$ & $\begin{array}{l}\text { Food sector productivity term } \\
\qquad\{\text { east } 1 \text {, west } 1 \text {, north } 1 \text {, central } 1\}\end{array}$ \\
\hline thetam $_{t}$ & $\begin{array}{l}\text { Manufacturing productivity (urban only) } \\
\text { thetam }_{t}=2\end{array}$ \\
\hline thetasr $_{i}$ & $\begin{array}{l}\text { Rural service productivity } \\
\qquad \text { (east } 2.66 \text {, west } 2.66 \text {, north } 2.66 \text {, central } 2.66\}\end{array}$ \\
\hline thetasu $_{t}$ & $\begin{array}{l}\text { Urban service productivity } \\
\qquad \text { thetasut }_{t}=3\end{array}$ \\
\hline uppersoil $_{i}$ & $\begin{array}{l}\text { Upper soil productivity threshold } \\
\qquad\{\text { east } 1.55, \text { west } 1.55, \text { north } 1.55 \text {, central } 1.55\}\end{array}$ \\
\hline
\end{tabular}




\section{REFERENCES}

Adam, Christopher, and David Bevan. 2006. "Aid and the Supply Side: Public Investment, Export Performance, and Dutch Disease in Low-Income Countries." World Bank Economic Review 20: 261-90.

Agenor, Pierre-Richard, Nihal Bayraktarb, and Karim El Aynaoui. 2005. Roads Out of Poverty? Assessing the Links between Aid, Public Investment, Growth, and Poverty Reduction. Policy Research Working Paper 3490. Washington: World Bank.

Agenor, Pierre-Richard, Nihal Bayraktarb, and Emmanuel Pinto. 2005. Achieving the Millennium Development Goals in Sub-Saharan Africa: A Macroeconomic Monitoring Framework. Policy Research Working Paper 3750. Washington: World Bank.

Alfsen, Knut H., Torstein Bye, Solveig Glomsrod, and Henrik Wiig. 1997. "Soil Degradation and Economic Development in Ghana." Environment and Development Economics 2: 119-43.

Aune, J. B., and R. Lal. 1995. "The Tropical Soil Productivity Calculator: A Model for Assessing Effects of Soil Management on Productivity" In Soil Management: Experimental Basis for Sustainability and Environmental Quality III, edited by R. Lal and B. A. Stewert. Boca Raton, Fla.: CRC Press.

Bourguignon, François, M. Bussolo, Pereira da Silva, Hans Timmer, and Dominique Van der Mensbrugghe. 2004. MAMS: Maquette for MDG Simulations. Washington: World Bank.

Bourguignon, François, and Mark Sundberg. 2006a. Absorptive Capacity and Achieving the MDGs. UNU-WIDER Research Paper 2006/47. Tokyo: United Nations University.

- 2006b. Constraints to Achieving the MDGs with Scaled-Up Aid. DESA Working Paper 15. New York: United Nations Department of Economic and Social Affairs.

Breisinger, Clemens, Xinshen Diao, James Thurlow, and Ramatu M. Al Hassan. 2011. "Potential Impacts of a Green Revolution in Africa: The Case of Ghana." Journal of International Development 23: 82-102.

Bussolo, Maurizio, Olivier Godard, Jann Lay, and Rainer Thiele. 2006. The Impact of Commodity Price Changes on Rural Households: The Case of Coffee in Uganda. Policy Research Working Paper 4088. Washington: World Bank.

Buys, Piet. 2006. Road Network Upgrading and Overland Trade Expansion in Sub-Saharan Africa. Policy Research Working Paper 4097. Washington: World Bank.

Clemens, Michael A, Steven Radelet, Rikhil R Bhavnani and Samuel Bazzi. 2012. "Counting Chickens when they Hatch: Timing and the Effects of Aid on Growth." The Economic Journal 122 (June): 590-617. 
Christiaensen, Luc, Lionel Demery, and Jesper Kuhl. 2011. "The (Evolving) Role of Agriculture in Poverty Reduction: An Empirical Perspective." Journal of Development Economics 96: 239-54.

Corden, W. M. 1984. "Booming Sector and Dutch Disease Economics: A Consolidation." Oxford Economic Papers 36, no. 3: 359-80.

de Jager, A., D. Onduru, and C. Walaga. 2003. "Facilitated Learning in Soil Fertility Management: Assessing Potentials of Low-External-Input Technologies in East African Farming Systems." Agricultural Systems.

Dervis, Kemal, Jaime de Melo, and Sherman Robinson. 1982. General Equilibrium Models for Development Policy. New York: Cambridge University Press.

Diao, Xinshen, Derek Headey, and Michael Johnson. 2008. "Toward a Green Revolution in Africa: What Would It Achieve, and What Would It Require?" Agricultural Economics 39 (Supplement): 539-50.

Dorosh, Paul, Moataz El-Said, and Hans Lofgren. 2002. Welfare and Production Effects of Technical Change, Market Incentives and Rural Incomes: A CGE Analysis of Uganda's Agriculture." Washington: International Food Policy Research Institute.

Duflo, Esther, Michael Kremer, and Jonathan Robinson. 2011. "Nudging Farmers to Use Fertilizer: Theory and Experimental Evidence from Kenya." American Economic Review 101, no. 6: 2350-90.

Eberhardt, Markus. 2006. "Technical Progress and Structural Change as Sources of Productivity Growth: Some Macroeconomic Evidence.” MPhil thesis, Department of Economics, University of Oxford.

Esilaba, A. O., P. Nyende, G. Nalukenge, J. B. Byalebeka, R. J. Delve, and H. Ssali. 2005. "Resource Flows and Nutrient Balances for Crop and Animal Production in Smallholder Farming Systems in Eastern Uganda." Agriculture, Ecosystems and Environment 109: 192-201.

Gomanee, Karuna, Sourafel Girma, and Oliver Morrissey. 2005. "Aid and Growth in Sub-Saharan Africa: Accounting for Transmission Mechanisms.” Journal of International Development 17: 1055-1075.

Gomanee, Karuna, Oliver Morrissey, Paul Mosley and Arjan Verschoor. 2005. "Aid, Government Expenditure, and Aggregate Welfare." World Development 33, no. 3: 355-370.

Henao, Julio, and Carlos Baanante. 2006. Agricultural Production and Soil Nutrient Mining in Africa: Implications for Resource Conservation and Policy Development. Muscle Shoals, Ala.: International Center for Soil Fertility and Agricultural Development.

Kaizzi, Crammer K. 2002. "The Potential Benefit of Green Manures and Inorganic Fertilizers in Cereal Production on Contrasting Soils in Eastern Uganda." PhD, thesis, University of Bonn and German Center for Development Research (ZEF). 
Kappel, Robert, Jann Lay, and Susan Steiner. 2005. “Uganda: No More Pro-Poor Growth?” Development Policy Review 23, no. 1: 27-53.

Lofgren, Hans, and Carolina Diaz-Bonilla. 2006. "MAMS: A Framework for Analyzing MDG and Poverty Reduction Strategies." MPIA Network Session Paper.

Lofgren, Hans, Martin Cicowiez, and Carolina Diaz-Bonilla. 2013. "MAMS - A Computable General Equilibrium Model for Developing Country Strategy Analysis." In Dixon, P B and D W Jorgenson (Eds.) Handbook of Computable General Equilibrium Modeling. North Holland: Elsevier. pp. 159-276.

Lofgren, Hans, Rebecca Lee Harris, and Sherman Robinson. 2002. A Standard Computable General Equilibrium Model in GAMS. Washington: International Food Policy Research Institute.

Marenya, Paswel P., and Christopher P. Barrett. 2009. "State-Conditional Fertilizer Yield Response on Western Kenyan Farms." American Journal of Agricultural Economics 91, no. 4: 991-1006.

Matsumoto, Tomoyama, and Takashi Yamano. 2009. Soil Fertility, Fertilizer, and the Maize Green Revolution in East Africa. Policy Research Working Paper 5158. Washington: World Bank.

Matsuyama, Kiminori. 1992. "Agricultural Productivity, Comparative Advantage, and Economic Growth." Journal of Economic Theory 58, no. 2: 317-34.

McArthur, John W. 2013. "Good Thing Grow in Scaled Packages: Africa's Agricultural Challenge in Historical Context." Brookings Institution. Africa Growth Initiative Working Paper 11.

Milner, Chris, Oliver Morrissey, and Nichodemus Rudaheranwa. 2000. "Policy and Non-Policy Barriers to Trade and Implicit Taxation of Exports in Uganda." The Journal of Development Studies 37, no. 2: 67-90.

Morris, Michael, Valerie A. Kelly, Ron J. Kopicki, and Derek Byerlee. 2007. Fertilizer Use in African Agriculture: Lessons Learned and Good Practice Guidelines. Washington: World Bank.

Musinguzi, Polycarp, and Peter Smith. 2000. Saving and Borrowing in Rural Uganda. Department of Economics, Discussion Papers in Economics and Econometrics. Southampton, U.K.: University of Southampton.

Nandwa, S. M. and Mateete Bekunda. 1998. "Research on Nutrient Flows and Balances in East and Southern Africa: State-of-the-Art." Agriculture, Ecosystems and Environment 71: 5-18.

Nkonya, Ephraim, Crammer Kaizzi, and John Pender. 2005. "Determinants of Nutrient Balances in a Maize Farming System in Eastern Uganda." Agricultural Systems 85: 155-82. 
Nkonya, Ephraim, John Pender, Crammer Kaizzi, Kato Edward, and Samuel Mugarura. 2005. "Policy Options for Increasing Crop Productivity and Reducing Soil Nutrient Depletion and Poverty in Uganda." IFPRI Environment and Production Technology Division Discussion Paper 134. Washington: International Food Policy Research Institute.

Okidi, John A, Sarah Ssewanyana, Lawrence Bategeka, and Fred Muhumuza. 2005a. "Distributional and Poverty Impacts of Uganda's Growth." Research Series 46. Kampala: Economic Policy Research Centre.

_. 2005b. Operationalizing Pro-Poor Growth. Kampala: Economic Policy Research Centre.

Okoboi, Geoffrey, and Mildred Barungi. 2012. Constraints to Fertiliser Use in Uganda: Insights from Uganda Census of Agriculture 2008/9. Research Series 88. Kampala: Economic Policy Research Centre.

Pender, John, Pamela Jagger, Ephraim Nkonya, and Dick Sserunkuuma. 2001. Development Pathways and Land Management in Uganda: Causes and Implications. IFPRI Discussion Paper 85. Washington: International Food Policy Research Institute.

Pinto, Emmanuel, and Nihal Bayraktarb. 2005. A Macroeconomic Framework for Quantifying Growth and Poverty Reduction Strategies in Niger. Policy Research Working Paper 3506. Washington: World Bank.

Rajan, Raghuram G., and Arvind Subramanian. 2008. "Aid and Growth: What Does the Cross-Country Evidence Really Show?" Review of Economics and Statistics 90, no. 4: 643-65.

—. 2011. "Aid, Dutch Disease, and Manufacturing Growth." Journal of Development Economics 94, no. 1: 106-18.

Robinson, Sherman, and Hans Lofgren. 2005. "Macro Models and Poverty Analysis: Theoretical Tensions and Empirical Practice." Development Policy Review 23, no. 3: 267-83.

Roodman, David. 2007. Macro Aid Effectiveness Research: A Guide for the Perplexed. Working Paper 135. Washington: Center for Global Development.

Rudaheranwa, Nichodemus. 2006. "Trade Policy and Transport Costs in Uganda." University of Nottingham CREDIT Research Paper 06/09.

Ruecker, G. R. 2005. "Spatial Variability of Soils on National and Hillslope Scale in Uganda." Ecology and Development Series 24. Bonn: University of Bonn ZEF.

Ruecker, G. R., S. J. Park, H. Ssali, and J. Pender. 2003. Strategic Targeting of Development Policies to a Complex Region: A GIS-Based Stratification Applied to Uganda. Discussion Papers on Development Policy 69. Bonn: University of Bonn ZEF. 
Sachs, Jeffrey D., John W. McArthur, Guido Schmidt-Traub, Margaret Kruk, Chandrika Bahadur, Michael Faye, and Gordon McCord. 2004. "Ending Africa's Poverty Trap." Brookings Papers on Economic Activity 34, no. 1: 160-250.

Sachs, Jeffrey D., and Andrew M. Warner. 1995. Natural Resource Abundance and Economic Growth. NBER Working Paper 5398. Cambridge, Mass.: National Bureau of Economic Research.

Sala-i-Martin, Xavier, Gernot Doppelhofer, and Ronald I. Miller. 2004. "Determinants of Long-Term Growth: A Bayesian Averaging of Classical Estimates (BACE) Approach.” American Economic Review 94, no. 4: 813-35.

Siriri, David, Mateete Bekunda, and Bashir Jama. 2002. "Presentation to Uganda Parliamentary Forum: November 2002." Unpublished paper.

—. 2005. "Limiting Soil Nutrients in Selected Farming Systems of Uganda." Unpublished paper.

Ssali, Henry. 2002. "Presentation to Uganda Parliamentary Forum: November 2002."

Stoorvogel, J. J., and E. M. A. Smaling. 1990. Assessment of Soil Nutrient Depletion in Sub-Saharan Africa: 19832000, Volume I: Main Report (Second Edition). Wageningen: Winand Staring Centre for Integrated Land, Soil, and Water Research.

Stoorvogel, J. J., E.M.A. Smaling, and B.H. Janssen. 1993. "Calculating soil nutrient balances in Africa at difference scales: I. Supra-national scale." Fertilizer Research, 35: 227-35.

Uganda Bureau of Statistics. 2002. "Uganda National Household Survey 1999/2000: Report on the Crop Survey Module." Entebbe: Uganda Bureau of Statistics. 2004. "Uganda Census 2002." 2005. "Ugandalnfo Database."

Uganda Ministry of Finance, Planning, and Economic Development. 2005. "Macroeconomic Data."

Uganda Ministry of Public Service. 2005. "Revised Public Service Pay Reform Strategy."

Uganda Ministry of Works, Housing, and Communications and TAHAL Engineers. 2005. "Uganda National Transport Plan."

van Wijnbergen, Sweder. 1984. “The ‘Dutch Disease’: A Disease After All?” Economic Journal 94: 41-55.

Werker, Eric D., Faisal Z. Ahmed, and Charles Cohen. 2009. "How Is Foreign Aid Spent? Evidence from a Natural Experiment." American Economic Journal: Macroeconomics 1, no. 2: 225-44. 
Wiig, Henrik, Jens B. Auneb, Solveig Glomsrød, and Vegard Iversen. 2001. "Structural Adjustment and Soil Degradation in Tanzania: A CGE Model Approach with Endogenous Soil Productivity." Agricultural Economics 24: 263-87.

Woomer, Paul L., Mateete Bekunda, and D. P. Bwamiki. 1998. "Modelling Banana Growth and Soil Organic Matter Dynamics with the Century Model." African Crop Science Journal 6, no. 2: 205-14.

World Bank. 2006. "Promoting Increased Fertilizer Use in Africa: Lessons Learned and Good Practice GuidelinesDiscussion Draft." African Fertilizer Summit Background Paper. Africa Region, World Bank, Washington. 2012. World Development Indicators Online. http://databank.worldbank.org/

Wortmann, C. S., and C. K. Kaizzi. 1998. "Nutrient Balances and Expected Effects of Alternative Practices in Farming Systems of Uganda." Agriculture, Ecosystems and Environment 71: 115-29. 


\section{Map 1. Uganda Regional Boundaries}

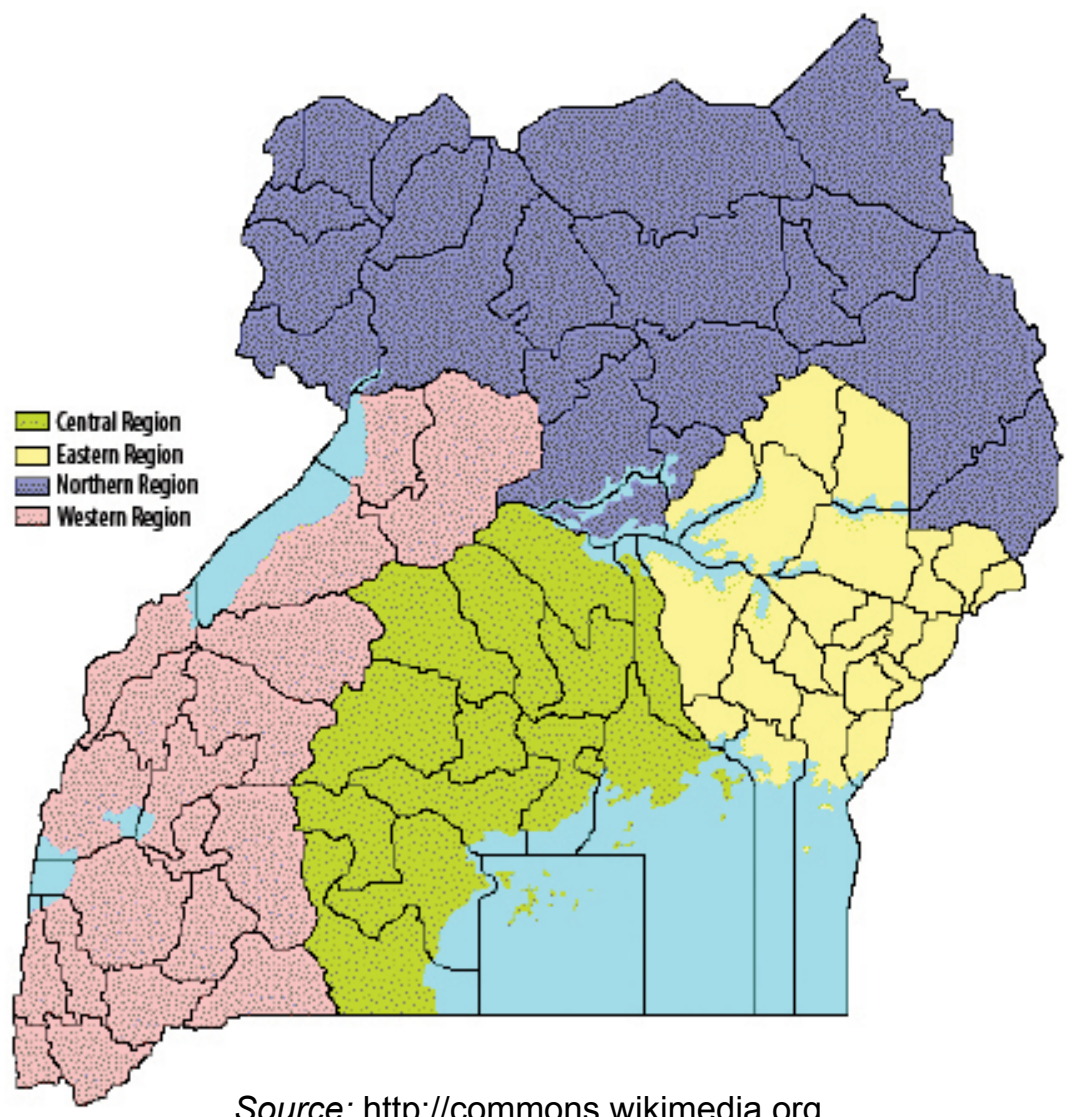

Source: http://commons.wikimedia.org. 
Map 2 (A-D). Seasonality, Length of Growing Period, Precipitation and Temperature Potential in Uganda

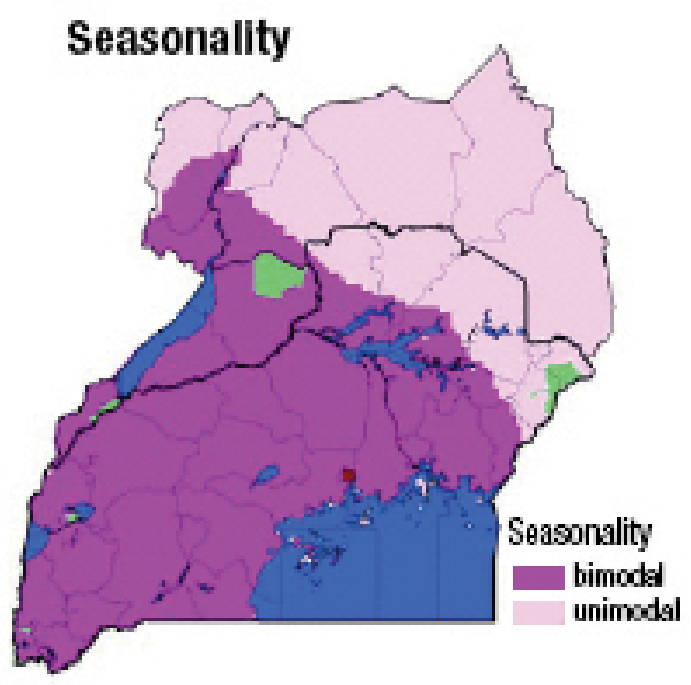

Annual precipitation potential

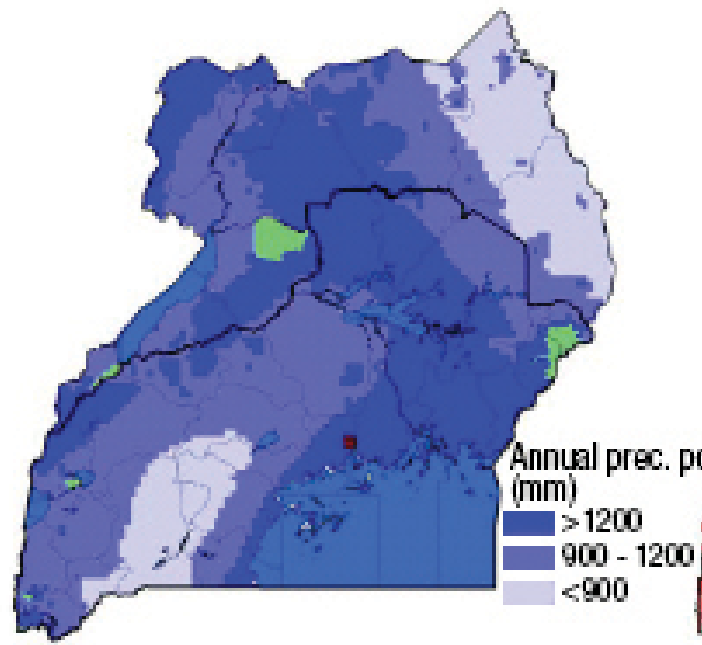

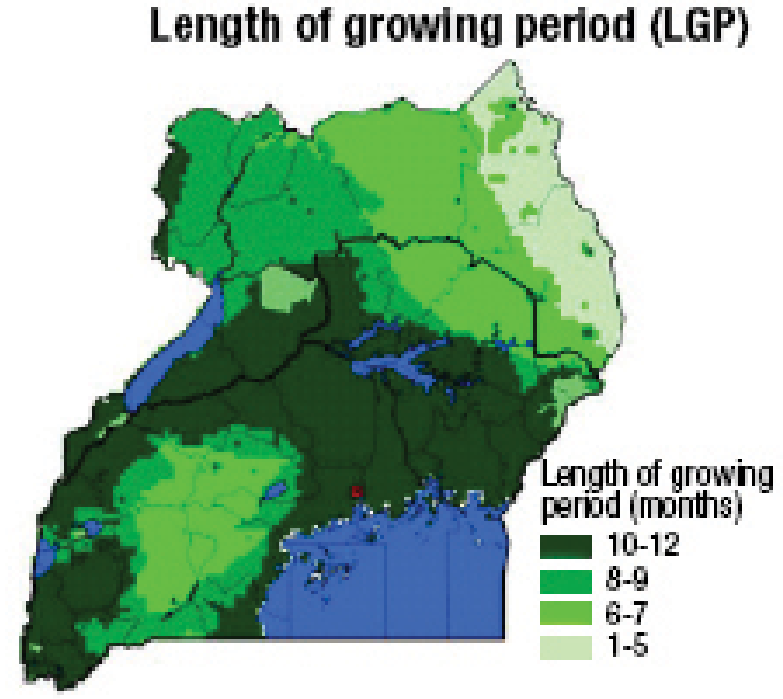

Temperature potential
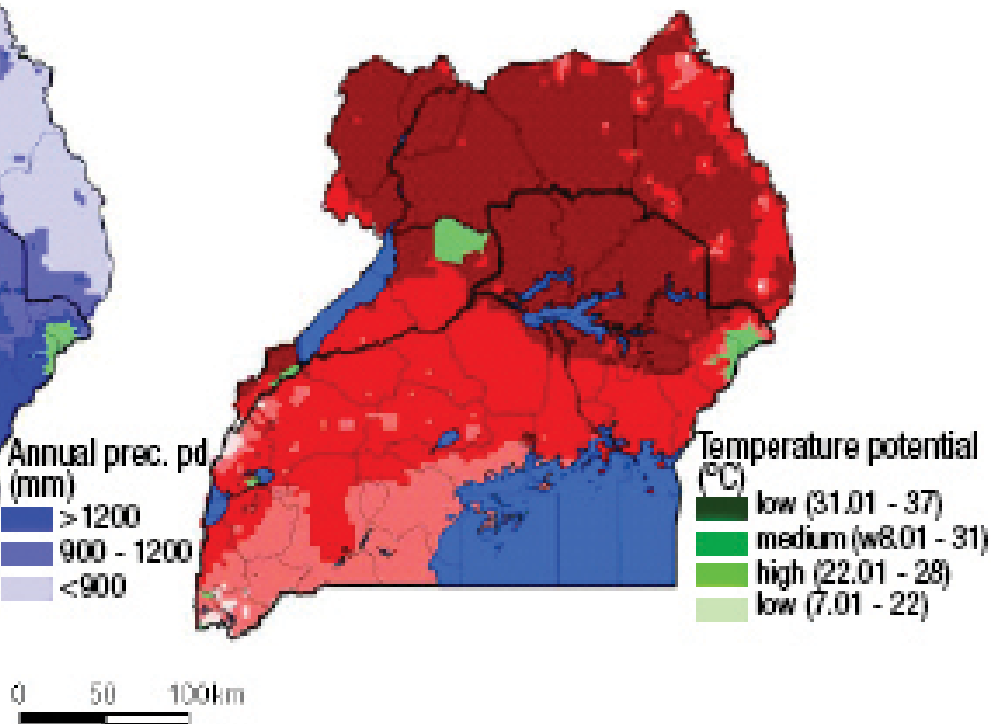

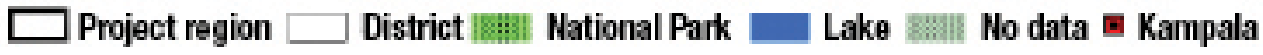

Source: Ruecker et al. 2003. 


\section{Map 3. Agricultural Potential in Uganda}

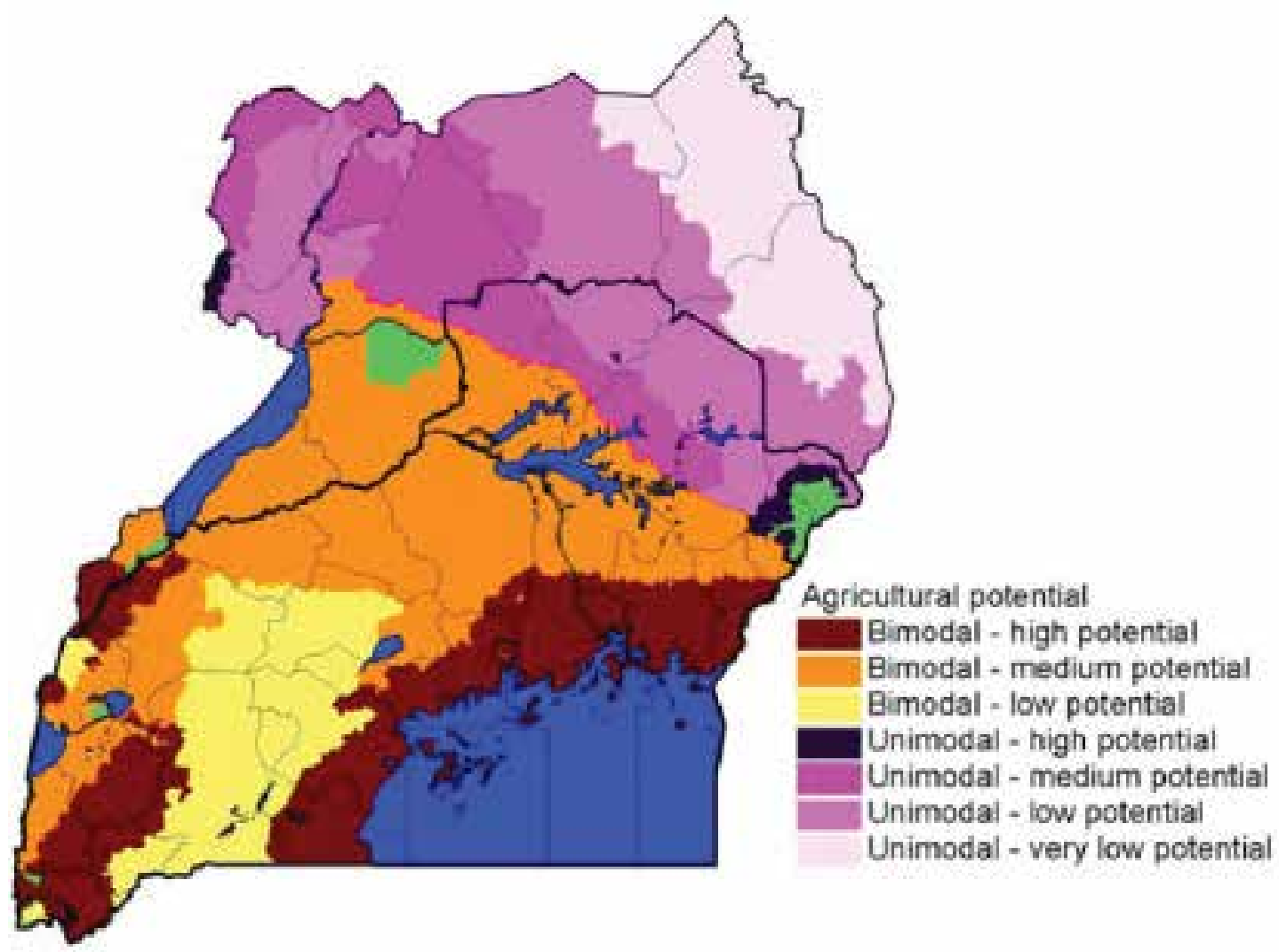

Source: Ruecker et al. 2003. 


\section{ENDNOTES}

1. Disclosure: In 2012, the first author gave speeches, for which he received compensation, at Mosaic AgCollege, at the Canadian Fertilizer Institute's annual meeting and at a CFI-organized sustainability event in Canada prior to the Rio+20 summit in Brazil. These speeches pertained to global agriculture and sustainability challenges. The aforementioned entities had no input whatsoever on the contents of either the original 2008 version of this study or on any of the research presented here.

2. Evidence from Ssali (2002) suggests that the country's arable land per person is approximately a tenth of what it was a century ago.

3. Woomer, Bekunda and Bwamiki (1998) estimate that the application of organic inputs alone could help Uganda increase its soil organic matter from 2.2 percent to 3.8 percent within less than a decade.

4. A precise model would assume two possible rates of nutrient loss through erosion, i.e., with and without agricultural extension services to teach basic land management techniques. For example, if extension services $(E X T)$ are defined as binary, then $\chi_{1}$ can be defined as erosion loss without extension $(E X T=0)$ and $\chi_{2}$ as loss with extension: $E_{t}=\chi_{1}\left(E X T_{t}\right)+\chi_{2}\left(1-E X T_{t}\right)$. However, it is difficult to estimate net soil movements at a country scale, although net erosion is a large driver of the main African soil balance estimates by Stoorvogel et al. (1993) and Henao and Baanante (2006).

5. The linear multiplier is consistent with cross-country regression results not reported here. 




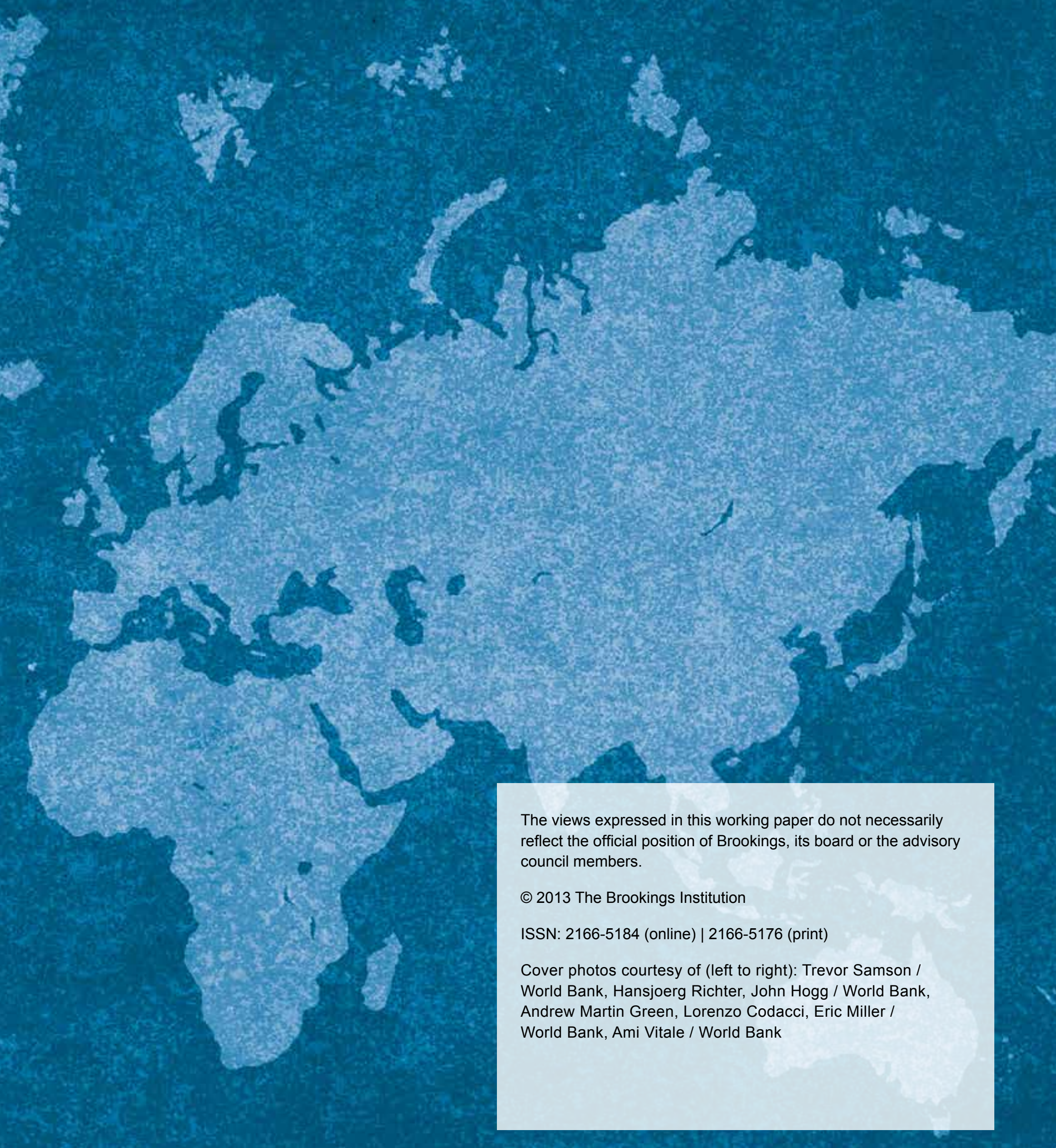




\section{BROOKINGS}

1775 Massachusetts Avenue, NW

Washington, DC 20036

202-797-6000

www.brookings.edu/global

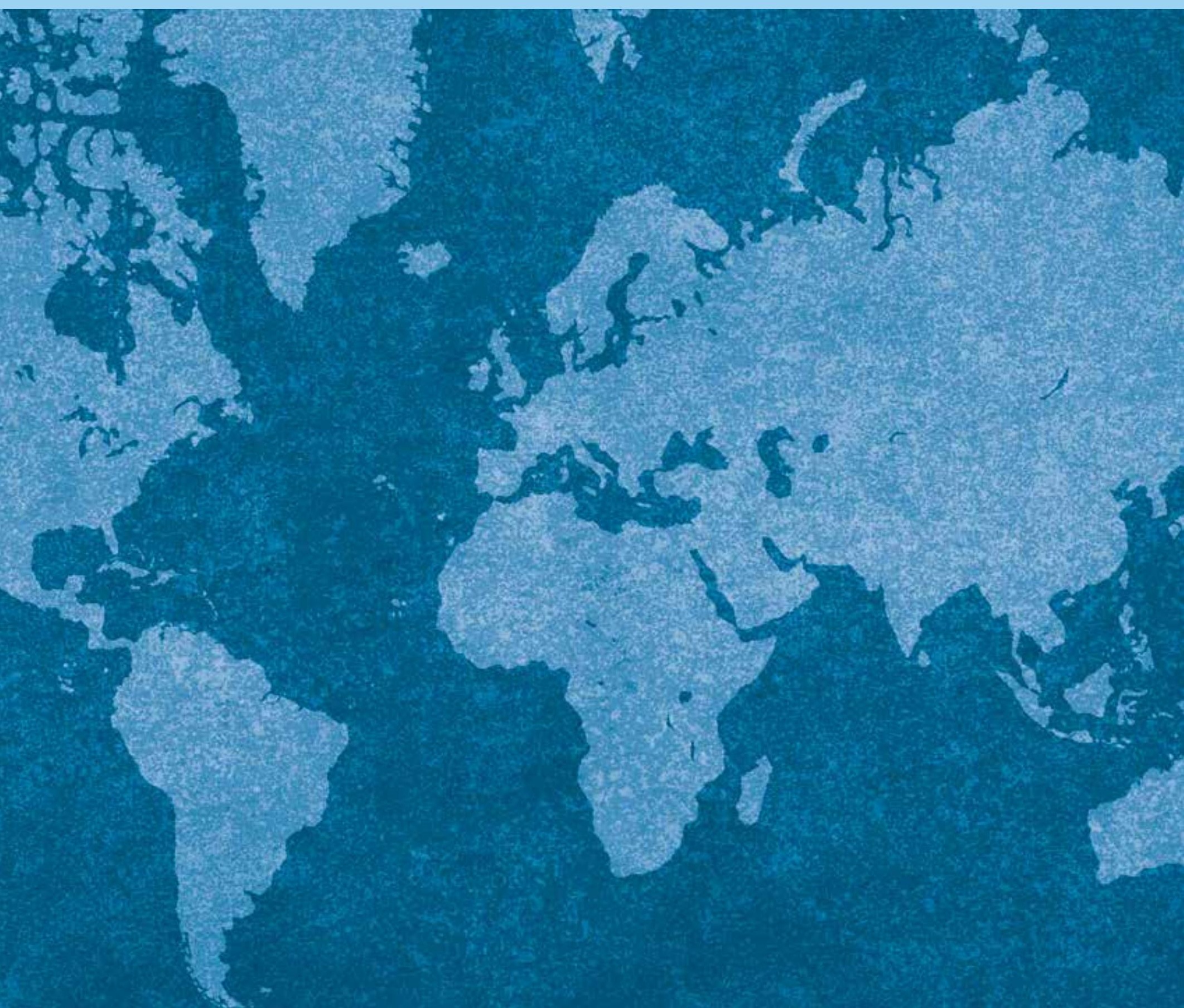

